\title{
5 Konversion: Bekehrung zu Gott und Mission
}

Im Kontext des legendarischen Erzählens ist der Begriff der Konversion von bezeichnender Doppelwertigkeit. Denn die Konversion der Heiden, die sich angesichts des Glaubenszeugnisses des Heiligen vom Heidentum abwenden und zum christlichen Glauben bekehren, steht in Analogie zu der Konversion des Heiligen aus allen immanenten Bindungen hin zur alleinigen Ausrichtung an den Ansprüchen der Transzendenz, die ihre finale Bestätigung in seiner Aufnahme in die communio sanctorum findet. Das erscheint axiologisch noch gesteigert, wenn der Heilige selbst zunächst noch ein Heide oder Sünder ist, der sich erst zu einem heiligmäßigen Leben bekehren muss. Aber auch die Legenden der ,Geburtsheiligen', die ohne einen solchen biographischen Bruch auskommen, müssen, um die Heiligkeit ihres Protagonisten erzählerisch darstellen zu können, diese in den Episoden seines Lebens jeweils als Heiligung prozessualisieren, als Wechselspiel von Selbstexklusion aus der Immanenz und gnadenhaft gewährter Inklusion in die Transzendenz. ${ }^{1}$ Der Heide konvertiert vom Heidentum zum Christentum, der Heilige aus der Masse der Gläubigen zur Heiligkeit.

Diese doppelte Bedeutung von Konversion als ,äußerem‘ Glaubenswechsel und ,innerer' Hinwendung zu Gott überschneidet sich mit der zweifachen Sinnrichtung des Begriffs ,Bekehrung': In einem transitiven Akt bekehrt man andere, in einem intransitiv-reflexiven sich selbst. ${ }^{2}$ Die ,innere und selbst vollzogene Konversion des Heiligen ist dabei nicht zu trennen von der ,äußeren‘ Konversion der Heiden im Sinne einer „durch missionarisches Handeln planmässig und legitim herbeigeführten Bekehrung grösserer Menschengruppen“3 , die im legendarischen Erzählen durch das Glaubenszeugnis eines Heiligen in Wort und Tat bewirkt wird. Indem der Heilige zur Heiligkeit ,konvertiert', bewirkt er die Konversion von Heiden, wobei letztere nicht nur Objekt, sondern auch Subjekt der Konversion sind, insofern sie diese wiederum selbst vollziehen und dann schließlich selbst zu Heiligen werden können.

In diesem Zusammenhang bleibt zunächst festzuhalten, dass Mission, verstanden als planmäßig betriebene Konversion von Heiden, kein eigentliches Heiligkeitsmodell darstellt. Einerseits ist Konversion als paradigmatischer Heiligkeitsbeweis quasi Nebenprodukt der legendarischen Konstruktion von Heiligkeit, andererseits wird sie dabei immer wieder verknüpft mit den hergebrachten Heiligkeitsmodellen. ${ }^{4}$ Mission wird im legendarischen Erzählen dabei im Muster der Apostelakten und Märtyrerbe-

1 Vgl. oben in Kap. 2.1.1 Legendarisches Erzählen zwischen Transzendenz und Immanenz.

2 Vgl. Wolfgang Lienemann: Einleitung. In: Religiöse Grenzüberschreitungen. Studien zu Bekehrung, Konfessions- und Religionswechsel. Hrsg. von Christine Lienemann-Perrin, Wolfgang Lienemann. Wiesbaden 2012 (Studien zur Außereuropäischen Christentumsgeschichte. Asien, Afrika, Lateinamerika. 20), S. 3-37, hier S. 29.

3 Ebd., S. 23.

4 So gesehen kann es keine genuinen ,heiligen Missionare' geben und auch unter den Neukanonisierten des 13. Jahrhunderts finden sich keine ,Missionsheiligen'. Vgl. dazu Ryan, Missionary Saints of the High Middle Ages und oben in Kap. 3.3.1 Martyrium und Mission im frühen Franziskanertum, S. 157.

○ OpenAccess. () 2021 Felix Prautzsch, publiziert von De Gruyter. (cc) BY Dieses Werk ist lizenziert unter der Creative Commons Attribution 4.0 International Lizenz. https://doi.org/10.1515/9783110664720-006 
richte dargestellt, die als literarische Form im 2. Jahrhundert etwa zeitgleich entstehen und im Motiv des gewaltsamen Todes des Glaubenszeugen verbunden sind. Die Jünger, die in die Welt gesandt sind zur Taufe und Unterweisung der Heiden, bezeugen ihren Glauben mit dem eigenen Leben und vollziehen als Märtyrer im Sterben für Gott die endgültige conversio, die sie in die Transzendenz eingehen lässt. So wie Apostelund Märtyrerideal miteinander verschmelzen, gehen Mission und Martyrium ineinander über: Mission führt fast zwangsläufig zum Martyrium und diesem wird eine missionarische Dimension zugeschrieben, ob in der Verkündigung des christlichen Glaubens im Wort oder im zeichenhaften Wunderhandeln Gottes durch und an seinem Heiligen. ${ }^{5}$ Der Missionar gilt also nicht deshalb als heilig, weil er missioniert, sondern weil er als solcher das Martyrium findet oder als Bekenner ohnehin heiligmäßig lebt beziehungsweise sich nach erfolgter Mission aus der Welt zurückzieht und als Asket heilig wird. ${ }^{6}$

Dennoch gehören Konversionserzählungen fest zum literarischen Kanon des Christentums, sei es in Gestalt persönlicher Bekehrungserlebnisse oder der Darstellung erfolgreicher Missionierung von Heiden. Das mag auch erklären, warum sich im mittelalterlichen Legendenbestand schließlich trotz der vorangestellten Einschränkungen zwei umfangreiche Stoffe finden, die als ,Missionslegenden“ beziehungsweise ,Konversionslegenden ${ }^{67}$ gelten können, weil sie von ,heiligen Missionaren` und der Konversion heidnischer Herrscher und ganzer Völkergruppen berichten: In der Silvesterlegende wird der heidnische Kaiser Konstantin durch das Wirken Silvesters, des ersten Papstes, der als Bekenner und nicht als Märtyrer heilig wird, vom Aussatz geheilt und zum Christentum bekehrt, woraufhin er sein Reich christianisiert. In der Legende von Barlaam und Josaphat bekehrt der christliche Eremit Barlaam in ausführlichen Glaubensgesprächen den heidnischen Königssohn Josaphat, der erst nach der Bekehrung seines Volkes seinem Lehrer in die Wüste folgen darf, wo beide als Anachoreten und Asketen die Heiligkeit erlangen. Beide Stoffe werden zunächst in der lateinischen Literatur tradiert und davon ausgehend in den Volksprachen vielfältig rezipiert und verbreitet. Gerade in der mittelhochdeutschen Literatur des 13. Jahr-

5 Vgl. oben in Kap. 3.1.2 Das Martyrium als Praxis der Differenz, S. 111.

6 Das Beispiel der Orientreise des heiligen Franziskus spiegelt diesen Wandel in seiner ganzen Breite, wenn die Legenden den Heiligen aus Sehnsucht nach dem Martyrium zu den Heiden reisen lassen, um diese (re-)konkretisierende Verbindung von heiligmäßigem Streben und Mission in seiner erfolglosen Rückkehr sogleich abzuwenden, um ersteres schließlich in der Stigmatisation sich vollenden zu lassen, die ihn als Ausweis höchstmöglicher Christusförmigkeit noch über das Märtyrerideal erhebt. Vgl. oben in Kap. 3.3.2 Franziskus als Vorbild apostolischen Lebens und missionarischer Sendung.

7 Vgl. zum Begriff der ,Konversionslegende“ meinen Beitrag: Vermittlung von Heilswissen und kollektive Heilsvergewisserung. Zur gemeinschaftsstiftenden Funktion von Konversionslegenden, am Beispiel von Rudolfs von Ems Barlaam und Josaphat. In: Zwischen Himmel und Alltag. Wissen und Gemeinschaft vom Hochmittelalter bis in die Frühe Neuzeit. Hrsg. von Angelika Kemper, Christian Domenig. Berlin [erscheint 2021] (Medieval to Early Modern Culture / Kultureller Wandel vom Mittelalter zur Frühen Neuzeit). 
hunderts erfahren sie eine charakteristische Transformation für ein mit der Sprache und den Werten höfischen Erzählens vertrautes Laienpublikum.

Neben der spezifischen Aktualisierung der tradierten Heiligkeitsmodelle des Bekenners und des Asketen ist dabei bemerkenswert, dass beide Legenden die Bekehrung von Herrschern mit der friedlichen Ausbreitung des christlichen Glaubens in ihren Herrschaftsbereichen verknüpfen. Gegenüber diese frühmittelalterlichen Missionsmethode, „die durch Massenkonversionen und den Aufbau einer Landeskirche auf eine oberflächliche Christianisierung, deren Symbol die Taufe war, zielte“8, orientierte sich die Neubegründung der Mission im 13. Jahrhundert wieder an den antiken Modellen, die auf den einzelnen Menschen zielten. Allerdings blieben mit Gewalt forcierte Bekehrungen, wie auf der Iberischen Halbinsel oder im Deutschordensland, weit ,erfolgreicher' ${ }^{9}$ Denn während in Gebieten unter christlicher Herrschaft Konversionen durch Druck von zumindest äußerem Erfolg gekrönt sein mochten, fehlten es für eine erfolgreiche Mission unter Muslimen im islamischen Herrschaftsbereich an erfolgversprechenden Modellen.

Diese Leerstelle füllen die beiden Legendenstoffe zumindest in dem Sinne, dass sie, in Ergänzung und produktivem Kontrast zur Kreuzzugsliteratur, Heidenmission in exemplarischen Konversionen narrativieren, die durch breit angelegte Glaubensdispute vermittelt werden. Diese tradieren die antiken Topoi christlicher Apologetik und Polemik, die die Wahrheit des christlichen Glaubens argumentativ beweisen sollen. Als Modelle gelingender Mission sind beide Stoffe damit aufschlussreich für die Frage nach den Potentialen der Konversion als Form der Aushandlung des religiösen Gegensatzes zum Heidentum. Denn wenn sie von Heiden erzählen, die zu Heiligen werden, realisieren sie auf narrative Weise die Prozessualität christlicher Identitätsbildung und halten diese in der Figur des Bekehrten präsent. ${ }^{10}$

Offen bleibt in dieser Narrativierung aber bezeichnenderweise, wie und warum Konversion sich letztlich vollzieht: Ob sie auf dem Weg diskursiver Vermittlung und

8 Vgl. Thomas Ertl: Mission im späten Mittelalter. Kontinuitäten und Neuansätze zwischen Spanien und China. In: Im Zeichen des Kreuzes. Mission, Macht und Kulturtransfer seit dem Mittelalter. Hrsg. von Bernd Hausberger. Wien 2004 (Expansion, Interaktion, Akkulturation. Historische Skizzen zur Europäisierung Europas und der Welt. 7), S. 51-78, hier S. 68.

9 Vgl. ebd.

10 Dabei sind die in den Legenden transportierten Modelle der Heidenmission durchaus auch als konkrete historische Optionen zu verstehen, auch wenn dahingehende Bemühungen erfolglos bleiben, wie die Predigt des heiligen Franziskus vor dem Sultan oder die päpstlichen Versuche ab der Mitte des 13. Jahrhunderts, die muslimischen Herrscher mittels dogmatischer Argumente zum Übertritt zum Christentum zu bewegen. Die Aktualisierung des Religionsdisputes als reale Form der Auseinandersetzung mit den Juden, 1240 in Paris und 1263 in Barcelona, steht hingegen zwar durchaus im Rahmen der mendikantischen Neubegründung der Mission innerhalb und außerhalb der christlichen Welt, vor allem aber ist sie Ausdruck des christlichen Strebens nach Selbstvergewisserung und Identitätsstiftung, das sich in diesem Fall an der einzigen anderen Glaubensgemeinschaft innerhalb der christianitas abarbeitet. Vgl. dazu unten in Kap. 5.2.2 Adversus Judaeos - Die Aushandlung des religiösen Gegensatzes zum Judentum. 
rationaler Erkenntnisprozesse überhaupt bewirkt werden kann, oder ob sie nicht vielmehr im Letzten Ergebnis eines durch göttliches Gnadenhandeln bewirkten religiösen Erleuchtungsmoments ist. Während Josaphat sich, zumindest vordergründig, durch die Unterweisung und das Vorbild Barlaams bekehrt und der Glaubensdisput mit den Heiden argumentativ entschieden wird, bekehrt sich Konstantin aufgrund seiner wundersamen Heilung und der Disput gegen die Juden wird durch ein von Silvester gewirktes Wunder entschieden.

Im Folgenden werde ich daher zunächst die Doppelwertigkeit der conversio zwischen ,äußerem‘ Glaubenswechsel und ,innerer‘ Bekehrung genauer herausarbeiten, indem ich zum einen die Funktion von Konversion als Grundmuster christlicher Identitätsbildung, zum anderen die Optionen der Narrativierung von Konversion zwischen einmaliger und wiederholter Umkehr sowie zwischen heilspräsentischem Umschlagphänomen und diskursivem Erkenntnisprozess darstelle. Auf dieser Grundlage werde ich dann anhand der beiden Legendenstoffe und ihrer Rezeption im 13. Jahrhundert untersuchen, welches Potential die entsprechenden Konversionsmodelle in Bezug auf die Aushandlung des religiösen Gegensatzes zum Heidentum entfalten.

\section{1 conversio - Religionswechsel und Bekehrung}

\subsubsection{Konversion als Grundmuster christlicher Identitätsbildung}

Die Religionswissenschaft definiert Bekehrung beziehungsweise Konversion als einen

religiös gedeuteten Prozeß ganzheitlicher Umorientierung, in welcher ein einzelner Mensch oder eine Gruppe das vergangene Leben reinterpretiert, die Abwendung von diesem vollzieht und das künftige in einem veränderten gesellschaftlichen Beziehungsnetz neu begründet und gestaltet. ${ }^{11}$

Als zentrales Merkmal gilt dabei „[d]ie ganzheitliche Umorientierung in der Wirklichkeitsauffassung“, die immer schon das Ergebnis einer narrativen Inszenierung ist:

Die Bekenntnisse und Bekehrungserzählungen bezeugen die Neuinterpretation des Lebens und sind als biographische Rekonstruktion zu verstehen. In dieser wird das Leben vor der Bekehrung als leer, unglücklich und gar schlecht gekennzeichnet, jenes nach der Bekehrung als sinnerfüllt und glücklich. ${ }^{12}$

Die polytheistische Glaubenswelt der griechisch-römischen Antike kennt das Phänomen eines Religionswechsels aufgrund persönlicher Bekehrung nicht, ebenso

11 Otto Bischofberger: Art. Bekehrung/Konversion I. Religionswissenschaftlich. In: ${ }^{4}$ RGG 1 (1998), Sp. 1228-1229, hier Sp. 1228.

12 Ebd. 
wenig die in engem Zusammenhang damit stehende Mission. Denn Religion ist in diesem Kontext einerseits eine Frage des Kultes, der an äußere Zugehörigkeiten, wie Familie und Volksstamm gebunden ist, während andererseits neue und fremde Kulte staatlicherseits integriert werden können, weil die persönliche Hinwendung zu einer bestimmten Gottheit die Anerkennung und Verehrung anderer Götter nicht ausschließt. ${ }^{13}$ Der alle Lebensbereiche umfassende Anspruch des christlichen Monotheismus, der eine Trennung von öffentlichem Kult und privater Frömmigkeit nicht zulässt, entfaltet vor diesem Hintergrund seine Anziehungskraft gerade in der radikalen Abgrenzung von allen anderen Göttern und Kulten. Dabei fordert er die völlige Konversion, die nötigenfalls im Martyrium zu bezeugen ist. ${ }^{14}$ Dem heidnischen Verständnis bleibt diese exklusive Vorstellung von religiöser Zugehörigkeit fremd:

Das Wortfeld für ,Übertritt, Zuwendung, Abkehr` ist zwar reich entfaltet, bezieht sich aber überwiegend auf philosophische und moralische ,Umkehr' [...] Das neutestamentliche Wort für (re-

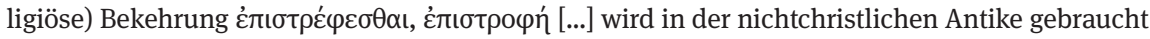
für die Hinwendung zur Philosophie oder die Hinwendung der Seele des Philosophen zur Gottheit. $^{15}$

Auch im Alten Testament findet sich noch „kein terminus technicus, durch den sich das Theologumenon Bekehrung von vergleichbaren Begriffen wie Buße, Gehorsam oder Reue klar abgrenzen lässt“. ${ }^{16}$ Bekehrung meint hier die an Israel gerichtete Forderung, zu Gott zurück- beziehungsweise umzukehren, nur selten wird sie mit missionarischem Anspruch nach außen formuliert. ${ }^{17}$ Das Konzept einer Bekehrung als

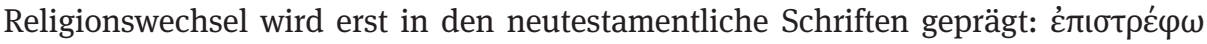
meint hier nun die „Hinwendung des Menschen zu dem in Jesus Christus geoffenbarten Gott“ “ ${ }^{18}$ Besonders im lukanischen Doppelwerk, und hier vor allem in der Apostelgeschichte, richtet sich die missionarische Verkündigung an Juden wie Heiden

13 Vgl. Hubert Cancik: Art. Bekehrung/Konversion II. Griechisch-römische Antike. In: ${ }^{4}$ RG 1 (1998), Sp. 1229-1230, hier Sp. 1229. Außerdem: Wolfgang A. Bienert: Art. Bekehrung/Konversion IV. Kirchengeschichtlich 1. Alte Kirche. In: Ebd., Sp. 1232-1233.

14 Insofern wirft die Vorstellung von Konversion als radikalem Wandel ein Licht auf die entsprechende Religion: „Vorausgesetzt ist dabei ein exklusives Verständnis von Mitgliedschaft: Die Person, die sich in einem Prozess radikalen Wandels einer religiösen Gemeinschaft zuwendet, kann nicht gleichzeitig einer anderen, ähnlich gearteten, angehören. Er geht - wo von Konversion im Sinne eines radikalen Wandels die Rede ist - um ein Entweder-oder, um eine Entscheidung für eine Form von Zugehörigkeit, die andere Zugehörigkeiten ausschließt.“ Monika Wohlrab-Sahr: Zwischen Besonderung und Konformität. Religiöse Konversion in soziologischer Perspektive. In: Figuren der Konversion. Friedrich Schlegels Übertritt zum Katholizismus im Kontext. Hrsg. von Winfried Eckel, Nikolaus Wegmann. Paderborn 2014 (Schlegel-Studien. 5), S. 25-55, hier S. 26.

15 Cancik, Art. Bekehrung/Konversion, Sp. 1229.

16 Ernst-Joachim Waschke: Art. Bekehrung/Konversion III. Bibel 1. Altes Testament. In: ${ }^{4}$ RGG 1 (1998), Sp. 1230 - 1231, hier Sp. 1230.

17 Vgl. ebd., Sp. 1231.

18 Jean Zumstein: Art. Bekehrung/Konversion III. Bibel 2. Neues Testament. In: ${ }^{4}$ RGG 1 (1998), Sp. 1231-1232, hier Sp. 1231. 
und damit alle Menschen gleichermaßen: Sich-Bekehren und Gläubig-Werden fallen

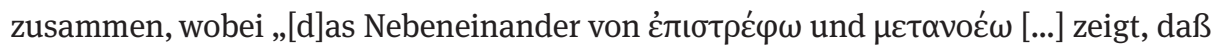
Bekehrung das Moment der Hinwendung zu Gott ausdrückt, welches jedoch ohne eine grundlegende Änderung des bisherigen Lebens nicht zu denken ist“ “. ${ }^{19}$ In den paulinischen Briefen wird Bekehrung dann konsequent als Zuwendung zum christlichen Glauben verstanden, wobei zwei Aspekte deutlich werden: Bekehrung „als Hinwendung zum wahren Gott und zugleich als Abkehr von den Götzen“ sowie der Erkenntnischarakter von Bekehrung, wonach „[e]rst die Hinwendung zu Christus [...] ein sachgemäßes Verständnis der Schrift“ ermöglicht. ${ }^{20}$ Im Zeichen des christlichen Offenbarungsglaubens sind äußerer Religionswechsel und innere Bekehrung, Kult und Gotteserkenntnis, eins.

Für die Ausbreitung und Etablierung des Christentums in den ersten Jahrhunderten wird die Konversion zum entscheidenden Faktor. Erst im 4. Jahrhundert soll sich der innere Zuwachs durch als Christen Geborene dem durch konvertierende Heiden angeglichen haben: „So ist die frühe Kirchengeschichte zunächst ausschließlich, dann überwiegend eine Geschichte des Glaubenswechsels vom Heidentum in seinen verschiedenen Spielarten zum Christentum hin“. ${ }^{21}$ Das entspricht vor allem dem Selbstbild der frühen Kirche, denn Konversionen zum Christentum sind ein zentrales Thema der Apostelgeschichte und der frühchristlichen Literatur, als solche aber eben auch immer schon Gegenstand retrospektiv-interpretierender wie prospektiv-normierender Deutungen. Die kirchlich tradierte Vorstellung einer erstaunlich raschen Ausbreitung des Christentums durch eine planmäßig betriebene Mission in Form öffentlicher Missionspredigten ist daher als narrative Inszenierungen kritisch zu hinterfragen und in der kulturwissenschaftlichen Interpretation fruchtbar zu machen. $\mathrm{Zu}$ revidieren ist sie insofern, als sich zeigen lässt, dass die tatsächlichen Modalitäten der Propaganda der Kirche in den ersten drei Jahrhunderten eben gerade nicht in der öffentlichen Werbung zu suchen sind, sondern im Kontakt mit Christen im persönlichen Lebensumfeld, und dass diese, individuelle Propaganda' ein wohl stetiges, aber nicht außergewöhnlich schnelles Wachstum der Kirche zur Folge hat, der vor der Konstantinischen Wende noch keinesfalls die Mehrheit der Bevölkerung des Römischen Reiches angehört. ${ }^{22}$

Die frühchristlichen Konversionserzählungen, wie sie sich im legendarischen Erzählen finden, sind dabei wie die Martyriumserzählungen nicht als Tatsachenberichte zu verstehen, sondern als Form narrativer Identitätsbildung des Christentums der ersten Jahrhunderte, also im Kontext seiner Behauptung gegenüber einer heid-

19 Ebd., Sp. 1232.

20 Ebd.

21 Kurt Aland: Über den Glaubenswechsel in der Geschichte des Christentums. Berlin 1961 (Theologische Bibliothek. 5), S. 15.

22 Vgl. Wolfgang Reinbold: Propaganda und Mission im ältesten Christentum. Eine Untersuchung zu den Modalitäten der Ausbreitung der frühen Kirche. Göttingen 2000 (Forschungen zur Religion und Literatur des Alten und Neuen Testaments), besonders S. 299-316 u. 349-353. 
nischen Mehrheitsgesellschaft. Im Diskurs christlicher Apologetik und Polemik spielen sie eben deshalb eine wichtige Rolle, ${ }^{23}$ weil sie die besondere Möglichkeit einer Identitätsbildung über die Verteidigung des religiös Eigenen und die Kritik des religiös Fremden bieten, insofern sie die diskursiven Argumente, wie sie die Präsentation von Glaubensinhalten oder die Darstellung theologischer Disputationen vermitteln, in einer narrativen Struktur exemplifizieren. ${ }^{24}$ Das individuelle Beispiel eines Konvertiten dient dabei der kollektiven Selbstvergewisserung. Wie das Martyrium erweist sich die Konversion somit als narrative wie diskursive Praxis, denn es handelt sich nicht nur um ein rückblickendes Deutungsmuster der Hinwendung anderer zum Christentum und ihrer Abkehr vom Heidentum, sondern um ein Modell für das eigene religiöse Erleben, in das sich neue Konvertiten in ihrer ganz persönlichen Konversion selbst immer wieder einschreiben.

Auf diese Weise sind Konversionserzählungen Teil eines Diskurses, der die Grenzen des christlichen Glaubens gegenüber dem Heidentum verhandelt und dabei theologische und dogmatische Probleme reflektiert. Hierin liegt ganz offensichtlich auch ihre Funktion über die historische Wende der Etablierung des Christentums zur Staatsreligion hinaus bis ins hohe Mittelalter, also unter gesellschaftlichen Bedingungen, unter denen tatsächliche Konversionen zum Christentum längst zum Randphänomen geworden sind. Die identitätsstiftende Funktion, die Konversionserzählungen auch in ihrem ,bloß` symbolischen Gehalt entfalten, erklärt schließlich ihre Verknüpfung mit dem legendarischen Erzählen:

Conversion narratives in medieval apologetic sources combine inward-looking apology and outward-looking polemic not through autobiography or historiography, but through what can be better described as a combination of hagiography and heresiography, an allegorization of the life of an individual believer combined with a defensive reflection on the boundaries of acceptable belief. ${ }^{25}$

Wenn allerdings auch Biographik und Historiographie immer schon durch Narrative wie das der Konversion bestimmt und im literarischen Kontext der christlichen Spätantike bis ins späte Mittelalter Gegenstand hagiographischer Stilisierungen sind, dann lassen sich Konversionserzählungen als heilsgeschichtlich codierte Lebens- und Geschichtsschreibung verstehen. Konversionsnarrative sind dabei ein allegorischer Ausdruck soteriologischer und ekklesiastischer Argumentation. ${ }^{26}$ Sie verschränken den polemisch abzulehnenden Unglauben des Heidentums und den apologetisch zu

23 Allerdings gilt das auch für die anderen beiden abrahamitischen Religionen. Die Paradigmen und Narrative werden in der Spätantike vorgebildet, sind aber gerade im hohen und späten Mittelalter im Mittelmeerraum, besonders im Westen, auf der iberischen Halbinsel, von großer Virulenz. Vgl. dazu Ryan Szpiech: Conversion and Narrative. Reading and religious authority in medieval polemic. Philadelphia 2013 (Middle Ages series), S. 3.

24 Zum Zusammenhang von Konversion und Polemik vgl. ebd., S. 4.

25 Ebd., S. 6.

26 Vgl. ebd., S. 23-24. 
verteidigenden wahren Glauben des Christentums im biographischen Vorher und Nachher einer Figur. Aufgrund dieser kontrastiven, dialektischen Struktur, die die heilsgeschichtliche Überwindung des Heidentums bezeugt und präsent hält, bilden sie eine besondere Form christlicher Gründungsmythen. Als solche bedürfen sie der beständigen Iteration, des Wieder-und-Wieder-Erzählens, sei es in neu imaginierten Konversionen oder in der symbolischen Wiederholung historischer Konversionen. ${ }^{27}$

Entscheidend für das Verständnis von Konversion als Form der religiösen Auseinandersetzung ist nun, auf welche Weise Christentum und Heidentum miteinander verhandelt werden. Während das Martyrium auf die Differenz zielt, die in der Scheidung des wahren Glaubens vom heidnischen Unglauben die christliche Identitätsbildung befördert, zugleich aber auf eine Entdifferenzierung, weil das Zeugnis des Märtyrers allen Menschen gilt, stellt sich die Praxis der Konversion anders dar. Auch hier wird die Differenz zwischen Christentum und Heidentum markiert, aber immer schon im Modus ihrer Überschreitung. Identität bildet sich hier nicht in der letzten Scheidung im Angesicht des Sterbens eines Glaubenszeugen, sondern in der Verschränkung des abgelegten falschen mit dem neugewonnenen richtigen Glauben in der Figur des Konvertiten. Einer ,Praxis der Differenz' steht damit eine ,Praxis der Integration' gegenüber, die freilich die grundlegende Differenz von Unglaube und Glaube nicht aufhebt, sondern das überwundene Heidentum als das religiös Fremde positiv - im Hinblick auf seine Bekehrungsfähigkeit - deutend in das christliche Eigene einordnet, in der dialektischen Struktur der Überschreitung des religiösen Gegensatzes auf das Heil hin.

Auf diese Weise stellen Konversionserzählungen eine besondere Form der Darstellung von Identitätsbildungsprozessen dar: Das biographische Selbstverständnis des Konvertiten besteht dabei aus zwei gegensätzlichen Teilen, die in einen „Geschehenszusammenhang gestellt [werden], der insofern identitätsbildend ist, als er ,Davor' und ,Danach' in ein Verhältnis setzt und in der Abgrenzung vom ,alten Ich paradoxal aufeinander bezieht: Nur im Wandel vom Saulus ist Paulus überhaupt denkbar.“28 Der Zeitraum vor der Konversion erscheint, aus der Perspektive der richtigen Ordnung, die durch die Konversion bestätigt wird, als defizitärer Zustand eines spirituellen Mangels. ${ }^{29}$ Dieser wird entweder als Sehnsucht inszeniert, also als „Be-

27 Vgl. ebd., S. 222.

28 Einleitung zu: Zwischen Ereignis und Erzählung. Konversion als Medium der Selbstbeschreibung in Mittelalter und Früher Neuzeit. Hrsg. von Ruth von Bernuth, Werner Röcke, Julia Weitbrecht. Berlin/ Boston 2016 (Transformationen der Antike. 39), S. 1-5, hier S. 2.

$29 \mathrm{Zu}$ den besonderen Strukturmerkmalen von Konversionserzählungen vgl. den in der Forschungsdiskussion maßgeblichen Beitrag von Thomas Luckmann: Kanon und Konversion. In: Kanon und Zensur. Hrsg. von Aleida Assmann. München 1987 (Beiträge zur Archäologie der literarischen Kommunikation. 2), S. 38-46. Die „merkwürdige Vorher/Nachher-Strukturierung der Zeiterfahrungen bei Konvertiten“ sieht er im Zusammenhang mit den in der sozialwissenschaftlichen Konversionsforschung herausgearbeiteten Merkmalen von Konversion beziehungsweise dem Denken und Reden über sie, „,biographische Rekonstruktion“ und die „Übernahme eine Generalschlüssels zum Verständnis der Wirklichkeit“, und beschreibt die Strukturmerkmale einer Gattung ,Konversionserzählung‘ als kom- 
standteil der Narration des ,Vorher““30, oder retrospektiv, wenn der Mangel erst im Nachhinein als ein solcher erkannt wird, also in der Narration des ,Nachher‘ klar wird, wonach die Figur gesucht hat. In letzterem Fall „wird die Erzählung von der Konversion selbst zum Medium von Belehrung und Bekehrung, indem der narrative Verlauf zugleich einen Erkenntnisprozess initiiert beziehungsweise transportiert"“31, der auf den Rezipienten der Konversionserzählung ausgreift. In der Figur des Konvertiten wird somit die Überwindung des Heidentums durch das Christentum und damit die Reflexivwerdung der eigenen Identität verklammert und dauerhaft präsent gehalten.

So wie die Grundspannung legendarischen Erzählens darin besteht, „dass das Heilige im Profanen, das neue Leben des Glaubens in fortwährender Auseinandersetzung mit dem alten Leben der Sünde realisiert und vergegenwärtigt wird“32, so scheint im Konvertiten und der Erzählung von seiner Konversion beständig das Alte im Neuen auf. Die Aushandlung des religiösen Gegensatzes zum Heidentum wird gerade dann akzentuiert, wenn in einer dreigliedrigen narrativen Struktur zwischen das ,Davor` und das ,Danach` eine, oftmals ausführlich auserzählte, ,Wende‘ tritt: Dabei werden in der „Zwischenphase des ,Vorher‘, in Annäherung zur Wende und in ihrer (vom ,Nachher` gedeuteten) Vorbereitung, ,falsche“ Alternativen ausprobiert“33, die freilich scheitern müssen. Der mit der Konversion übernommene neue ,Generalschlüssel für die Wirklichkeit“ bietet dabei den Maßstab für die „Ausgrenzung des ,Falschen“ und die Eingrenzung des ,Richtigen““. ${ }^{34}$ Die Figur des Konvertiten hält diese Verhandlung des religiös Fremdem mit dem religiös Eigenen in der Konversion als dem entscheidenden biographischen Wendepunkt, der die Unterschiede zuspitzt und zur Wende verdichtet, präsent - das andere und falsche ,Vorher' ist mit einem regelrechten ,Amnesieverbot' belegt; ${ }^{35}$ auch wenn sein Geltungsanspruch getilgt wird, bleibt es integraler Bestandteil der Identität des Konvertiten, auf sie bezogen und damit ins Eigene vermittelt.

Damit verkörpert der Konvertit die christliche Vorstellung des Menschen als homo viator: Weil er in der Welt, die die Gottesferne bezeichnet, grundsätzlich fremd ist,

munikative „,Lösung‘ ihres besonderen ,Problems‘, der glaubwürdigen Darstellung des Wirklichkeitscharakters außerordentlicher Erfahrungen“. Ebd., S. 42.

30 Julia Weitbrecht: Bewegung - Belehrung - Bekehrung. Die räumliche und emotionale Kodierung religiöser Erkenntnis im Straßburger Alexander. In: Zwischen Ereignis und Erzählung. Konversion als Medium der Selbstbeschreibung in Mittelalter und Früher Neuzeit. Hrsg. von Ruth von Bernuth, Werner Röcke, Julia Weitbrecht. Berlin/Boston 2016 (Transformationen der Antike. 39), S. 109-142, hier S. 1. 31 Ebd.

32 Werner Röcke: Das Alte im Neuen. Paradoxe Entwürfe von Konversion und Askese in Legende und Roman des Mittelalters (Eustachius-Typus). In: Askese und Identität in Spätantike, Mittelalter und Früher Neuzeit. Hrsg. von dems., Julia Weitbrecht. Berlin/New York 2010 (Transformationen der Antike. 14), S. 157-173, S. 158.

33 Luckmann, Kanon und Konversion, S. 43.

34 Ebd.

35 Vgl. ebd., S. 44. 
muss er bis zur endgültigen Scheidung von Heil und Verdammnis, Glaube und Unglaube, Heiligen und Heiden als Pilger zwischen zwei Welten wandern. ${ }^{36}$ Dabei überlagern sich zwei Sichtweisen auf das Motiv der Fremdheit: Einmal erscheint sie als etwas Negatives, nämlich als schuldhafte Entfremdung von Gott, die unter allen Umständen vermieden werden muss: „Alienation in this sense is indeed essentially a failure to love God and a refusal to adhere to the order which he had given. ${ }^{\text {“37 }}$ Die andere Sichtweise wertet sie auf, wenn sie das Fremd-Sein in der Welt als irdisches Los des Christen versteht. ${ }^{38}$ Fremdheit wird dann zum Heilsweg, zum Weg aus der persönlich verschuldeten oder qua Sündenfall allen Menschen auferlegten Gottesferne hin zum Heil in Gott. So wird sie zu einem zentralen Motiv der asketischen und monastischen Literatur:

The topoi of xeniteia and peregrinatio, of pilgrimage, of homelessness, of strangeness in this world, are among the most widespread in early Christian ascetic literature, and not a few ascetics, monastic and otherwise, practiced it by voluntary and migratory exile from their fatherland. ${ }^{39}$

Damit umfasst Fremdheit im religiös-geistlichen Verständnis also zwei entgegengesetzte, sich aber dennoch ergänzende Dimensionen: die mit dem Sündenfall vollzogene Abkehr von Gott und die zur Heilung dieser Verfehlung und der Wiedereingliederung in die göttliche Ordnung von jedem Christen zu vollziehende Abkehr von der Welt. ${ }^{40}$ Diese Forderung lässt sich natürlich spirituell verstehen und dann in einer asketischen und klösterlichen Lebensweise erfüllen. Die religiösen Bewegungen des hohen Mittelalters, ob in der laikalen Frömmigkeit oder im Ordenswesen, zeigen aber, dass der Gedanke des Fremd-Seins in der Welt als eines tatsächlichen UnterwegsSeins in ihr lebendig bleibt und sich immer wieder als Modell neuer, vom Charisma ursprünglichen apostolischen Lebens in der Nachfolge Christi getragener Aufbrüche aus den institutionalisierten religiösen Lebensformen anbietet:

Within the monastic order a shift from the stationary to the wayfaring and missionary habitus repeats itself on a vast scale between the eleventh and the thirteenth centuries, supplementing and in part replacing Benedictine stabilitas by various forms of ascetic and ,apostolic' peregrinatio. ${ }^{41}$

So gilt Franziskus, der das Ideal existentieller Unsicherheit in apostolischer Armut, Wanderschaft und Verkündigung des Glaubens wie kein anderer Heiliger verkörpert, seinem Hagiographen Thomas von Celano als felix viator, als glücklicher Wanderer:

36 Vgl. Gerhart B. Ladner: Homo Viator. Mediaeval Ideas on Alienation and Order. In: Speculum 42, 2 (1967), S. 233-259.

37 Ebd., S. 235.

38 Vgl. ebd., S. 236.

39 Ebd., S. 237.

40 Vgl. ebd., S. 238.

41 Ebd., S. 245. 
Obwohl er die Welt als „Verbannungsort unserer Pilgerschaft“ begriffen habe, habe er seine Freude an den Dingen der Welt gehabt: „Gegen die Fürsten der Finsternis“ sei sie ihm ein „Kampfplatz“ gewesen und Gott gegenüber „Spiegel seiner Güte“ (2 Cel 126, 165). ${ }^{42}$ Fremdheit ist im christlichen Verständnis also nicht auf das religiös Andere den ,Unglauben‘ der Heiden als Gegenbild zum wahren Glauben der Christenheit beschränkt und entfaltet in diesem Sinne auch gar nicht ihr eigentliches identitätsstiftendes Potential.Vielmehr ist sie als conditio humana wesentlich ein Phänomen im religiös Eigenen: Alle Menschen sind in dieser Welt fremd und auf dem Weg zu Gott, in dem allein sie ihre eigene Identität finden beziehungsweise wiederfinden können und sollen. Das gilt für die Heiden gleichermaßen wie für die Christen, bestimmt aber im Sinne kollektiver Identitätsbildung das Selbstverständnis der christianitas, zu der sich die Heiden erst noch bekehren müssen.

Der Effekt einer verklammernden Präsenthaltung der Überwindung des Heidentums durch das Christentum, der Integration des religiös Fremden ins religiös Eigene, kann schließlich noch dadurch verstärkt werden, dass der Bekehrte selbst zum Bekehrer wird. Diese Konstellation bestimmt gerade das Urbild der christlichen Mission, den Apostel Paulus, der zugleich eine, wenn nicht die zentrale Gründungsfigur der christlichen Kirche ist, insofern diese ihren Verkündigungsanspruch mit ihm erstmals konsequent auf alle Menschen, Juden wie Heiden, bezieht, Mission als universale Völkermission versteht und sich als ,Heidenchristentum' aus dem Judentum löst. Seine Berufung zum Apostel wird als Bekehrung narrativiert, die im, allerdings wohl unhistorischen, Namenswechsel ,vom Saulus zum Paulus‘ sprichwörtlich geworden ist. Sie markiert den radikalen Umschwung vom Christenverfolger zum wichtigsten Verbreiter des Christusglaubens - den er als jüdischer Schriftgelehrter und Pharisäer freilich nicht als Abkehr vom Judentum versteht, sondern als dessen eigentliche Erfüllung, so zumindest deuten es die paulinischen Schriften.

Die Figur des Paulus steht damit für die Möglichkeit der Umkehr selbst aus größtmöglicher Verstockung und Gottesferne hin zur Erkenntnis des christlichen Heils, dem er als Missionar der frühen Kirche den Weg zu Weltgeltung ebnet. Das findet sich im ,Damaskuserlebnis‘ eindrucksvoll inszeniert, wenn Saulus in einer Lichterscheinung vom Himmel die Stimme Jesu hört, der ihn fragt, warum er ihn verfolge. Er verliert dabei sein Sehvermögen und erhält es erst drei Tage später wieder, als Gott einen Mann zu ihm schickt, der ihm die Hand auflegt und den Heiligen Geist verheißt: et confestim ceciderunt ab oculis eius tamquam squamae et visum recepit, et surgens baptizatus est (Apg 9, 18). ${ }^{43}$ Das Böse, das er zuvor den Christen angetan hat,

42 Mundum quasi peregrinationis exsilium exire festinans, iuvabatur felix iste viator iis quae in mundo sunt non modicum quidem. Nempe ad principes tenebrarum utebatur eo ut campo certaminis, ad Deum vero ut clarissimo speculo bonitatis. Zum Franziskusbild bei Thomas von Celano vgl. Oben in Kap. 3.3.2 Franziskus als Vorbild apostolischen Lebens und missionarischer Sendung, S. 165.

43 „Und sogleich fiel es von seinen Augen wie Schuppen, und er wurde wieder sehend; und er stand auf, ließ sich taufen“. 
wird abgelöst durch seine Erwählung zum Werkzeug der Verkündigung und zum Glaubenszeugnis in der Nachfolge Christi:

respondit autem Ananias, Domine audivi a multis de viro hoc quanta mala sanctis tuis fecerit in Hierusalem, et hic habet potestatem a principibus sacerdotum alligandi omnes qui invocant nomen tuum, dixit autem ad eum Dominus, vade quoniam vas electionis est mihi iste, ut portet nomen meum coram gentibus et regibus et filiis Israhel, ego enim ostendam illi quanta oporteat eum pro nomine meo pati (Apg 9, 13-16).

Hananias aber antwortete: ,Herr, ich habe von vielen gehört über diesen Mann, wie viel Böses er deinen Heiligen in Jerusalem angetan hat; und hier hat er Vollmacht von den Hohenpriestern, alle gefangen zu nehmen, die deinen Namen anrufen. Doch der Herr sprach zu ihm: Geh nur hin; denn dieser ist mein auserwähltes Werkzeug, dass er meinen Namen trage vor Heiden und vor Könige und vor das Volk Israel. Ich will ihm zeigen, wie viel er leiden muss um meines Namens willen.

Damit aber bleibt Paulus eine Spannungsfigur: Gerade als von Gott berufener Völkerapostel wird er nun seinerseits Opfer der gegen das Christentum gerichteten Verfolgung, schließlich zum Märtyrer, der für den wahren Glauben stirbt. Er verkörpert darin die für Heiligkeit konstitutive Spannung zwischen Immanenz und Transzendenz, der zufolge die Verwirklichung des christlichen Glaubens nicht „zum behaglichen Sich-Einrichten in der Welt, [...] auch nicht zur Beruhigung" ${ }^{44}$, taugt und die Zugehörigkeit zum Christentum ein existentielles Ereignis, eine lebenswendende Entscheidung ist, die den Menschen ganz ergreift und verwandelt. ${ }^{45}$ Er verkörpert dadurch zugleich die Weiterführung des christlichen Glaubens über den engen Kreis der Jünger Jesu und unmittelbaren Zeugen seiner Auferstehung hinaus: Die Präsenz des alle immanenten Bindungen übersteigenden Heils ist auch den Nachgeborenen erfahrbar und fordert ihre völlige Hingabe. Die paulinischen Briefe, die einen wesentlichen Teil des Neuen Testaments darstellen, reflektieren die existentielle Fremdheit des Christen in der Welt und die sich daraus ergebende Notwendigkeit der beständigen inneren Umkehr zu Gott: non enim habemus hic manentem civitatem, sed futuram inquirimus (Hebr 13, 14). ${ }^{46}$

\subsubsection{Zwischen äußerer und innerer, einmaliger und beständiger Umkehr}

Im Kontext des neuen Testaments bezeichnet der Begriff conversio zunächst selten explizit den Religionswechsel. Synonym oder doch zumindest in engem Zusammen-

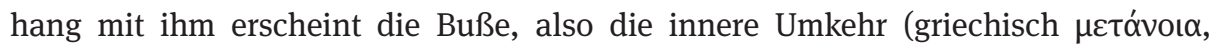
lateinisch poenitentia), so heißt es beispielsweise: paenitemini igitur et convertimini ut deleantur vestra peccata (Apg 3, 19) ${ }^{47}$ Der Aufruf zur conversio ist hier wie in anderen

44 Lauster, Die Verzauberung der Welt, S. 48.

45 Vgl. ebd., S. 60.

46 „Denn wir haben hier keine bleibende Stadt, sondern die zukünftige suchen wir.“

47 „So tut nun Buße und bekehrt euch, dass eure Sünden getilgt werde“. 
Fällen also ad intra gerichtet, es geht „um die dualistisch begründete Abkehr von der säkularen Welt, um die Korrektur verfehlten Lebens innerhalb einer Religion““48, wie sie die Figur des Paulus verkörpert. Erst mit der expliziten Ausweitung des missionarischen Anspruchs auf die Heiden wird der Religionswechsel zum zentralen Motiv christlicher Verkündigung und Identitätsbildung. Der Begriff der Bekehrung beziehungsweise Konversion hat daher einen doppelten Sinn, denn er

bezeichnet in der Antike und im frühen Christentum zwei unterschiedliche, aber doch verwandte Vorgänge. Einmal beinhaltet er eine moralische Besserung des Einzelnen, eine gesteigerte Selbsterkenntnis, die als der Abkehr von unguten Einstellungen und einer vornehmlich von der Philosophie geprägten Entscheidung für eine gemäße Lebensführung erwächst, und zum anderen schließt er die Verwerfung eines ethisch-religiösen Wertsystems zugunsten eines anderen in sich. ${ }^{49}$

Doch überlagern sich im Begriff der Konversion nicht nur ,äußerer‘ Religionswechsel und ,innere‘ Bekehrung, sondern es bleibt auch offen, ob es sich um ein singuläres Ereignis oder einen längeren Prozess handelt. Im Neuen Testament stehen dabei Aussagen zur Umkehr im Sinne einmaliger wie auch wiederholter beziehungsweise beständiger Bekehrung nebeneinander. ${ }^{50}$ Während die Deutung von conversio als Herrschaftswechsel - ut convertantur a tenebris ad lucem et de potestate Satanae ad

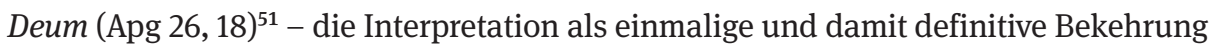
nahelegt, scheinen sich an anderen Stellen die einmal erfolgte Erlösung durch Gott und das beständige, lebenslange Mühen des Menschen um Vergebung der Sünden und Erlangung des Heils zu entsprechen: qui eripuit nos de potestate tenebrarum, et transtulit in regnum Filii dilectionis suae, in quo habemus redemptionem remissionem peccatorum (Kol 1, 13-14). ${ }^{52}$ Diese beiden Optionen markieren zwei theologische Modelle, die ineinandergreifen: Konversion als plötzliche Bekehrung, die jeden Glaubenszweifel zu überwinden scheint, und ein „aktualistisches Verständnis“, wonach „Bekehrung ein lebenslanger, täglicher Prozess“ “ist. ${ }^{53}$

Die einmalige Umkehr kann daher als Voraussetzung für die wiederholte Umkehr verstanden werden, gerade dann, wenn der Gegensatz zwischen Christentum und Heidentum $\mathrm{zu}$ einem geistlichen geworden ist, also kein Religionswechsel mehr zu vollziehen ist, dafür umso mehr die individuelle Bekehrung zu Gott als ein prinzipiell

48 Fidel Rädle: Konversion. Zur Einführung. In: Konversionen im Mittelalter und in der Frühneuzeit. Hrsg. von Friedrich Niewöhner und Fidel Rädle. Hildesheim 1999 (Hildesheimer Forschungen. 1), S. 1-3, hier S. 1.

49 William H. C. Frend: Art. Bekehrung I. Alte Kirche und Mittelalter. In: TRE 5 (1980), Sp. 440 - 458, hier Sp. 440.

50 Vgl. dazu Peter Zimmerling: Gottesgeschenk oder menschliche Entscheidung? In: Evangelische Orientierung 2017, 2, S. 8-9, hier S. 8.

51 „[D]ass sie sich bekehren von der Finsternis zum Licht und von der Gewalt des Satans zu Gott“. 52 „Er hat uns errettet von der Macht der Finsternis und hat uns versetzt in das Reich seines lieben Sohnes, in dem wir die Erlösung haben, nämlich die Vergebung der Sünden.“

53 Zimmerling, Gottesgeschenk oder menschliche Entscheidung?, S. 8. 
offenes Geschehen, das sein Ende erst mit der Scheidung von Glaube und Unglaube, Heiligen und Heiden, am Jüngsten Tag finden wird. Beide Modelle bleiben bis ins hohe Mittelalter präsent, werden aber in ihren Potentialen unterschiedlich realisiert, wobei sich diese Bedeutungsachse mit der doppelten Bedeutung von Konversion als ,äußerem‘ Glaubenswechsel und ,innerer‘ Hinwendung zu Gott kreuzt: Angesichts des exklusiven Anspruchs der christlichen Glaubenslehre und einer ablehnenden bis offen feindlichen heidnischen Mehrheitsgesellschaft, so zumindest die Selbstwahrnehmung des frühen Christentums, bedeutet Konversion beispielsweise für Justin den Märtyrer, einen Kirchenvater und Apologeten des 2. Jahrhunderts, „nicht nur Anerkennung der verstandesmäßigen Wahrheit des Christentums, sondern auch moralische Umgestaltung und bewußtes Eintreten in einen Gegensatz zu den bestehenden Gesetzen“"54, mithin eine radikale existenzielle Entscheidung, die in letzter Konsequenz zur Hingabe des Lebens im Sterben für Gott führen kann.

Aus Sicht der frühchristlichen Apologetik lieferten „Bekehrung, sittliche Besserung und Martyriumsbereitschaft [...] in ihrem Zusammentreffen [...] den Beweis der Überlegenheit des Christentums über das Heidentum. "55 In nachkonstantinischer Zeit verliert der Gedanke der Konversion zunehmend diese äußere Dimension des Religionswechsels, dafür wird die innerchristliche Bekehrung umso wichtiger, also die „Hinwendung zu vertiefter christlicher Frömmigkeit und einem wortgetreuen Verständnis der Weisungen Jesu“56, die zum zentralen Moment christlichen Heiligkeitsstrebens wird. Im frühen Mittelalter wird conversio zu einem Begriff des benediktinischen Mönchtums und erfährt dabei eine Bedeutungsverengung, die ihn praktisch gleichbedeutend mit dem Eintritt ins Kloster macht. ${ }^{57}$ Insofern meint er dann ein einmaliges Ereignis, das nur wenigen Gläubigen vorbehalten bleibt, die die Welt verlassen, um sich ganz einer geistlichen Lebensweise zu widmen, andererseits bleibt die prozessuale Bedeutung lebendig, wenn conversio im Zeichen der vita spiritualis eben nicht nur einen einmaligen Wechsel bezeichnet, sondern eine Lebensform, die das andauernde Streben nach der Vollendung in Gott verlangt und das ganze christliche Leben als eine Bekehrung begreift. ${ }^{58}$

Eine breitere Bedeutung im Sinne, innerer‘ Umkehr gewinnt der Gedanke der Bekehrung dann wieder im 12. und 13. Jahrhundert, im Kontext der Armutsbewegung und der mendikantischen Förderung der Laienfrömmigkeit, wobei der einseitig monastisch belegte Begriff der conversio durch den der poenitentia abgelöst wird. ${ }^{59}$ Bekehrung und Buße werden damit begrifflich und inhaltlich praktisch austauschbar, wie sie auch davor schon, ausgehend von den neutestamentlichen Schriften, in einem

54 Frend, Art. Bekehrung, S. 444.

55 Ebd., S. 446.

56 Ebd., S. 449.

57 Vgl. ebd., S. 458.

58 Vgl. ebd.

59 Vgl. ebd. 
engen Zusammenhang stehen, und conversio umfasst dann den Dreischritt von Bekenntnis, Reue und Buße. ${ }^{60}$

Die Bedeutung des Konversionsgedankens für die mittelalterliche Frömmigkeit lässt sich auch anhand des deutschen Begriffs ,bekehren' nachvollziehen, in dessen Verwendung sich seit dem Mittelalter die konzeptuelle Bedeutungsebene gegenüber dem zunächst rein motorischen Gebrauch durchsetzt, wie Matthias Rein in einer groß angelegten Begriffsstudie gezeigt hat: Beide Ebenen stehen in Analogie zueinander im Sinne von ,umkehren“, also „die Richtung seiner bisherigen Bewegung um $180^{\circ}$ ändern“, wobei die physische Bewegung im Konzept der Konversion zu einer geistigen metaphorisiert wird und dann bedeutet, „die eigene mentale Einstellung zu etwas (oder jemandem, im Falle des personal gedachten Gottes) radikal (womöglich ins Gegenteil) [zu] ändern“. ${ }^{61}$ Rein unterscheidet dabei zwischen einem institutionalistischen und einem existentialistischen Aspekt des Konzepts Bekehrung. Es sei

,institutionalistisch' insofern, als der Akzent hier auf der Institution oder den Institutionen Religionsgemeinschaft/Kirche beziehungsweise auch Klerus/Orden liegt, ,existentialistisch insofern, als Sein und Leben des Menschen als Ganzes und eben radikal - von ihrer Wurzel her - vor Gottes Angesicht zu gänzlichem Wandel in Form vollständiger Umkehr verpflichtet sind. ${ }^{62}$

Das entspricht letztlich der ,äußeren‘ und ,inneren“ Dimension von Konversion als Religionswechsel beziehungsweise hier dann dem Eintritt in den geistlichen Stand als zunächst einmal ,äußere‘ Lebensform und der völligen Hinwendung zu Gott, die ich weiterhin als ,innere“ bezeichnen möchte, weil mir damit deutlicher als in Reins begrifflicher Unterscheidung zu werden scheint, dass es sich dabei um eine binnenchristliche und persönliche Bewegung handelt, die dem Streben nach Heiligkeit als dem Maximalpunkt des christlichen Eigenen entspricht.

Der Begriff conversio bezeichnet also zwei unterschiedliche Realitäten: den ,äußeren' Religionswechsel oder Eintritt in den geistlichen Stand und die ,innere‘ Bekehrung als „umfassende[r] Sinneswandel und Austausch der Sinnbildungsinstanzen“63. Sowohl die doppelten Bedeutung von Konversion als ,äußerem“ Glaubenswechsel und ,innerer' Hinwendung zu Gott als auch die von Ereignishaftigkeit oder Prozessualität können sich aber überlagern: Konversion erscheint dann als der Beginn des christlichen Lebens einer Person in einer radikalen und exklusiven Hinwendung zum christlichen Glauben und zugleich als innerchristlicher Prozess einer

60 Vgl. Wolfgang Haubrichs: Bekennen und Bekehren (confessio und conversio). Probleme einer historischen Begriffs- und Verhaltenssemantik im zwölften Jahrhundert. In: Aspekte des 12. Jahrhunderts. Freisinger Kolloquium 1998. Hrsg. von dems. Berlin 2000 (Wolfram-Studien. 16), S. 121-156. 61 Matthias Rein: Conversio deutsch. Studien zur Geschichte von Wort und Konzept ,bekehren', insbesondere in der deutschen Sprache des Mittelalters. Göttingen 2012 (Historische Semantik. 16), S. 516. 62 Ebd., S. 517.

63 Weitbrecht, Bewegung - Belehrung - Bekehrung, S. 112. 
Vertiefung oder Intensivierung dieses Glaubens in einer ,vertikalen Konversion'.64 Letztere Bedeutung wird gerade dann wichtig, wenn das Christentum schon zur etablierten und vorherrschenden Glaubensrichtung geworden ist, und hier liegt auch das Potential von Konversionserzählungen: Sie stellen auf einer primären und eben ,äußerlichen' Ebene metaphorisch dar, was sonst schwer zu veranschaulichen ist, denn Religionswechsel sind einfacher darstellbar als innere geistige Prozesse.

Deshalb mag der religionswissenschaftliche Vorschlag, zwischen Konversion als dem „Religionswechsel, der ad hoc geschieht und vom Konvertiten die Anerkennung einer neuen religiösen Wahrheit (bei gleichzeitigem Widerruf der alten) verlangt“, und der Bekehrung als innerer Umwandlung, die „einen allmählichen Aufstieg zum Absoluten und [...] eine Rückkehr zum Ursprung“ meine, ${ }^{65} \mathrm{zu}$ unterscheiden, systematisch sicher berechtigt sein. Er verfehlt aber den inneren Zusammenhang dieser beiden Phänomene beziehungsweise deren Inszenierung und erzählerische Vermittlung im christlichen Binnendiskurs: Bekehrung als innere Hinwendung zu Gott wird von allen, Christen wie Heiden, gefordert und Religionswechsel werden als Bekehrungen imaginiert. Konversionserzählungen narrativieren die von jedem Menschen zu vollziehende innere Umkehr in der klaren äußeren Axiologie eines exemplarischen Übertritts vom Heidentum zum Christentum, und mehr noch: Sie verdichten dabei den längeren, möglicherweise lebenslangen Prozess der ,Rückkehr zum Ursprung‘ in einem ereignishaften exemplarischen Umschlagmoment.

Das wird an der, nach der Bekehrung des Paulus, zweiten grundlegenden christlichen Konversionserzählung deutlich, der Bekehrung des lateinischen Kirchenlehrers Augustinus, wie er selbst sie in seinen Confessiones schildert. ${ }^{66}$ Auch sein Weg führt nicht einfach vom Heidentum zum Christentum, vom Unglauben zum Glauben, sondern durch Wirrungen, die ihn zwar nicht wie Saulus zum Christenverfolger werden lassen, ihn aber zunächst vom christlichen Heil entfernen und das, nur scheinbar paradoxerweise, im Streben nach Erkenntnis. 354 in Nordafrika als Sohn einer christlichen Mutter geboren und von dieser entsprechend erzogen, aber nicht getauft, studiert er Rhetorik und befasst sich mit der heidnischen Philosophie Ciceros. Von der Bibel, vor allem den alttestamentlichen Schriften abgestoßen, wendet er sich zunächst dem Manichäismus (Conf. III 9-10) und später, auch von diesem enttäuscht,

64 Vgl. Ulrich Luz: Conversion in the New Testament. In: Religiöse Grenzüberschreitungen. Studien zu Bekehrung, Konfessions- und Religionswechsel. Hrsg. von Christine Lienemann-Perrin, Wolfgang Lienemann. Wiesbaden 2012 (Studien zur Außereuropäischen Christentumsgeschichte. Asien, Afrika, Lateinamerika. 20), S. 227-250, der Begriff der ,vertikalen Konversion“ auf S. 250. Diese Vielschichtigkeit bewahren die romanischen Sprachen bis heute, wenn dort conversion(e) „das gesamte Spektrum von (individueller) Bekehrung, Umkehr, Konfessions- oder Kirchenwechsel (auch „Übertritt“) sowie von Religionswechsel (im Sinne einer Veränderung der Zugehörigkeit)“ umfasst, so Lienemann, Einleitung, S. 17.

65 Peter Gerlitz: Art. Konversion I. Religionsgeschichtlich. In: TRE 20 (1990), Sp. 559-563, hier Sp. 559. 66 Lateinischer Text und deutsche Übersetzung im Folgenden nach der Ausgabe: Aurelius Augustinus: Confessiones/Bekenntnisse. Lateinisch-deutsch. Übersetzt von Wilhelm Thimme. Mit einer Einführung von Norbert Fischer. Düsseldorf/Zürich 2004 (Sammlung Tusculum). 
dem Skeptizismus zu. Neben diese geistigen Abwege treten jugendliche Ausschweifungen in der Studienzeit (Conf. II 1-4 und III 1) sowie eine 15 Jahre währende uneheliche Beziehung zu einer nicht standesgemäßen Frau, mit der er einen Sohn hat. Als Rhetoriklehrer in Mailand lernt er schließlich über Ambrosius die neuplatonische Bibelauslegung kennen (Conf. VI 3-4), befasst sich in der Folge mit dem christlichen Neuplatonismus, gleichzeitig mit den paulinischen Schriften und ihrer Gnadenlehre (Conf. VII 27), und ist schließlich von einer Lebensbeschreibung des Mönchsvaters Antonius tief beeindruckt (Conf. VII 13-18).

Seine endgültige Rückkehr zum Christentum vollzieht sich aber nicht in einem diskursiven Prozess, sondern wird in den Confessiones narrativ verdichtet zu einem gnadenhaft bewirkten Umschlagmoment, der zu einer völligen inneren Umkehr und Hinwendung zu Gott führt: Inmitten einer intellektuellen Krise, die sich auch psychisch und körperlich manifestiert, hört er im Garten seines Hauses unter einem Feigenbaum liegend eine Kinderstimme, die ihn auffordert: Tolle lege, „Nimm und lies!“ (Conf. VIII 29) Wenn er daraufhin wie zufällig eine Bibelstelle aufschlägt und sie als persönliche Botschaft Gottes versteht, die ihn zur Umkehr veranlasst, erscheint Bekehrung als ereignishafter Einbruch der Transzendenz in die Immanenz, in dem Kontingenz derart radikal ausgestellt wird, dass sie in Providenz umschlägt: In Gottes Ratschluss gibt es keinen Zufall, durch die nur scheinbar zufällig aufgeschlagene Bibelstelle spricht Gott selbst zu ihm. ${ }^{67}$ Im Römerbrief liest Augustinus eine sittliche Ermahnung just des Apostels Paulus, die er unmittelbar auf seinen bisherigen Lebenswandel beziehen kann:

sicut in die honeste ambulemus, non in comesationibus et ebrietatibus, non in cubilibus et impudicitiis, non in contentione et aemulatione, sed induite Dominum Iesum Christum, et carnis curam ne feceritis in desideriis (Röm 13,13-14).

Lasst uns ehrbar leben wie am Tage, nicht in Fressen und Saufen, nicht in Unzucht und Ausschweifung, nicht in Hader und Eifersucht; sondern zieht an den Herrn Jesus Christus und sorgt für den Leib nicht so, dass ihr den Begierden verfallt.

67 Das Motiv einer ,zufälligen 'Bibellektüre, in der sich Gottes Wille offenbart, findet sich - schon Augustinus folgt dabei dem Vorbild des Antonius, von dem er Ähnliches zu berichten weiß - im legendarischen Erzählen in unterschiedlichen Konstellationen wieder: Als das Volk Martin zum Bischof erheben will, halten ihn einige der anderen Bischöfe ob seines - infolge des asketischen Lebensstils ungepflegten Äußeren für unwürdig, allen voran ein Bischof mit dem sprechenden Namen Defensor (i. e. Widersacher). Weil der Lektor in der Menschenmenge nicht zum Ort seines Amtes dringen kann, greift einer der Umstehenden, vermutlich also ein Laie, den Psalter und liest den ersten Vers, den er findet und in dem es heißt: „Aus dem Mund von Kindern und Säuglingen hast du Lob bereitet wegen deiner Feinde, um den Feind und Widersacher (defensor) zu vernichten." Die Bedeutung dieser Lesung wird in der Vita sancti Martini explizit gemacht: Das Kirchenvolk sei der Ansicht gewesen, dass der Psalm auf göttliche Eingebung gelesen worden sei, damit der genannte Widersacher ein Schriftzeugnis zu seinem Handeln höre. Die Wahl Martins erscheint damit als unstrittig. Vgl. VM 9, 3-7. 
Angesichts dieser Mahnung - „ein Licht der Gewissheit“ habe ihn plötzlich durchströmt ${ }^{68}$ - vollzieht er eine völlige Umkehr, entsagt seinem Beruf und der Ehe, die seine Mutter inzwischen mit einer standesgemäßen Christin angebahnt hatte, und zieht sich mit seinen Freunden auf ein Landgut zurück, wo sie gemeinsam in klosterähnlicher Weise zusammenleben, bevor er, mittlerweile getauft, vom Volk zum Priesteramt berufen wird. Die einmalige Konversion zum Christentum ist nur der Anfang eines längeren Prozesses, der in einer vertikalen Konversion allmählich zum Absoluten hinauf- und zurückführt. Sie markiert daher den Beginn einer christlichen Lebensweise, die hier nicht anders als asketisch sein kann: „,Bekehrung“ meint hier Bekehrung zum asketischen Leben. Christlicher Glaube, so nun die Einsicht Augustins, erfüllt sich erst in der Askese.“69

Dass es bei seiner Bekehrung nicht nur um einen Wechsel der Glaubenssysteme gehen kann, sondern um eine konsequent vollzogene Umkehr und Rückkehr zum Ursprung, dessen biographische Markierung in der christlichen Erziehung seiner Kindheit nur vordergründig ist, reflektiert Augustinus an einer früheren Stelle seiner Confessiones. Seinen persönlichen Lebensweg, der ihn zunächst in rein menschlichem Erkenntnisstreben auf zugleich intellektuelle und sittliche Abwege führt, aus der ihn nur die göttliche Gnade retten kann, ordnet er ein in die allgemeine Entfremdung des Menschen von Gott und der daher rührenden Notwendigkeit einer existentiellen Umkehr:

vivit apud te semper bonum nostrum, et quia inde aversi sumus, perversi sumus. revertamur iam, domine, ut non evertamur, quia vivit apud te sine ullo defectu bonum nostrum, quod tu ipse es (Conf. IV, 16, 31).

Bei dir ist's gut sein immerdar, und ganz verkehrt, sich abkehren von dir. Zurückkommen, Herr, wollen wir zu dir, daß wir nicht umkommen, denn bei dir ist's gut sein, wahrhaft gut und ohne Mangel, denn du selbst bist unser Gut.

Das heilsgeschichtliche Schema der Abwendung des Menschen von und der zu seiner Rettung nötigen Wiederzuwendung zu Gott, verdeutlicht Augustinus hier im Spiel mit den Bedeutungsdimensionen von lateinisch verto, „wenden“ oder „kehren“: Die Abkehr von Gott als dem Ursprung und der Fülle des Lebens ist eine Verkehrung, des Menschen und der ihm bestimmten Ordnung, die ihn ins Verderben führen muss, wenn er nicht wieder um- und zurückkehrt. Diese Umkehr aber ist kein einmaliges Ereignis, sondern eine lebenslange Aufgabe. Seine Bekehrung, die er in einer einzigen Szene narrativ verdichtet, ist in diesem Sinne nur eine, wenngleich die erste und entscheidende Etappe eines Weges, an dessen Ende auch seine Verehrung als Heiliger

68 Statim quippe cum fine huiusce sententiae quasi luce securitatis infusa cordi meo omnes dubitationis tenebrae diffugerunt. (Conf. VIII 29)

69 Jörg Ulrich: Kommentar. In: Augustinus: Bekenntnisse. Confessiones. Aus dem Lateinischen übersetzt von Joseph Bernhart. Hrsg. von Jörg Ulrich. Frankfurt a. M./Leipzig 2007, S. 367-580, hier S. 399. 
stehen wird. ${ }^{70}$ Das asketische und monastische Streben gehört daher fest zum Bild des Augustinus, dessen theologische und philosophische Lehre die westliche Kirche bis ins hohe Mittelalter, und weit darüber hinaus, maßgeblich geprägt hat. Auch er wird letztlich vom Heiden, gar vom Häretiker, zum Heiligen, der nun als Kirchenlehrer die theologischen Fundamente der Kirche setzt und dabei auch das Christentum gegen das Heidentum verteidigt. ${ }^{71}$

\subsubsection{Die Narrativierung von Konversion zwischen Ereignis und Prozess}

Die beiden für die christliche Tradition modellbildenden Beispiele narrativieren Konversion auf unterschiedliche Weise: Das ,Gartenerlebnis‘ des Augustinus lässt einen offenkundig längeren diskursiven Prozess der Suche und Hinwendung zum Christentum in einer einzigen Schlüsselszene kulminieren, in der durch den gnadenhaften Eingriff Gottes der entscheidende Umschwung vom Unglauben zum Glauben, vom sündhaften zum heiligmäßigen Leben bewirkt wird. Das ,Damaskuserlebnis‘ des Paulus narrativiert die axiologisch noch stärker kontrastiv besetzte und daher auf diskursivem Wege noch weniger plausibilisierbare Umkehr vom Christenverfolger zum Völkerapostel als unmittelbare göttliche Erwählung in der Heilspräsenz, die jedes menschliche Erkenntnisvermögen kategorial übersteigt.

Konversion lässt sich also einmal darstellen als diskursiver Prozess einer Auseinandersetzung mit und einer sukzessiven Hinwendung zu den Inhalten des christlichen Glaubens. Einem solchen Erkenntnisprozess steht ein Verständnis gegenüber, das Konversion als ereignishaftes, plötzliches Umschlagphänomen erzählt, nämlich als Effekt einer unmittelbaren Erfahrung von Transzendenz, vor der herkömmliche Erkenntnismodelle versagen müssen und die unmittelbar die Bekehrung zu Gott bewirkt. ${ }^{72}$ Diese zweite Option scheint gegenüber der ersten als ,überdeterminiert ${ }^{\text {“73 }}$ und verweist auf das Grundproblem legendarischen Erzählens. Denn ebenso wenig wie Heiligkeit als solche, sondern nur in ihren Wirkungen darstellbar ist, so auch die ,innere‘ Bekehrung, die den ,äußeren` Religionswechsel begleiten oder den christlichen Glauben vertikal vertiefen soll. Denn es kann wohl erzählt werden, dass sich jemand taufen lässt oder eine geistliche Lebensform wählt, aber nicht, was im Hin-

70 „Mit dem Begriff conversio nimmt Augustinus diesen ganzen, über Jahrzehnte sich erstreckenden Prozeß in den Blick, die Einzelereignisse sind für ihn lediglich Etappen auf diesem Weg, der sein halbes Leben in Anspruch nimmt, nicht conversiones je eigenen Anspruchs." Rein, Conversio deutsch, S. 62. 71 Erinnert sei hier nur an De civitate Dei, eine seiner berühmtesten theologisch-philosophischen Schriften, die mit der Scheidung von irdischem Staat und Gottesstaat nicht nur das christliche Selbstverständnis prägen wird, sondern auch als Antwort auf zeitgenössische Vorwürfe von heidnischer Seite zu verstehen ist, das Christentum sei für den Niedergang des Römischen Reiches verantwortlich. Vgl. oben in Kap. 2.2.1 Heidentum als dynamischer Gegenbegriff, S. 48.

$72 \mathrm{Zu}$ diesen beiden Modellen vgl. Hammer, Seidl, Die Ausschließlichkeit des Heiligen, S. 281-282. 73 Vgl. ebd., S. 280. 
blick auf den geistlichen Gehalt von Konversionserzählungen eigentlich interessiert, nämlich das innere Wie und Warum: Der eigentliche Kern, die innere Hinwendung zu Gott, bleibt ein eigentümlich blinder Fleck, der je und je narrativ vermittelnd eingeholt werden muss. Diskursiv bleiben Konversionen daher prekär, das zeigt gerade das für einschneidende Selbsterkenntnisse aller Art emblematisch gewordene ,Damaskuserlebnis‘. Denn alles, was über die Bekehrung und Erwählung des Saulus gesagt wird, ist narrative, zeichenhafte Vermittlung des eigentlich Nicht-Darstellbaren:

Es ist [...] nicht das göttliche Wort, das die conversio bewirkt, auch und auch nicht jene Phänomene wie das Licht, die den anderen nicht wahrnehmbar sind; es ist vielmehr die Erfahrung der Unmittelbarkeit des Göttlichen, wofür die beschriebenen Effekte lediglich narrative Ausdrucksformen sind, Begleiterscheinungen, die den Einbruch der Transzendenz auf der Ebene des Erzählens veranschaulichen. Gott überzeugt Saulus nicht mit Argumenten, er überzeugt ihn mit seiner Präsenz. ${ }^{74}$

Diese Darstellung kann als plausibel angenommen, geglaubt und in der Rezeption wirksam werden, weil es den christlichen Rezipienten der Apostelgeschichte wie anderer Konversionslegenden zunächst nicht darauf ankommt, „zu erfahren, wie [der Heide] überzeugt worden ist, entscheidend ist allein, dass er es ist “ ${ }^{75}$ Das verweist auf ein grundlegendes narratologisches Problem: Wenn Konversionen Gegenstand von anschlussfähiger Kommunikation sein sollen, braucht es Mitteilungsformen, also sprachliche Muster und Metaphern, während der Anspruch unmittelbarer religiöser Erfahrung dem gerade entgegensteht und sprachloses, nicht mitteilbares Staunen angesichts des heilspräsentischen Einbruchs der Transzendenz in die Immanenz evoziert, intradiegetisch wie in der extradiegetischen Repräsentation. Wenn von solchen Konversionen erzählt werden soll, braucht es Codes, also schematische Kategorisierungen in Gestalt binärer Oppositionen, zwischen denen ein gradueller oder plötzlicher Prozess darstellbar ist. ${ }^{76}$ Narrativ prozessualisieren lässt sich Konversion dann, indem Leerstellen erzeugt werden, die mit dem Einbruch von Transzendenz gefüllt werden können, der den entscheidenden Umschlag zur Heiligkeit bewirkt. Solche Umschlagphänomene können nun gerade in der Narrativierung von Bekehrungserlebnissen überdeutlich markiert werden, ${ }^{77}$ weil hier Schuld in Gnade, Unglaube in Glaube, Gottesferne in Gottesnähe umschlägt.

Diese narratologisch-religionswissenschaftlichen Überlegungen decken sich bezeichnenderweise mit den Ergebnissen der empirisch fundierten religionspsychologischen und religionssoziologischen Konversionsforschung, wie sie sich seit dem Anfang des 20. Jahrhunderts vor allem in den Vereinigten Staaten etabliert hat. Zunächst einmal decken sie sich in der ganz basalen Beobachtung, dass Konversionen meist als Umschlagmomente, als einmalige und besondere Ereignisse imaginiert und

74 Vgl. Hammer, Zwischen ratio und Erleuchtung, S. 330.

75 Mit Bezug auf die Legende der heiligen Cäcilia und die Bekehrung des Tyburcius ebd., S. 334.

76 Vgl. Lienemann, Einleitung, S. 29-30.

77 Vgl. Hammer, Erzählen vom Heiligen, S. 361. 
inszeniert werden, demgegenüber sie als empirisches Phänomen Ergebnisse langwieriger Prozesse sind - wenn überhaupt ein solcher Endpunkt ausgemacht werden kann und Konversionen nicht grundsätzlich eine lebenslange Annäherung und Entwicklung bedeuten. ${ }^{78}$ Diese Verdichtung von Prozessen zu Ereignissen, von beständigen Entwicklungen zu einmaligen Umschlagmomenten, entspricht nun der normativen und deskriptiven Definition von Konversion in der jüdisch-christlichen Tradition als vollkommene Ablehnung alles Bösen beziehungsweise der Gottesferne und Eintritt in eine Beziehung mit Gott, der dabei Ursache wie Ziel der Konversion ist. $^{79}$

Aus dieser eigentümlichen Verschränkung erklärt sich der Doppelcharakter von Konversionen zwischen Ereignis und Prozess: Sie sind gleichermaßen als punktueller Einbruch der Transzendenz in die Immanenz - als gnadenhaftes Wirken Gottes am Menschen - wie als Bewegung aus der Immanenz in die Transzendenz - als sukzessive Annäherung des Menschen an Gott, die ihrerseits gnadenhaft vermittelt ist - zu verstehen. In dieser Überlagerung der beiden Bewegungsrichtungen, die aber in jedem Fall von Gott ausgehen und der menschlichen Verfügbarkeit entzogen sind, liegt die Aufgabe der Narrativierung von Konversion. Das Glaubensereignis, das als der Konversion zugrundeliegend und für diese eigentlich bedeutsam angenommen wird, muss vermittelnd dargestellt werden in einer Prozessualisierung, in der Gott als der Handelnde hervortritt: Der Mensch kehrt nicht aus eigenem Vermögen um, erlöst sich nicht selbst, sondern Gott bewirkt seine Konversion und holt ihn zu sich ,zurück'. Transitive und intransitive Konversion fallen in Gott - beziehungsweise in der religiösen Kommunikation, die die Immanenz unter dem Gesichtspunkt der Transzendenz betrachtet - zusammen.

Dieser theologischen Zuordnung von menschlichem Streben und göttlichem Gnadenhandeln in der Konversion entspricht nun der empirische Befund der Religionssoziologie, wonach Konversionsprozesse von zwei möglichen Ausgangspunkten ausgehen, die freilich miteinander korrelieren können: Entweder vom Auftreten eines Glaubensvertreters, der eine neue Weltdeutung anbietet, durch die der sich zu Konvertierende in einem neuen Licht sieht, oder von irgendeiner Form der Krise, die den Glaubensprozess auslöst, auf den die neue, richtige und vollkommene Weltdeutung schließlich die Antwort bietet. ${ }^{80} \mathrm{Zu}$ den Katalysatoren von Krisen gehören dabei, psychologisch formuliert, ,mystische Erlebnisse“ - man könnte auch sagen: Transzendenzerfahrungen - ebenso wie Lebenskrisen in Form von Todesnähe, Krankheit, Alter. ${ }^{81}$ Der Übergang von der alten zur neuen Weltdeutung, den die Konversion markiert, ist nun, entgegen der üblichen Inszenierung als ereignishafter Umschlag,

78 Vgl. Lewis R. Rambo: Understanding religious conversion. New Haven/London 1993, S. 5-7. 79 Vgl. ebd., S.10. Hier freilich allgemeiner und systematisch formuliert: „Religion is the sacred - the encounter with the holy that, according to many religions, constitutes both the source and goal of an conversion."

80 Vgl. ebd., S. 44.

81 Vgl. ebd., S. $48-49$. 
kein rein ,inneres‘ und spontanes Geschehen, sondern in einen Kommunikations- und Interaktionszusammenhang eingebettet und von diesem vermittelt, insofern also immer schon ein Prozess:

Trotz der Bedeutung, welche Bekehrte sehr oft einer akut empfundenen Krise oder einem einzelnen Ereignis zuschreiben, darf Bekehrung nicht als unvermittelt-plötzliche Umkehr verstanden werden, sondern als Prozeß. Dieser ist im spezifischen Milieu zu situieren, welches die Erfahrung der Krise auslöst, aber auch das aktive Suchen nach neuer Orientierung beeinflußt. ${ }^{82}$

Die Interaktion zwischen den Vertretern des neuen Glaubens und dem Konvertierenden vollzieht sich auf sprachlicher wie symbolischer Ebene, die nicht nur den präskriptiv normierten Vollzug von Konversionen, sondern auch deren deskriptive Inszenierung und Erinnerung bestimmen. Die Sprache der Konversion ist eine der Transformation, wobei Konzeptualisierung und Interpretation der Veränderungen in enger Wechselwirkung stehen. ${ }^{83}$ Neben der Rhetorik aber sind Rituale von besonderer Bedeutung, weil sie religiöses Wissen nicht nur kognitiv vermitteln, sondern ausagieren. Konversionsstrategien setzen dabei auf zwei unterschiedliche Typen von Ritualen: dekonstruktive und rekonstruktive, ${ }^{84}$ also solche, die das alte Weltbild entwerten, und solche, die dem Konvertierenden ein neues Weltbild erschließen und ihn als Neophyten in seiner neuen Identität bestärken, damit die Inszenierung dramatischer Umbrüche ermöglichen. ${ }^{85}$

Rituale binden und verpflichten also den Konvertierenden, indem sie die Ablehnung des Alten, den Übergang und schließlich Eingliederung in die neue Glaubensgemeinschaft inszenieren, ${ }^{86}$ bieten zudem die Möglichkeit einer dramatisierenden und effektvollen Aushandlung der Konversion, die über eine rein sprachliche Vermittlung, die immer nur ein Sprechen über etwas ist, hinausgeht, indem sie sie symbolisch vollziehen. ${ }^{87}$ Damit aber haben Rituale im Zusammenhang mit Konversionen eine doppelte Funktion: Der Konvertierende wird durch ihren Vollzug in seinen Überzeugungen bestärkt, ebenso aber die Glaubensgemeinschaft, der er sich anschließt: „Seeing the initiation ritual enacted reminds other members of their own

82 Bischofberger, Art. Bekehrung/Konversion, Sp. 1228-1229.

83 Vgl. Rambo, Understanding religious conversion, S. 118-119.

84 Vgl. ebd., S. 116.

$85 \mathrm{Zu}$ denken wäre hier, personal gedacht, an die Taufe, der ein Exorzismus als rituelle Absage an das Böse und die ,alten' Götter vorausgeht und die den Täufling mit dem Wasser von seinen Sünden reinwäscht - oder noch stärker symbolhaft verstanden: ihn mit Christus sterben und auferstehen lässt - und ihn in die Gemeinschaft der Kirche eingliedert, außerdem, auf die Christenheit als Kollektiv bezogen, an die missiongeschichtliche Unterscheidung von ,negativer‘ und ,positiver‘ Missionsarbeit, von ,Entpaganisierung‘ durch Zerstörung heidnischer Kultstätten und Götzenbilder, die aus christlicher Sicht deren Ohnmacht erweisen, und ,Christianisierung‘ durch Taufe und Unterweisung. Vgl. dazu noch ausführlicher unten S. 333, Anm. 225.

86 Vgl. Rambo, Understanding religious conversion, S. 124.

87 Vgl. ebd., S. 128. 
commitment to a new way of life; they re-experience their own transformation. "88 Durch diese symbolische Wiederholung und Erinnerung der Überwindung des alten durch den neuen Glauben aktualisieren Konversionen immer wieder die Glaubensgrenze, die das Selbstbild der Gemeinschaft, nach außen wie innen, bestimmt: Die als ereignishafter Umschlagmoment inszenierte Konversion eines exemplarischen Einzelnen ist in einen rituellen Prozess eingebunden, der die kollektive Identität der Gemeinschaft befördert, zu der er konvertiert.

In diesem Zusammenhang zeigt sich schließlich auch die eigentliche Bedeutung der Inszenierung von Konversionen als diskursiven Prozessen, also bewirkt und bestimmt durch die erkenntnisgeleitete Beschäftigung mit den Inhalten des neuen Glaubens. Denn diese ist ihrerseits keinesfalls $\mathrm{zu}$ verstehen als ,realistische“ Beschreibung, die ihre Funktion unmittelbar in der Verteidigung und als Modell einer gelingenden Verbreitung des christlichen Glaubens finden könnte, sondern als spezifische Narrativierung von Konversion, die der kollektiven christlichen Identitätsbildung in der immer wieder neu zu aktualisierenden Überwindung des heidnischen Unglaubens dient. Die christliche Kirche kennt daher eine lange, in ihre Entstehungszeit zurückreichende, und breite Tradition dialogisch inszenierter Auseinandersetzungen mit dem Heidentum, die weit weniger apologetisch und polemisch nach außen gerichtet sind, als dass sie in ihrer Topik der innerchristlichen Belehrung, Ermahnung und Selbstreflexion dienen. Schon in den Schriften des Apostels Paulus zeigt sich, dass die Auseinandersetzung mit dem Heidentum keinem historischen heidnischen Gegenüber gilt:

Paulus übernimmt die traditionellen Topoi jüdischer Heidenpolemik, verwendet diese aber nicht so sehr zu Polemik nach außen gegen die Heiden, sondern setzt sie vor allem im Rahmen seiner Paränese zur Schelte von innergemeindlichen Mißständen ein oder benutzt sie als Negativfolie, von der sich die Christen in ihrem Verhalten positiv abheben sollen. ${ }^{89}$

Von daher scheint es mehr als fraglich, ob Konversionserzählungen, auch unter den Bedingungen tatsächlicher religiöser Auseinandersetzungen in der Spätantike, wirklich, wie mitunter emphatisch behauptet, so etwas wie eine „Dialogisierung religiöser Wahrheiten“90 ermöglichen. Unbestreitbar bieten sie „den Diskussionen und Disputationen religiösen Wissens viel Raum, sie sind also nicht nur Medien der Festschreibung, sondern auch der Zirkulation religiöser Inhalte“.${ }^{91}$ Von einer veritablen Verhandlung und Neudefinition religiöser Selbst- und Fremdbilder im Konversionsparadigma kann dabei aber keine Rede sein, denn die christlichen Konversionser-

88 Ebd., S. 129.

89 Ulrich Heckel: Das Bild der Heiden und die Identität der Christen bei Paulus. In: Die Heiden. Juden, Christen und das Problem des Fremden. Hrsg. von Reinhard Feldmeier, Ulrich Heckel. Tübingen 1994 (Wissenschaftliche Untersuchungen zum Neuen Testament. 70), S. 269-296, hier S. 282.

90 Bernuth/Röcke/Weitbrecht, Einleitung, S. 3.

91 Ebd. 
zählungen schreiben ja gerade die christliche Religion als alleiniges Deutungsmuster fest, das es immer wieder neu zu bewähren gilt:

\begin{abstract}
Voraussetzung dafür ist jedoch zugleich die Existenz anderer, als falsch abgewiesener Konzepte, die in der jeweiligen Konversionserzählung immer wieder aufgerufen und aktualisiert, inkludiert oder aber in der Exklusion sichtbar gehalten werden. Somit ermöglicht Konversion grundsätzlich die Verhandlung divergierender Deutungsangebote, diese werden jedoch nicht [...] argumentativ gegeneinander abgewogen, sondern vielmehr im Prisma der einen ,richtigen` Weltanschauung einer universalen Interpretation unterworfen..$^{92}$
\end{abstract}

Als literarisch inszenierte Auseinandersetzung von wahrem und falschem Glauben haben Religionsdispute apologetischen Charakter: Sie sind nie unparteiisch, sondern setzen die Überlegenheit des eigenen, christlichen Glaubens immer schon voraus, leisten aber für die Aushandlung des religiösen Gegensatzes eine narrative Diskursivierung des religiösen und theologischen Wissens im Umgang mit dem Heidentum, auch im Hinblick auf die Möglichkeiten einer Bekehrung der Heiden. Denn sie konstruieren oder reproduzieren nicht simple Feindbilder, sondern zeigen das religiös Eigene in der Aushandlung mit und seiner Bewährung gegenüber dem religiös Fremden.

Im Hinblick auf die hochmittelalterlichen Bemühungen in der Heidenmission muss sich die Reichweite solcher Erzählungen allerdings als begrenzt erweisen, weil sie keine realen Glaubensgegner darstellen, sondern ein typologisch-hermeneutisch begründetes Heidenbild in einem christlichen Binnendiskurs, und damit eben keine adäquate Missionsmethode entwerfen oder reflektieren: Die päpstlichen Versuche, muslimische Herrscher durch diskursive Glaubensvermittlung in Form dogmatischer Argumente zur Konversion zum Christentum zu bewegen, scheinen in ihrem Anliegen wie in ihrer Methodik die tatsächlichen Gegebenheiten und damit vor allem auch die Gelingensbedingungen von Glaubensgesprächen eklatant zu verkennen - sie zeugen in ihrer scheinbaren ,Naivität‘ aber vor allem von der Wirkmacht der seit den Zeiten der alten Kirche tradierten Konversionserzählungen.

Ihre Funktion finden diese in der Vergegenwärtigung der Überwindung des historischen Heidentums und damit der grundlegenden, heilsgeschichtlichen Wende durch das Christentum in ihrer Bedeutung für die Kirche und den einzelnen Gläubigen. Sie wiederholen die historische Widerlegung also nicht, sondern aktualisieren sie in einer spiritualisierenden Neu-Interpretation, bei der sich der Christ im konvertierenden Heiden selbst erkennen und zur eigenen Umkehr angeleitet werden soll. ${ }^{93}$

92 Ebd.

93 Ein solches aktualistisches und spiritualisierendes Verständnis des Heidentums findet sich nicht nur im Kontext geistlicher Literatur im engeren Sinne, sondern strahlt auch auf das weltliche Erzählen aus, wie einige interessante Untersuchungen zum Heidenbild im höfischen Roman zeigen: Der Heide erscheint hier als der bessere ,Doppelgänger', der dem Christen einen Spiegel vorhält - seiner Selbst wie seiner mythischen und biblischen Vergangenheit - und dessen Integration ins Eigene nicht nur dogmatischen Notwendigkeiten entspringt, die bei laikalen Autoren nur zurückhaltend geäußert 
Diese Spiritualisierung des Heidentums, wie der Konversion insgesamt, ist freilich bereits im Neuen Testament, im Motiv der Ablösung des alten, sündhaften durch den neuen, heiligen Menschen, angelegt: deponere vos secundum pristinam conversationem veterem hominem, qui corrumpitur secundum desideria erroris, renovamini autem spiritu mentis vestrae, et induite novum hominem qui secundum Deum creatus est in iustitia et sanctitate veritatis (Eph 4, 22-24). ${ }^{94}$

Für die Narrativierung von Konversion ergibt sich daraus eine Verknüpfung von Umschlagphänomenen als heilspräsentischen Ereignissen mit diskursiven Prozessen in der Vermittlung von Glaubensinhalten. Schon in der Apostelgeschichte werden beide Extreme geschildert: „Bekehrung allein auf ein Wunder hin - Bekehrung allein durch die Missionspredigt ohne irgend welche Wunderzutat. "95 Häufiger als die jeweilige Reinform ist ihre Verschränkung miteinander: Wunder können die Predigt begleiten und, nachträglich, beglaubigen oder, anders herum, Ausgangspunkt für die Predigt sein. ${ }^{96}$ Das heilspräsentische Ereignis, wenn es nicht der Bestätigung zuvor diskursiv dargestellter Glaubensinhalte in actu dient, bildet den Anlass für eine entsprechende Unterweisung, denn es bedarf einer diskursiven Vermittlung, die den Einbruch der Transzendenz in die Immanenz verstehbar macht und in seiner Bedeutung auslegt, weil sonst nur sprachloses Staunen und folgenloses Nicht-Verstehen des Wunders bliebe. ${ }^{97}$

Das Staunen aber „wird in Bekehrungsnarrativen immer wieder als Initialmoment der conversio eingesetzt“98, sei es das erschreckte Staunen vor der sich im Irdischen manifestierenden Wundermacht Gottes oder das epistemologische Staunen, das einen reflektierenden Erkenntnisdiskurs eröffnet: Vollzieht sich Konversion im ersten Fall „als ein Überwältigtsein von der sichtbar gewordenen Macht Gottes“, also in einem öffentlich und kollektiv in der performativen Präsenz ausgetragenen Machtdiskurs,

werden, vielmehr gilt: „la conversion du païen est un prétexte pour la métanoïa du chrétien qui, à son contact, évolue et s’améliore“. Catalina Gîrbea: Le double romanesque et la conversion. Le Sarrasin, le Juif et le Grec dans les romans allemande (XIIe-XIIIe siècles). In: Cahiers de civilisation médiévale 54, 3 (2011), S. 243-286, hier S. 286. Ähnliche Beobachtungen auch bei Hathaway, Stephanie: Saracens and Conversion. Chivalric Ideals in Aliscans and Wolfram's Willehalm. Frankfurt a. M. 2012 (Studies in Old Germanic Languages and Literatures. 6). Vgl. in diesem Zusammenhang auch Manuela Schotte: Christen, Heiden und der Gral. Die Heidendarstellung als Instrument der Rezeptionslenkung in den mittelhochdeutschen Gralsromanen des 13. Jahrhunderts. Frankfurt a. M. [u. a.] 2009 (Germanistische Arbeiten zu Sprach und Kulturgeschichte. 49).

94 „Legt von euch ab den alten Menschen mit seinem früheren Wandel, der sich durch trügerische Begierden zugrunde richtet. Erneuert euch aber in eurem Geist und Sinn und zieht den neuen Menschen an, der nach Gott geschaffen ist in wahrer Gerechtigkeit und Heiligkeit.“

95 Aland, Über den Glaubenswechsel in der Geschichte des Christentums, S. 16.

96 Vgl. ebd., S. 16-20.

97 Wobei das Unverständnis beziehungsweise gar die mangelnde Wahrnehmungsfähigkeit der Heiden in Bezug auf das sich ereignende Heil dazu dienen kann, die Differenz zwischen Christen und Heiden, oder, auf der anderen Seite, die Differenz zwischen dem Heiligen und den gewöhnlichen Gläubigen zu markieren. Vgl. Hammer, Seidl, Die Entfremdung vom Eigenen, S. 144 u. 149.

98 Schnyder, Staunen und conversio, S. 170. 
der zu Massenkonversionen führen kann, ist sie im zweiten Fall das Erlebnis eines einzelnen Suchenden, „ein in der Regel zeugenloser Moment der Erkenntnis, Umschlag eines rationalen Prozesses“, und als solcher auf Sprache und Schrift verwiesen. ${ }^{99}$ Konversion bedarf dabei der Erzählung, die sie in ihren konkreten Wirkungen darstellt, um überhaupt sichtbar zu sein:

Die subjektive conversio muss sich in der Welt bewähren (bewahrheiten). Der stumme, regungslose Konvertit existiert im wahrsten Sinne des Wortes nicht. [...] In der Prozessualisierung des Umkehrmoments im Narrativ realisiert sich über die Sprache und die Zeichenhandlung die innerliche, subjektive conversio in der äußeren, intersubjektiven Welt. ${ }^{100}$

\subsection{Bekehrung als Wunder und Bekehrung durch Wunder: Silvester}

\subsubsection{Die Bekehrung des Kaisers durch den Papst als heilsgeschichtliche Wende}

Silvester ist der erste Papst, der nicht als Märtyrer zum Heiligen wird, sondern als Bekenner. Als heiliger Bischof verkörpert er ein wichtiges altkirchliches und frühmittelalterliches Heiligkeitsideal und gilt überdies als Begründer des römischen Kirchenwesens. ${ }^{101}$ Seine Vita verknüpft ihn mit Konstantin als dem ersten christlichem Kaiser und symbolisiert auf diese Weise die Wechselwirkung von sacerdotium und imperium, wie sie das Selbstverständnis der mittelalterlichen christianitas prägen wird. Die Verknüpfung der beiden Gestalten ist dabei eine fiktive: Zwar fällt das Pontifikat Silvesters I. (314-335) hauptsächlich in die Regierungszeit Konstantins (306 - 337), doch spielt er bei der Etablierung des Christentums keine tragende Rolle. Die religionspolitische Initiative liegt in dieser Zeit allein beim Kaiser und eine persönliche Begegnung zwischen beiden ist nicht überliefert. ${ }^{102}$

$\mathrm{Zu}$ historischer Bedeutung gelangt Silvester erst durch die Actus Silvestri, deren älteste Fassung wohl schon im 4. Jahrhundert entstanden ist und die ihn zu einer „Gegenfigur zum Kaiser“103 macht, indem sie ihn mit dessen Bekehrung verbindet. Konstantin wird hier in den üblichen legendarischen Mustern als heidnischer Herrscher vorgestellt, der die Christen verfolgen lässt, dafür aber von Gott mit Aussatz gestraft wird. Nachdem ihm in einem Traum die Apostel Petrus und Paulus erschienen sind, wendet er sich an Silvester und erlangt mit der Taufe die Heilung, privilegiert in der Folge das Christentum gegenüber dem Heidentum und macht den römischen Bischof zum Oberhaupt der christlichen Kirche. Die Kaiserinmutter aber hängt dem

99 Ebd., S. 171.

100 Ebd., S. 181.

101 Vgl. Brinker, Formen der Heiligkeit, S. 12.

102 Vgl. Ursula Schmitt: Art. Silvester I. In: BBKL 10 (1995), Sp. 338-341, hier Sp. 338-339.

103 Ebd., Sp. 339. 
jüdischen Glauben an und tadelt ihren Sohn ob seiner Konversion, der daraufhin eine öffentliche Disputation zwischen Christen und Juden einberuft, die den wahren Glauben erweisen soll. Silvester überwindet dabei mühelos die 12 besten jüdischen Gelehrten und erweist die Wahrheit des christlichen Glaubens zusätzlich noch in einem Wunder, der Auferweckung eines riesigen Stiers, was schließlich zur Bekehrung der Juden führt.

Dass es sich bei der Taufe Konstantins durch Silvester um einen frei erfundenen Zusammenhang handelt, Konstantin tatsächlich von einem arianischen Bischof und erst auf dem Sterbebett getauft wurde, erhellt die identitätsstiftende Dimension der Legende, die die fundamentalen dogmatischen Auseinandersetzungen mit dem Arianismus ausblendet, den ersten christlichen Kaiser damit posthum vom Häretiker zum Rechtgläubigen macht, neben dieser theologischen Funktion aber zugleich einer politischen Zielsetzung dient:

Die Legende war gewissermaßen Beweismittel für den römischen Klerus zur Durchsetzung seiner weltlichen Interessen. Voraussetzung dafür war die Verknüpfung, ja fast Identifizierung von Kirche und Staat. Deshalb mußten die historischen Fakten über Papst Silvester, die ihn als eher unbedeutenden Papst ausweisen, zugunsten einer Aufwertung seiner Person nachhaltig korrigiert werden. ${ }^{104}$

Indem Silvester zum Täufer Konstantins avanciert, wird er zum Symbol für den Sieg des Christentums in der religiösen Auseinandersetzung mit dem Heidentum sowie dem Judentum. ${ }^{105}$ Dass er damit bis ins hohe Mittelalter hinein ein besonderes Integrationspotential für ein christliches Publikum entfalten kann, zeigt sich in der eigenständigen Bearbeitung der Legende durch Konrad von Würzburg, die zwischen 1258/60 und 1274 datiert wird und sich vergleichsweise genau in einem bestimmten Entstehungs- und Rezeptionszusammenhang verorten lässt.

Lange mit dem Verdikt der Epigonalität belegt, gilt Konrad heute als „der profilierteste deutsche Autor der 2. Hälfte des 13. Jahrhunderts und zugleich - was man sowohl vom Umfang der Überlieferung seiner Werke als auch ihrer Wirkung ablesen kann - der erfolgreichste“. ${ }^{106}$ Als Berufsautor lebte er in Basel, wo er auch viele seiner Auftraggeber fand: „Inhalt und Umfang seines Euvres kennzeichnen ihn als überdurchschnittlich gebildeten Autor; der gesellschaftliche Rang seiner Auftraggeber verweist auf eine herausgehobene Stellung unter den Autoren seiner Zeit." ${ }^{\text {107 }}$ Sein

104 Lydia Miklautsch: Der Antijudaismus in den mittelalterlichen Legenden am Beispiel der Silvesterlegende in der Fassung des Konrad von Würzburg. In: Die Juden in ihrer mittelalterlichen Umwelt. Hrsg. von Alfred Ebenbauer, Klaus Zatloukal. Wien/Köln 1991, S. 173-182, hier S. 175.

105 Vgl. Horst Brunner: Art. Konrad von Würzburg. In: ${ }^{2}$ VL 5 (1985), Sp. 272-304, hier Sp. 287.

106 Ebd., Sp. 299-300.

107 Vgl. das Kapitel „Biographie und Werk“ in Rüdiger Brandt: Konrad von Würzburg. Kleinere epische Werke. 2. Aufl. Berlin 2009 (Klassiker-Lektüren. 2), S. 15-31, Zitat S. 30; außerdem ders.: Konrad von Würzburg. In: German literature of the High Middle Ages. Hrsg. von Will Hasty. Rochester, New Work 2006 (The Camden House history of German literature. 3), S. 243-253. Zur Entwicklung Basels im 
literarisches Schaffen, das von Legenden über Minneromane und verschiedene höfische Verserzählungen, Minne- und Sangspruchdichtung bis zum Trojanerkrieg reicht, steht im Funktionszusammenhang der Rezeption höfischer Literatur im städtischen Kontext und ist dem Hintergrund der spezifischen Interessen seiner jeweiligen Mäzene $\mathrm{zu}$ verstehen.

Seine Silvesterlegende verfasste Konrad nach Auskunft des Prologs (S 80) im Auftrag des Basler Domherren Liutold von Roeteln. Über die ,allgemeine“ religiöse Funktion der Legende hinaus sind daher in der Forschung drei spezifische Faktoren diskutiert worden: ${ }^{108}$ das klerikale Repräsentationsbedürfnis seines Auftragsgebers; dessen Beziehungen zu den Basler Zünften, denn Silvester galt als Patron unter anderem der Maurer; schließlich die kriegerische Auseinandersetzung des Basler Bischofs Heinrich von Isny mit Graf Rudolf von Habsburg seit 1286, die 1273 sogar zur Belagerung Basels führt, die Rudolf erst beendet, als er von seiner Wahl zum König erfährt - in dieser Situation, so jedenfalls eine Hypothese, könnte die Silvesterlegende im Auftrag Liutolds, der selbst Ambitionen auf das Bischofsamt hegte, ihre Funktion als Symbol einer vorbildlichen Zusammenarbeit zwischen geistlicher und weltlicher Macht, von imperium und sacerdotium gehabt haben. ${ }^{109}$ Im Gegensatz zum Asketen Alexius und dem Märtyrer Pantaleon, den beiden anderen Heiligen, deren Legenden Konrad von Würzburg im Auftrag verschiedener, geistlicher wie bürgerlicher, Mäzene in mittelhochdeutschen Versen verfasst, „verkörpert Silvester einen ganz anderen, ausgesprochen dominierend-aktiven Heiligentyp“, was ihn für eine „gezielte Repräsentation geistlicher Macht“ als besonders geeignet erscheinen lässt, ${ }^{110}$ zumal sein Kult in Basel durch eine Reliquie im Dom verankert war. ${ }^{111}$

13. Jahrhundert, deren politischer und wirtschaftlicher Aufschwung die Grundlage einer „glanzvollen Blütezeit ritterlicher Kultur“ und höfischer Dichtung bildet, vgl. Werner Meyer: Basel im 13. Jahrhundert. In: Das ritterliche Basel. Zum 700. Todestag Konrads von Würzburg. Katalog zur Ausstellung. Hrsg. von Christian Schmid-Cadalbert. Basel 1987, S. 23-31, Zitat S. 23.

108 Vgl. Brandt, Konrad von Würzburg, S. 21.

109 Zum letzten Punkt vgl. Timothy R. Jackson: The Legends of Konrad von Würzburg. Form, Content, Function. Erlangen 1983 (Erlanger Studien. 45), S. 41- 42 und zur Kritik daran mit Verweis auf Lütolds eigenen Konflikt mit dem Papsttum das Kapitel zum Silvester in Inge Leipold: Die Auftraggeber und Gönner Konrads von Würzburg. Versuch einer Theorie der Literatur als soziales Handeln. Göppingen 1976 (Göppinger Arbeiten zur Germanistik. 176), S. 46-65. Zwar wird Lütold 1309 vom Basler Domkapitel mit breiter Unterstützung der Bürgerschaft tatsächlich zum Bischof gewählt, diese Wahl findet aber nicht die Zustimmung des Papstes und führt zu langwierigen Auseinandersetzungen, die sogar so weit führen, dass der Papst das Interdikt über die Stadt verhängt und Lütold und seine Anhänger exkommuniziert, bis diese 1311 schließlich nachgeben. In diesem Sinne argumentiert auch Karin Cieslik: Die Legenden Rudolfs von Ems und Konrads von Würzburg. Eine vergleichende Untersuchung. In: Deutsche Literatur des Spätmittelalters. Ergebnisse, Probleme, Perspektiven der Forschung. Hrsg. von Wolfgang Spiewok. Greifswald 1986, S. 193-204, hier S. 195.

110 Rüdiger Brandt: Konrad von Würzburg. Darmstadt 1987 (Erträge der Forschung. 249), S. 73.

111 Dazu gehörte auch eine Reliquie der Kaiserinmutter Helena, die zum festen Bestand der Silvesterlegende gehört. Vgl. Leipold, Die Auftraggeber und Gönner Konrads von Würzburg, S. 47-49. 
Angesichts der Stellung des heiligen Silvesters im gesamtkirchlichen Kult sowie der Signifikanz seiner Legende für das Selbstverständnis der mittelalterlichen Christenheit scheint mir die Frage nach einer konkreten politischen Zweckbindung von Konrads Bearbeitung aber von untergeordneter Bedeutung. Denn das zentrale Thema der Silvesterlegende - die Überwindung des Heidentums sowie des Judentums durch das Christentum und die Demonstration seiner Überlegenheit - ist im Kontext der Fragen nach den Formen religiöser Auseinandersetzung im 13. Jahrhundert virulent. ${ }^{112}$ Dass dieser Stoff Gegenstand einer ausführlichen mittelhochdeutschen Bearbeitung wird, entspricht zudem dem Phänomen der zunehmenden Volkssprachigkeit und der Übertragung lateinischer Texte, besonders religiöser Erbauungsliteratur, für ein laikales Publikum. ${ }^{113}$ Solch einem Rezeptionsinteresse sieht sich offenbar auch Konrad verpflichtet, wenn er seinen Erzähler im Prolog des Silvester den Grund für seine Beauftragung durch Liutold erläutern lässt:

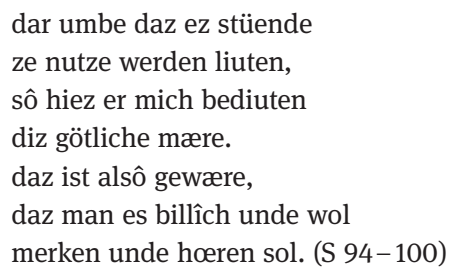

Vor dem Hintergrund des volkssprachigen Interesses an religiösen Stoffen ist auch die Qualität von Konrads Bearbeitung der Silvesterlegende zu verstehen: Zwar folgt er inhaltlich und bis in Wortlaut und Satzbau sehr getreu seiner lateinischen Vorlage, doch ist das nicht, wie es die ältere Forschung gern getan hat, als „sklavisch[e]“114 Abhängigkeit zu werten, sondern als spezifische Vermittlungsleistung, die eben nicht eine ,bloß' sprachliche Übersetzung, sondern immer schon eine semantisch-kulturelle Transformation ist und daher angemessener als ,interpretierende Übertragung “115 $\mathrm{zu}$ bezeichnen ist.

112 Vgl. dazu auch Hartmut Kokott: Konrad von Würzburg. Ein Autor zwischen Auftrag und Autonomie. Stuttgart 1989, S. 128, der auf das Konzil von Lyon 1274 verweist, das die Vereinigung mit der Ostkirche bringen sollte, wobei mir der Bezug zur Silvesterlegende dabei sehr vage scheint.

113 Vgl. Timothy R. Jackson: Konrad von Würzburg's legends. Their historical context and the poets' approach to his material. In: Probleme mittelhochdeutscher Erzählformen. Marburger Colloquium 1967. Hrsg. von Peter Felix Ganz, Werner Schröder. Berlin 1972, S. 197-213, hier S. 199.

114 Georg Prochnow: Mittelhochdeutsche Silvesterlegenden und ihre Quellen. In: ZfdPh 33 (1901), S. $145-212$, hier S. 147.

115 Brinker, Formen der Heiligkeit, S. 182. Knapp 28\% des Textes, wenn man solch einer numerischen Logik folgen will, seien keine direkte Übersetzung, sondern eigenständige Ausarbeitung: „Dabei handelt es sich nicht um inhaltliche Zusätze, sondern um Ausmalungen, die den Text trotz des geringen Gestaltungsspielraumes modellieren, interessanter und ansprechender machen sollen." Herma Kliege-Biller: und ez in tiusch getihte bringe von latîne. Der Silvester Konrads von Würzburg und seine Vorlage in den Actus Silvestri. Möglichkeiten und Grenzen einer Rekonstruktion. In: Edition und 
Die Forschung hat in diesem Zusammenhang festgestellt, dass sich die Legenden Konrads von seinen sonstigen Werken „,vor allem durch ihren schlichten Stil und den verhältnismäßig engen Anschluß an die lateinischen Vorlagen“ unterscheiden, wodurch zugleich „eine erhebliche Differenz zu der im 12. und 13. Jahrhundert sonst mehrfach begegnenden ,romanhaften' Legendenepik in deutscher Sprache“ entstehe. ${ }^{116}$ Doch unterscheidet sich Konrads Silvesterlegende nicht nur von zeitgenössischen ,romanhaften' Legenden, beispielsweise zu Reinbots Georgslegende und zum Barlaam und Josaphat Rudolfs von Ems. Vielmehr scheint sie auch „relativ weit entfernt von den ,üblichen“ legendarischen Erzählkonzeptionen“, insofern sie „in einen nicht primär hagiographischen Kontext eingebettet“ ist und „sich offenbar weniger an ein geistlich-klerikales denn an ein laikal-adeliges Publikum“ richtet. ${ }^{117}$ Es verfehlt daher ihren Funktionszusammenhang, den religiös-erbaulichen Anspruch gegen die ästhetisch-literarische Qualität ausspielen, letztere gar an der vermeintlichen Stilhöhe ,höfischer Legenden“ messen zu wollen.

Denn die Vermittlungsleistung Konrads liegt darin, einen Legendenstoff von unstrittiger religiöser Verbindlichkeit einem mit der mittelhochdeutschen Literatursprache des 13. Jahrhunderts vertrauten, städtischen Publikum zu Erbauung wie Unterhaltung darzubieten, eben daz man es billîch unde wol / merken unde horen sol. Die dazu zur Verfügung stehenden sprachlichen Muster sind die der höfischen Literatur, ohne dass damit gleich schon eine inhaltliche Veränderung einhergehen müsste, die den ,geistlichen Kern` der Legende zu Gunsten dezidiert höfisch-weltlicher Werte verändern würde. ${ }^{118}$ Es lässt sich vielmehr zeigen, dass Konrads ausführliche

Übersetzung. Zur wissenschaftlichen Dokumentation des interkulturellen Texttransfers. Beiträge der Internationalen Fachtagung der Arbeitsgemeinschaft für germanistische Edition, 8. bis 11. März 2002. Hrsg. von Bodo Plachta. Tübingen 2002, S. 45-54, hier S. 50.

116 Horst Brunner: Konrad von Würzburg. Versuch eines Porträts. In: Ders.: Studien zur deutschen Literatur des Mittelalters und der Frühen Neuzeit. Berlin 2008 (Philologische Studien und Quellen. 210), S. 173-184, hier S. 179.

117 Hammer, Erzählen vom Heiligen, S. 410.

118 So die ewige Schimäre der älteren Forschung in der Diskussion um das Phänomen ,höfischer Legenden' und ,Legendenromane', also der Adaption von Legendenstoffen in der volkssprachigen Literatur des 13. Jahrhunderts. Speziell für Konrad und seine Legenden kommt hinzu, dass man hier „die gläubige Hingabe des Verfassers“ zu vermissen müssen glaubte, denn in ihnen stünde „das Fehlen frommen Engagements in einem auffallenden, ja geradezu peinlich berührenden Gegensatz zur gekonnten sprachlichen und formalen Gestaltung des Stoffes“, so Achim Masser: Bibel- und Legendepik des deutschen Mittelalters. Berlin 1976 (Grundlagen der Germanistik. 19), S. 160. Und ganz ähnlich meint Jackson, The Legends of Konrad von Würzburg, S. 404 einen Kontrast feststellen zu können zwischen „on the one hand, a faithful adherence to the events of the legends and an ostensible advocation of the principles of imitation and cult, and, on the other, the author's apparent lack of genuine spiritual commitment of the material of the legends, their values and their saints". Anders hingegen schon Kokott, Konrad von Würzburg, S. 123: „Offenbar erweitert Konrad [...] mit einer ganzen Reihe teilweise sehr subtiler, insgesamt aber keineswegs aufdringlich eingesetzter Mittel das VerständigungsAngebot des Werkes. In einem solchen Zusammenhang möchte ich weniger von einer unangemesse- 
Bearbeitung des Stoffes ${ }^{119}$ dessen religiöse Thematik konsequent herausarbeitet und ihm dabei eine geschlossene Form gibt, in der gegenüber der ursprünglich eher losen Reihung von Episoden eine stringente Gesamtkomposition erkennbar wird.

Explizit wird das im Prolog, der eine eigenständige Erweiterung Konrads ist und einen eigenen Verständnisrahmen eröffnet, indem er nicht nur die ideale Rezeptionshaltung umreißt, sondern eine Deutung des Stoffes formuliert, die die lateinische Vorlage so explizit noch nicht enthält. ${ }^{120}$ Anders als vergleichbare mittelhochdeutsche Legendenprologe beginnt der des Silvesters nicht mit einem Gebetsruf, sondern mit einer Art didaktisch-ästhetischer Sentenz zur Aufgabe und Relevanz des Legendenerzählens:

\author{
Ez bringet zweiger hande friuht \\ daz man die wârheit mit genuht \\ von götlichen mæren saget. \\ ez trîbet vürder und verjaget \\ den liuten swæren urdrutz \\ und gît dâ bî sô rîchen nutz \\ daz man dervon gebezzert wirt. (S 1-7)
}

Der Funktionszusammenhang, der hier den götlichen mæren allgemein und diesem Werk im Besonderen zugeschrieben wird, umfasst das ethisch-erbauliche Element ebenso wie das ästhetisch-unterhaltende, ganz im Sinne des klassischen prodesse et delectare, denn nütz unde vöudebære (S 12) zugleich könne und solle eine solche Erzählung sein. ${ }^{121}$ Der spezifisch geistliche Nutzen liegt zunächst in der aedificatio, wobei auch die imitatio anklingt, im Sinne einer Hinwendung zu Gott und der Abkehr von der Sünde, die sich am heilsgeschichtlichen Beispiel der Heiligen orientieren kann:

\author{
dar umbe ist harte guot gelesen \\ von guoten liuten etewaz, \\ die gotes rîche sunder haz \\ gedienet hânt vil ebene. \\ man vindet an ir lebene \\ sô rehte nütze bîschaft \\ daz man gote diensthaft
}

nen Verhöfischung der vorher idealen Legende sprechen, sondern darin eher eine angemessene Reaktion auf eine besondere, für Legenden neuartige Rezeptionssituation sehen.“

119 Mit seinen über 5000 Versen hebt sich der Silvester von den beiden anderen, deutlich kürzeren Legenden ab.

120 Vgl. Brinker, Formen der Heiligkeit, S. 179, vgl. auch ebd., S. 181. Eine Rekonstruktion von Konrads lateinischer Vorlage, die dessen Umgang mit dem Stoff erkennbar macht, bietet Herma Kliege-Biller, und ez in tiusch getihte bringe von latîne. Studien zum Silvester Konrads von Würzburg auf der Basis der Actus Silvestri. Münster 2000, S. 33-48, S. $70-138$.

121 Zum Prolog vgl. ebd., S. 170 -171, außerdem Sebastian Coxon: The presentation of authorship in medieval German literature, 1220-1290. Oxford 2001, S. 99-101. 
muoz werden deste harter.
swâ man ir reinen marter
und ir tugend hœret sagen,
dâ muoz ein edel herze tagen
vil starke bezzerunge von
und wirt der sælden vil gewon,
daz im die sünde ist wilde.
von guoter liute bilde
den liuten wehset allez guot. (S 14-29)

Wenn der Prolog des Silvester also die innere Konversion des Gläubigen in der Rezeption der Legende und besonders der Vorbildhaftigkeit ihres Heiligen in den Fokus rückt, dann liegt es nahe, „eine Konzeption der Heiligkeit“ zu vermuten, „die vornehmlich durch den religiös-ethischen Bereich konstituiert wird“, demgegenüber „[d]ie kultische Komponente der Heiligkeit“ zurücktritt. ${ }^{122}$ Als Beleg dafür ließe sich auch das Fehlen eines Eingangsgebets an den Heiligen anführen, allerdings wird das Publikum dann im Epilog ausdrücklich zur admiratio aufgefordert:

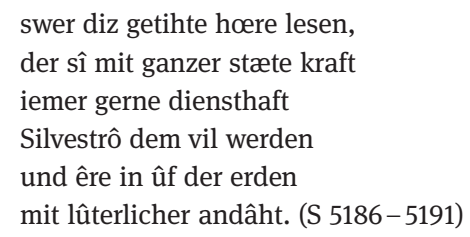

Die heilsgeschichtliche Bedeutung Silvesters ist damit also nicht nur Anlass zur individuellen Erbauung des einzelnen Gläubigen, sondern diese erscheint in die kultische Verehrung der Kirche als Gemeinschaft eingebettet. Als Ausdruck von Silvesters tugent gilt dabei ausdrücklich seine getât (S 77), die in der Bekehrung Konstantins und der damit bewirkten heilsgeschichtlichen Wende liegt:

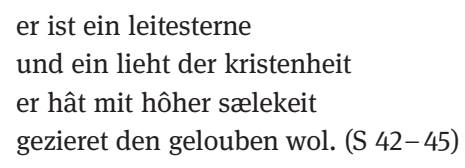

Diese Charakterisierung entspricht durchaus der Topik mittelhochdeutscher Legendenprologe, sie erhält hier aber ,dadurch einen besonderen Sinn, daß Konrad dem Papst Silvester einen bestimmten Platz in der Geschichte der Ausbreitung des Christentums zuweist" ${ }^{\text {123. }}$ 


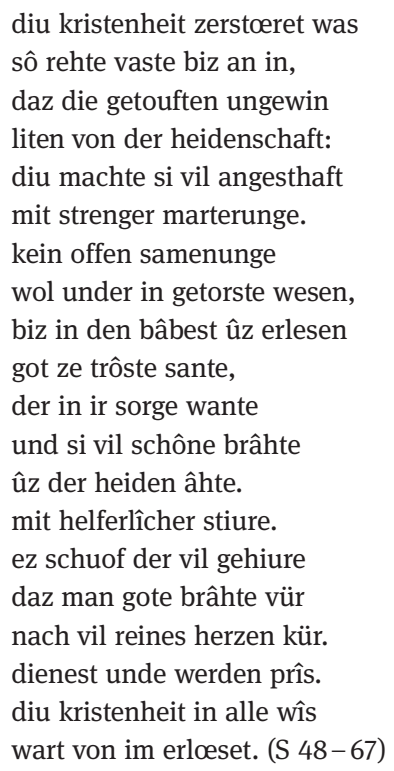

Mit Silvester enden die blutigen Verfolgungen der Christen durch die Heiden und es „beginnt der Siegeszug des Christentums in der Welt““. ${ }^{124}$ Allein diese heilsgeschichtliche Tat, die ,absolut spezifisch“"125 ist für diesen Heiligen und ihn von allen anderen Heiligen unterscheidet, erscheint als relevant und ist, in der Logik der narrativen Konstruktion und Beglaubigung von Heiligkeit in der paradigmatischen Reihung der Bekennerlegende, für sich schon, pars pro toto, hinreichend für den Silvester zugesprochenen Rang des Heiligen: daz er gezieret hât den touf / und in den himel ist getreten (S 74-75). Gerade dass er sich selbst in die Reihe der Heiligen der Kirche einreiht und ihre förmliche Verehrung begründet, lässt ihn diese als ihre institutionelle Erfüllung überragen:

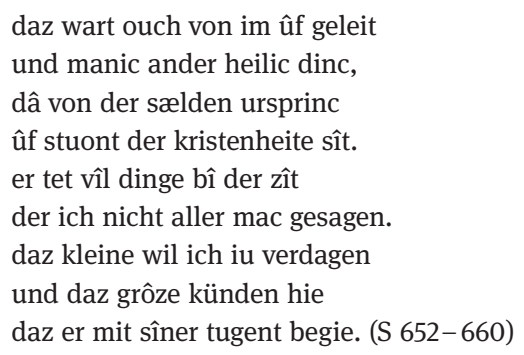

Dabei wird Silvester zuvor nach allen Regeln der legendarischen Topik und ihrer rühmenden Rhetorik in tugend und sælekeit (S 505) als vollkommener Heiliger ge- 
schildert, dessen werc (S 498) und leben (S 507) als überaus heilig gelten und der wegen seiner süeze predigunge (S 482) und seines heiligmäßigen Wandels von den Gläubigen - natürlich gegen seinen demütigen Willen - zeime geistlichen vater (S 539) und in Amt und Würde erhoben wird, zunächst als liutpriester (S 473), dann als bâbest (S 563). Als solcher erscheint er als direkter Nachfolger des Apostelfürsten:

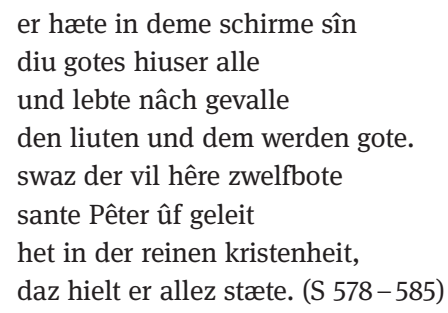

Die Formulierung nâch gevalle / den liuten und dem werden gote erinnert explizit „,an das Gott-Welt-Problem der höfischen Dichter, das hier - wenn auch in anderer Weise in der Gestalt des heiligen Papstes gelöst wird““. ${ }^{126}$ Im Passional heißt es schon vor seiner Papstwahl, er habe die Menschen mit seinem tugenhaftem lebene gewonnen: daz er geviel in beiden, / den cristen und den heiden (P 64, 51 und 53-54), womit seine Integrationsfähigkeit als Heiliger, der die Christen in ihrem Glauben bestärken und die Heiden zu Gott bekehren kann, vorweggenommen ist. Charisma und Amt, transzendente Ansprüche und immanente Bindungen scheinen im Bild des heiligen Bekenners versöhnt. Dass diese Idealität nicht selbstverständlich ist, das Papsttum nicht zwangsläufig mit der Heiligkeit beziehungsweise einem heiligmäßigen Lebenswandel verbunden ist und auch ein Papst erst heilig werden muss, wird deutlich, wenn der Erzähler im Kontrast die besondere Heiligkeit Silvesters herausstellt:

was touc hie lange von geseit?
er was nâch wunsche vollekomen
und hæte gar an sich genomen
swâ mite ein bâbest werden
mac heilic ûf der erden. (S 604-608)

Morphologisch folgt die Legende dem Modell sich entfaltender Geburtsheiligkeit: ${ }^{127}$ Die Einleitung beziehungsweise Vorgeschichte schildert Silvesters Jugendzeit, der, als Kind einer christlichen Witwe und von einem Priester im Glauben unterwiesen, von Beginn an ein heiligmäßiges Leben führt, das ihn in Gegensatz zu seiner heidnischen Umgebung bringt. Als ihn der heidnische Richter Tarquinus verhört und unter Androhung von Martern zum heidnischen Götteropfer zwingen will, lässt sich Silvester davon, ganz in der Logik des Märtyrerlegenden, nicht schrecken und kehrt die Drohung in die Ankündigung göttlicher Strafe um, ,alsô daz dû dar under / erkennen

126 Brinker, Formen der Heiligkeit, S. 177.

127 Vgl. zur Gliederung im Folgenden ebd., S. 172-173. 
müezest und dâ bî / daz gotes sun von himel sî‘ (S 374-376). Der Heide stirbt, wie von Silvester prophezeit, eines qualvollen Todes; er erstickt an der Gräte eines Fisches. Interessant ist diese Episode deshalb, weil hier in der Vorgeschichte zu Silvesters eigentlichem Handeln als Bekehrer des Kaisers und des Reiches das Märtyrermodell verhandelt wird.

Der tödliche Ernst christlicher Existenz in heidnischer Umgebung wird zuvor in einer anderen Figur narrativ verhandelt: Der für seine Gastfreundschaft bekannte Silvester beherbergt bei sich Timotheus, von Anthioch ein heilic man (S 158), der damit beginnt, ze Rôme lêren gotes wort / und êweclicher sælden hort / der heidenschaft entsliezen (S 199-201). Das führt schließlich aber zu seiner Verhaftung, Folterung und Hinrichtung, sodass er selbst den sælden hort (S 240) erreicht, sprich: zum Märtyrer und Heiligen wird. ${ }^{128}$ Timotheus ist aber mehr als ein Beispiel für die Christenverfolgung, die Silvester mit der Taufe Konstantins beenden wird: Er ist eine „Präfiguration Silvesters; beide sind in einem Signalreim vereint“"129, wenn nun auch Silvester vom selben Richter als Christ angeklagt wird:

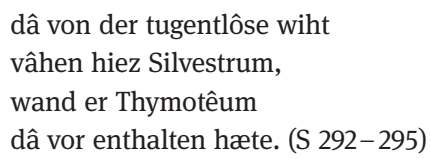

Silvester wird aber eben nicht zum Märtyrer, sondern seine Aufgabe ist es, diese Option zu überwinden. Die heilsgeschichtliche Wende, die sich mit Silvester verbindet, wird also auch in der Ablösung der beiden Heiligkeitsmodelle, dem des Märtyrers durch den Bekenner, deutlich, wenngleich diese Opposition historisch gesehen ja keineswegs eine chronologische, sondern zunächst eine typologische ist. ${ }^{130}$ Das Sterben für Gott, das den Märtyrer zum Heiligen macht und angesichts dessen sich Heil oder Verdammnis der Heiden erweist, wird als Modell keinesfalls entwertet, aber abgelöst von der Verkündigung und Demonstration des Glaubens durch den Bekenner. Silvester verkörpert beide Modelle: Das narrative Muster der Märtyrerlegende verknüpft das standhafte Bekenntnis zum christlichen Glauben mit dem sicheren Tod. Doch bewahrt hier nun die göttliche Bestrafung des Christenverfolgers den Heiligen und durchkreuzt das Schema der Märtyrerlegende: „Der Tod des Richters aber ist als eine Präfiguration des endgültigen Sieges Silvesters über das Heidentum zu interpretieren.“131 Damit werden „Märtyrer- und Bekennertypus“ nicht nur „allgemein ineinander geblendet“, sondern: „Die Narration liefert eine Erklärung ihrer eigenen

128 In der Legenda aurea wird ihm daher später noch ein eigenes Kapitel gewidmet, das nicht von Jacobus de Voragine stammt.Vgl. LA 265, Anm. 6. Bei Konrad ist sein Martyrium hingegen denkbar kurz ausgeführt.

129 Köbele, Die Illusion der ,einfachen Form‘, S. 387.

130 Vgl. oben in der Einleitung zu Kap. 3 Martyrium: Sterben für Gott als Glaubenszeugnis, S. 87-88.

131 Brinker, Formen der Heiligkeit, S. 183. 
paradigmatischen Wirkung. “132 Das Martyrium, das Timotheus erleidet, wird mit Silvester ins Bekenntnis, dieses wiederum ins Wunder gewendet, das schließlich zur Konversion der Heiden führen wird:

Als Folge dieses Wunders, das den Richter richtet, wendet sich nicht Silvester vom Christentum ab, sondern die Heiden wenden sich Silvester zu. Der Heilige bekennt seinen Glauben und bleibt darin statisch, ihm geschieht nichts. Die geschichtliche Bewegung vollziehen die anderen, die narrative Dynamik liegt bei ihnen. ${ }^{133}$

Die Korrelation von Martyrium und Bekenntnis erscheint daher als „Rezeptionsbeziehung“, denn wenn Silvester dem Beispiel des Timotheus folgt, die Heiden aber das Bekenntnis und Wunder Silvesters sehen und damit eine „Umkehrbewegung zum Christentum“ einsetzt, dann setzt die Geschichte „die Ausführungen der Erzählers aus dem Prolog faktisch fort und deutet ein Rezeptions- und Wirkungsverhältnis an, das auch für die Narration insgesamt gilt“. ${ }^{134}$

Der Hauptteil der Erzählung ist dem Wirken Silvesters als Papst gewidmet, das in drei wundersamen Begebenheiten besteht, deren Umfang klimaktisch zunimmt: dem Drachenkampf, der Bekehrung Konstantins und schließlich dem Glaubensdisput inklusive dem Stierwunder. So wie in verschiedenen anderen Legenden eine Drachenepisode den siegreichen Glaubenskampf des Märtyrers und die Überwindung des Unglaubens auf symbolische Weise darstellt, ${ }^{135}$ so setzt auch Silvesters Drachenkampf die zuvor in den Mustern der Märtyrerlegende gestaltete Konfrontation mit dem Heidentum fort - nur dass sein Sieg eben nicht im durchlittenen Martyrium bestehen wird, sondern im standhaften Bekenntnis und der Bekehrung der Heiden. Im Drachenkampf tritt er als furchtloser Bekenner im unerschütterlichen Vertrauen auf Gottes Beistand dem Unglauben in Gestalt des kreatürlich Bösen entgegen. Dabei wird sein Sieg in typologischer Entsprechung mit der Höllenfahrt Christi inszeniert, ${ }^{136}$ denn der Drache haust nahe der Stadt in einer Höhle tief unter einem Berg, zu der 365 Stufen hinabführen und die als Hölle erscheint:

im wurden müede sîniu bein, swer dar în solte stîgen:

132 Bleumer, Metalegendarisches Erzählen, S. 243.

133 Ebd., S. 244.

134 Ebd., S. 245. Bleumers insgesamt schlüssige Argumentation hat allerdings - abgesehen vom problematischen Umgang mit den Begriffen ,paradigmatisch“ und ,syntagmatisch', die seinem ,metalegendarischen' Ansatz geschuldet sind (vgl. dazu oben in Kap. 2.1.1 Legendarisches Erzählen zwischen Transzendenz und Immanenz, S. 28, Anm. 18) - den ,Schönheitsfehler‘, dass an dieser Stelle des Textes noch gar nicht von der Wirkung von Silvesters Taten auf die Heiden berichtet wird: Es ist der getouften liute schar (S 433), die Silvester aus dem Kerker befreit und zu ihrem Priester macht.

135 Zum metaphorischen Potential des Drachenkampfes im Kontext der religiösen Konfrontation des Heiligen mit dem Heidentum vgl. oben vor allem in 4.3.1 Drachenkampf und Martyrium: Georg in der kirchlichen Tradition.

136 Vgl. Köbele, Die Illusion der ,einfachen Form‘, S. 387. 
in dûhte daz er sîgen

zuo der helle müeste.

in dirre tiefen wüeste

lac der trache mære. (S 670-675)

Die Bedrohung durch den Drachen ist zudem nicht nur motivisch, sondern ganz konkret mit dem heidnischen Opferkult verknüpft, der damit zugleich als Betrug entlarvt wird: Im Land treiben etliche Zauberer allerhand lüppe und aller slahte list, / dâ mite si den werden Krist / betriegen lîhte wânden (S 679-681). Auf dem besagten Berg haben sie ihr kapitel (S 684) eingerichtet und ernähren mit ihren Opfern den Drachen, der mit seinem tödlichen Atem die Luft verpestet und die Einwohner Roms in Angst und Schrecken versetzt. Silvesters Kampf gegen den Drachen wird daher explizit als Teil des umfassenden Glaubenskampfes zwischen Heiden und Christen geschildert:

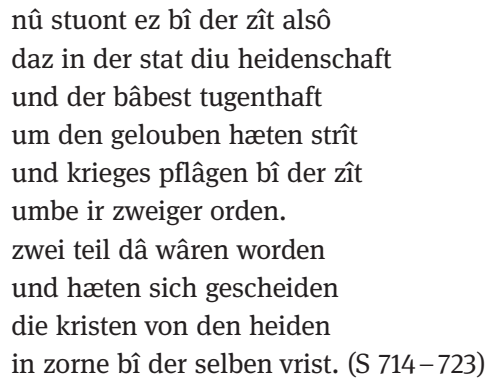

Im Kontext dieses globalen und heilsgeschichtlichen Glaubenskampfes ist Silvesters wundersame Überwindung des Drachen nicht nur ein paradigmatischer Beweis seiner eigenen Heiligkeit, sondern als öffentlicher Glaubensbeweis zugleich syntagmatisch in die Handlung eingebunden: Die Heiden nämlich fordern Silvester heraus, er möge den Drachen besiegen, dann wollten sie sofort glauben,

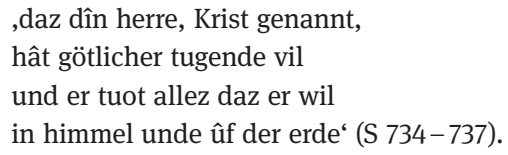

Silvester erwidert daraufhin, dass sich die Macht Christi wohl , an dirre sache erzeigen (S 745) solle, ist sich aber des für eine wirkliche, also innere Bekehrung prekären Status eines solch äußerlichen Glaubensbeweises bewusst, wenn er den Heiden entgegenhält:

,vil kleine daz vervâhet doch daz er in überwindet: iuwer ungeloube vindet ein ander widerwertekeit, 
diu sîner reinen gotheit

und sîner hôhen êre

muoz missevallen sêre.' (S 748-754)

Dennoch bittet Silvester Gott um Hilfe für die Erlösung der Heiden vom Drachen und predigt der gesamte christlichen Gemeinde, sie möge unter dreitägigem Fasten beten, dass Gott sîne tugent lieze / vil offenlîche erschînen / den heiden und den sînen (S 768 770). Der folgende Machterweis Gottes ist wundersam vermittelt, und zwar durch den Heiligen, mit dem sich die Begründung des Papsttums verbindet: In einer Vision trägt der Apostel Petrus Silvester auf, er solle mit einer großen Kette die Tür tief drinnen im Berg in seinem Namen verschließen, auf dass sie bis zum Jüngsten Tag verschlossen bleibe (S 774-814). Die Begnadung Silvesters durch den Apostelfürsten erscheint in der erzählerischen Gestaltung als der eigentliche Kern der Drachenepisode, denn der Vollzug dieser Anweisung wird nur noch knapp erwähnt, ebenso wie die folgenden Bekehrungen. Silvesters Sieg über den Drachen ist damit, wie schon sein Sieg über den heidnischen Richter, Vorbereitung für seine eigentlich entscheidende Tat, zugleich aber eine Präfiguration seines endgültigen Sieges über das Heidentum.

Die Silvesterlegenden der Legenda aurea und des Passionals folgen hingegen einer anderen Überlieferungstradition, in der die Drachenepisode erst nach der Bekehrung Konstantins und dem Religionsdisput erzählt wird. ${ }^{137}$ Motiviert ist sie durch die heidnische Infragestellung des Christentums, dass sich doch im Disput eben erst siegreich erwiesen hat: Nach einigen Tagen halten die heidnischen Priester, die als dies idolorum pontifices (LA 284), als Götzendiener charakterisiert sind, dem Kaiser vor, seit seiner Bekehrung zum Christentum habe der Drache über dreihundert Menschen umgebracht. Silvester besiegt den Drachen wiederum auf die Weise, die der heilige Petrus ihm offenbart; hier besteht sie nun aber darin, dass er dem Ungeheuer mit einer Schnur das Maul zubindet, die er mit einem Ring versiegelt, der das Kreuzzeichen trägt. Mit den beiden Priestern, die sich cum multitudine infinita, sprich: mitsamt allen Heiden bekehren, ist auch der Unglaube insgesamt überwunden, wie der Erzähler zusammenfasst: sicque populus Romanorum a morte duplici liberatus est, scilicet a cultura daemonis et veneno draconis (LA 286). ${ }^{138}$ Die Silvesterlegende des Passionals folgt in ihrer Gestaltung der Drachenepisode der Legenda aurea, schmückt dabei aber manches aus, so die abschließende Massenbekehrung der Heiden ausgehend von der Taufe der beiden Priester:

137 Konrad folgt der Ursprungsfassung B2, während die ältere Ursprungsfassung A1 die Drachenepisode erst nach der Bekehrung Konstantins und dem Religionsdisput bringt, außerdem noch nicht den bekehrten Kaiser als Schiedsrichter im Disput hat, sondern zwei Heiden. Die Silvesterlegenden der Legenda aurea und des Passionals gehören hingegen einem Mischtyp C. Zur Textgeschichte der Actus Silvestri vgl. Herma Kliege-Biller, Studien zum Silvester Konrads von Würzburg, S. 33-48.

138 „Und so wurde das römische Volk von einem doppelten Tod erlöst, von der Anbetung des Teufels und vom Gift des Drachens.“ 


\begin{abstract}
als den wie warheit erfchein, do touften fi fich alle. mit eime gemeinen fchalle drungen fi zu Criftes lobe wol vlizeclichen und dar obe wart an den criftenlichen touf ein harte witer zulouf von allen Romeren. (P 92, 7-14)
\end{abstract}

Im Ganzen ergibt sich aber im Passional das gleiche Bild wie in der Legenda aurea: Die Drachenepisode ist hier jeweils ein finales Bestätigungswunder, das die mit der Bekehrung Konstantins und dem Religionsdisput erreichte Etablierung des Christentums verteidigt. Nicht zufällig trägt Petrus seinem Nachfolger einen Bannspruch für den Drachen auf, der Teile des christlichen Glaubensbekenntnisses nutzt, in der Legenda aurea gar mit wörtlichem Anklang an das in der römischen Liturgie verwendete Credo: ,Dominus noster Iesus Christus de virgine natus, cruxificus et sepultus, qui resurrexit et sedet ad dextram patris, hic venturus est iudicare vivos et mortuos. Tu ergo, Satana, eum in hic loco, donec venerit, exspecta. ' (LA 284) ${ }^{139}$ Die Überwindung des Ungeheuers, im Passional von Silvester als ,du tuvel tuvelhafter bote` (P 91, 28) angesprochen, versinnbildlicht den auch im Kult immer wieder vergegenwärtigten Sieg Christi über Tod und Teufel.

Bei Konrad zeigt sich indes eine, in der Stofftradition, der er folgt, angelegte, von ihm aber bewusst gestaltete, „konstitutive Zweiteiligkeit der Geschichte“, deren beiden Teile in einer gezielten Symmetrie stehen, „die Spiegelungseffekte sucht“"140: Der erste Teil erzählt mit dem Drachenwunder und der Bekehrung Konstantins von der Konfrontation mit dem Heidentum, die zweite von der Konfrontation mit den Judentum im Glaubensdisput und Stierwunder. Der Drachenkampf ist hier „die erste Wundertat Silvesters als Papst und Oberhaupt der Christenheit, mit der er das römische Volk für den christlichen Glauben gewinnt“. ${ }^{141}$ Die Bekehrungen, die das Drachenwunder hervorruft, sind dabei zunächst Anlass für eine neue Welle blutiger Christenverfolgungen, denen Silvester und sein Klerus entgehen, indem sie sich außerhalb Roms verborgen halten. ${ }^{142}$ Konstantin wird an dieser Stelle nach den Mustern

139 „,Unser Herr Jesus Christus, von einer Jungfrau geboren, gekreuzigt und begraben, der auferstanden ist und zur Rechten des Vaters sitzt, wird kommen zu richten die Lebendigen und die Toten. Du Satan, erwarte ihn nun an diesem Ort, bis er kommt.““ Vgl. dazu Hammer, Erzählen vom Heiligen, S. 424.

140 Köbele, Die Illusion der ,einfachen Form', S. 385.

141 Hammer, Erzählen vom Heiligen, S. 422.

142 Die heilsgeschichtliche Wende ist, handlungslogisch gesprochen, wichtiger als seine persönliche Heiligkeit, die er im Martyrium schneller hätte erreichen können. Im Passional beteuert der Erzähler, dass Silvester nicht aus zageheit, sondern im Bewusstsein höherer Verantwortung geflohen sei: durch nutz wolde er fich fparn / und die criftenheit bewarn (P 65, 38 und 39-40). 
der Märtyrerlegende als mächtiger Herrscher vorgestellt, dem aber der richtige Glaube fehlt:
doch was er ungeloubhaft
und streit vil sêre wider gote.
er hæte dô mit sîme gebote
verderbet vil der kristen,
ern wolte keine vristen
der an got geloubte. (S $880-885)$

Doch trifft ihn dafür die Strafe Gottes, sodass sich seine weltliche Macht und Ansehen in ihr Gegenteil verkehrt:

\author{
er sluoc in mit der miselsuht \\ dur sîne bîtterlichen art, \\ so daz er ûzsetzicc wart \\ und amme lîbe wart enstalt. \\ des wart betrüebet sîn gewalt \\ und al sîn keiserlicher ruom. (S 896-901)
}

Seine heidnischen Meister wissen schließlich nur ein Heilmittel: Er solle sich ein piscîne (S 910) machen lassen und darin im Blut unschuldiger Kinder baden. Konstantin folgt zunächst diesem Rat und lässt 3000 Kinder nach Rom bringen, doch begegnet ihm auf dem Weg zum Kapitol, wo dieses ,Blutbad'stattfinden soll, der Jammerzug der Mütter, sodass schließlich - all das wird versreich und dramatisch dargestellt: die Anordnung der Meister, das Wehklagen der Mütter, Konstantins Erschütterung, schließlich seine Tränen - Konstantins keiserliche milte über die grimmekeite der heidnischen Meister siegt (S 1030 und 1033).

Im Passional, das den Kaiser bis auf sein Heidentum, an dem nun vom Stoff her nicht vorbeizukommen ist, zum höfisch-idealen Herrscher stilisiert, wird des keifers miltekeit (P 67, 22), die nun der untugend (P 66, 77) des Kindermordes gegenübersteht, zum Signum herrscherlicher Würde: die keiferliche werdekeit / uz mildekeit entfpringet (P 66, 40-41), ist Konstantin in den Mund gelegt. ${ }^{143}$ Bei Konrad ist wohl hingegen weniger an die Freigiebigkeit des Herrschers gedacht als an die christliche Tugend der Barmherzigkeit, wenn diu keiserlichen ougen sîn / von rehter milte wurden naz (S 1038 1039). Denn Konstantin hat erkannt, so spricht er selbst, dass die Opferung der Kinder ihn ,vor gotes ougen' (S 1025) schuldig werden lassen würde - und das ist insofern bemerkenswert, als ihm hier eine erste Gotteserkenntnis in den Mund gelegt wird, die schließlich zu seiner Konversion führt: Er sieht sich dem einen Gott verantwortlich, von dem er eigentlich noch gar nicht weiß, und sorgt sich, schon ganz in den

143 Vgl. dazu Hammer, Erzählen vom Heiligen, S. 413. Während es in der Legenda aurea „[d]ie Würde des römischen Volkes“ ist, die „aus dem Quell der Barmherzigkeit“ schöpft: Dignitas Romani imperii de fonte nascitur pietatis (LA 268). 
christlichen Kategorien von irdischer Vergänglichkeit und himmlischer Seligkeit denkend, um sein Seelenheil:

,sol ich ûf der erde

durch daz verwirken al mîn heil

daz ich in hôher sælden teil

gewinne, daz ist tumplich.' (S 1064-1067)

Die Opferung der Kinder führt ihn in eine Krise, die den Bekehrungsprozess auslöst, auf den der christliche Glaube, den ihm Silvester predigt, schließlich die Antwort geben wird. Seinen inneren Wandel reflektiert Konstantin in einer öffentlichen Rede an seine Vasallen, die das narrative Umschlagsmoment diskursiv nachvollziehbar macht. Vor seinem intra- wie dem extradiegetischen Publikum formuliert der Kaiser die Erkenntnis, dass alle irdische Herrschaft vergänglich sei und allein der geistliche Kampf gegen das Böse ewige Stärke bringe:

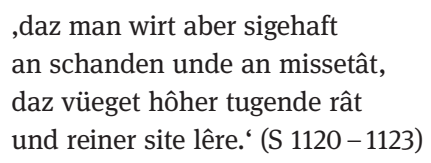

Die völlige innere Umkehr, die konkret-existentielle Implikationen hat, insofern sie die Möglichkeit der Heilung ausschlägt, vollzieht er schließlich, wenn er sich und sein Schicksal in Gottes Hände legt, damit die Krankheit als Strafe annimmt und ihrem Erdulden einen geistlichen Gewinn sieht:

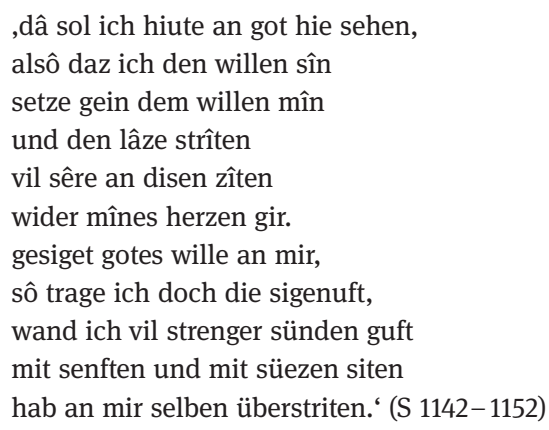

Die Heilung vom Aussatz ist schließlich auch keine unmittelbare Folge dieser inneren Bekehrung. Denn erst nachdem er die unschuldigen Kinder hat gehen lassen, erscheinen ihm im Traum die beiden wichtigsten Apostel, Petrus und Paulus, die überdies Silvester und Konstantin präfigurieren: Petrus ist der oberste Apostel und erster Bischof Roms, Paulus der ehemalige Christenverfolger, dessen Bekehrung 
gleichbedeutend ist mit seiner Berufung als Missionar des Christentums. ${ }^{144}$ Sie versprechen ihm die Heilung als Belohnung für seine Tugendhaftigkeit. Er soll Silvester zu sich holen lassen, der werde ihm - in typologischem Kontrast zum ,Blutbad“ der Heiden - ,ein piscîne / der êweclichen gotheit‘ (S 1240 -1241) bereiten, das ihn von ,der swære dîn' (S 1245) erlösen werde.

Bei Konrad widerfährt ihm diese Vision ,einfach so', sie erscheint als logische Konsequenz seiner innerlich und unwissend vollzogenen Bekehrung, während im Passional an dieser Stelle Gott als Urheber der folgenden Heilung deutlich genannt wird:

Got, aller tugende ein ummerinc,

fach an die gutelichen dinc,

die Conftantinus begie.

nicht ungelonet er im lie

fwie er was ein heiden (P 67, 52-56).

Das Konversionsgeschehen wird damit, der paränetisch-katechetischen Tendenz des Passionals entsprechend, geistlich ausgedeutet und besonders der Verdienstgedanke betont: Wenn selbst ein Ungläubiger auf göttliche Belohnung hoffen darf, wenn er sich zu Gott bekehrt und Gutes tut, dann umso mehr noch jeder christliche Gläubige - im geistlichen Sinne sind beide Heiden, die der Umkehr und Erneuerung bedürfen. Die Heilung vom Aussatz im ,Bad‘ der Taufe steht daher metonymisch für die Reinigung von der Sünde und vom Unglauben.

Am deutlichsten wird das wieder bei Konrad, denn die Verheißung der Apostel: ,sô wirt dîn siecher lîp gesunt" (S 1248) meint in der breiteren mittelhochdeutschen Semantik von lip die Heilung von Leib und Leben. In der Taufe vollzieht sich damit das Wunder der Heilung, aber nicht als „kausaler Auslöser einer Bekehrung“, sondern als „Symbol des Heils“. ${ }^{145}$ Die wundersame, weil unvermittelte, plötzliche innere Bekehrung des Kaisers wird durch die Heilung vom Aussatz äußerlich bestätigt. Die völlige geistliche Erneuerung, deren Zeichen die Taufe ist, betrifft aber im Fall Konstantins nicht allein das persönlich Schicksal eines Konvertierenden: Seine Konversion und die des Reichs sind als ein Geschehen gedacht, denn als Dank für die Gnade Gottes soll er die Verfolgung der Christen beenden und sich vom heidnischen Unglauben zum Glauben an Christus bekehren:

,und swaz in dînem rîche sî

der kristenheit zerstœret nû,

daz solt vil harte schiere dû

mit helfe widerbringen,

und lâ niht vürbaz twingen

die getouften gotes knehte.

144 Vgl. Hammer, Erzählen vom Heiligen, S. 413-414.

145 Bleumer, Metalegendarisches Erzählen, S. 252. 


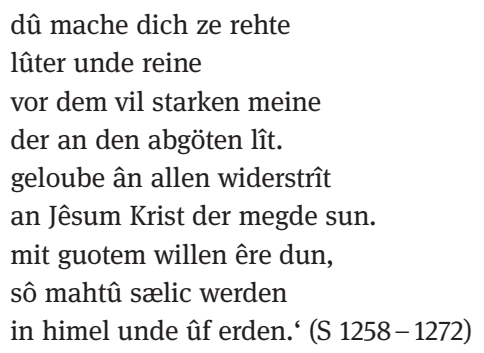

Wenn Konstantin nun nach Silvester schicken lässt und von ihm im christlichen Glauben unterwiesen wird, dann bringt das für die ,eigentliche' Konversion nichts Neues, sondern dient dazu, in der Verhandlung von Heidentum zum Christentum die bereits vollzogene innere Umkehr als einen diskursiven Prozess verständlich zu machen. So beispielsweise, wenn Konstantin Silvester fragt, was für Götter Petrus und Paulus seien, und der Papst ihm daraufhin darlegt, dass allein Christus Gott sei, die beiden Apostel nur seine Diener, die den Glauben an ihn in der Welt als erste verbreitet haben (S 1407-1458). Und noch sinnfälliger, wenn Konstantin ein Bild der beiden zu sehen wünscht um sicher gehen zu können, dass wirklich sie es gewesen sind, die er gesehen hat (S 1465-1511). Hier wird das heilspräsentische Ereignis seiner persönlichen Begegnung mit den beiden Heiligen in ein öffentliches diskursives Verstehen überführt: Der Heide erkennt die Heiligen auf einem Kultbild - mit bilden und mit buochstaben / entworfen oder schône ergraben (S 1483-1484) - und beweist dem intrawie extradiegetischen Publikum die Echtheit seiner Vision.

Die längeren Lehrreden Silvesters und die darauf antwortenden Bekenntnisse Konstantins formulieren vor allem die Absage an die heidnischen Götter und die Hinwendung zu dem einen wahren Gott. Interessant in diesem Zusammenhang, dass Taufe und Heilung Konstantins mehrfach als Wende benannt werden. Die im Hinblick auf die Identität des Konvertierenden dekonstruktive wie rekonstruktive Funktion des ausführlich dargestellten Taufrituals versinnbildlicht die heilsgeschichtliche Abkehr des ganzen Reiches vom Heidentum und seine Zuwendung zum Christentum. So bittet Silvester unmittelbar über der Taufe, dass Gott Konstantin heilen möge,

\author{
,dar umbe daz diu kristenheit \\ sîn vröuwe zeime herren sich \\ und einen schirmer lobelich \\ an im gewinnen müeze‘ (S 1818-1821).
}

Dadurch wird auch die Rolle des Papstes als Mittler herausgestellt: „Nicht allein die Taufe, sondern damit verbunden die Fürbitte Silvesters heilt den Kaiser; die Finalität der Legende nimmt diese Fürbittfunktion bereits vorweg. “146 Das folgende Heilungswunder, das mit himmlischen Licht- und Klangerscheinungen als Einbruch der 
Transzendenz narrativiert wird, bestätigt genau diese Wirksamkeit des Heiligen und damit Gottes Wirken in der Welt.

Auf Konstantins Bekehrung folgt die Missionierung des Reichs. Zunächst noch rein defensiv und ohne offenen Zwang zur Konversion legt Konstantin durch Verordnungen an sieben aufeinanderfolgenden Tagen, dem Schöpfungswerk gleich, die Grundordnung für ein christliches Reich: Er ordnet an, dass man Christus als wahren Gott anerkennen solle und empfiehlt seine Verehrung ,mit ganzer vrîheit‘ (S 1878), verbietet jede Schmähung Christi, schützt die Christen vor Unrecht, macht Silvester zum Oberhaupt der römischen Kirche, stellt die Kirchen unter kaiserlichen Schutz, gebietet, dass Kirchen nur mit Einverständnis des Papstes gebaut werden dürfen und legt schließlich den Zehnten als verbindliche Abgabe an die Kirche fest. Am achten Tag dann geht er zum Petrusgrab und beginnt eigenhändig mit dem Bau einer Kirche, legt am neunten fest, dass auch in sîme sal ze Lateran / ein münster dem vil werden got (S 2006-2007) gebaut werden soll. ${ }^{147}$ Die Bekehrung der Heiden wird aber nicht erzwungen, sondern sogar mit Hürden versehen, denn eine Zwangsabgabe bei der Taufe soll verhindern, dass jemand durch der gâben girekeit (S 2045) zum Christentum konvertiert: man wolte daz er kæme / willeclîche in gotes ê / und âne valsch (S 2050).

Binnen Jahresfrist bekehrt sich ein großer Teil der Heiden, allerdings nicht die Würdenträger der Stadt, was dazu führt, dass Konstantin seine Maßnahmen verschärft. In einer der Kirchen sitzt er zu Gericht und verkündet seinen Untertanen, ganz in der Topik christlicher antiheidnischer Polemik, dass die Wahrheit des christlichen Glaubens allen offenbar sei und die heidnischen Götter nutzlose Götzen; alle Menschen sollten den wahren Schöpfer ehren. Seine Heilung gilt nun als Prüfstein für Gottes Macht und als Legitimation für eine aktive Bekämpfung des Heidentums:

\footnotetext{
,dar umbe sol ein einde

der ungeloube nemen hie,

der mit stætem willen ie

von abgöten ist getragen.

ir sult den valsch von hinnen jagen,

den iuwer tumpheit hât erzogen.

den wâren got vil unbetrogen

üebent alters eine.' (S 2180-2187)
}

Konstantin verordnet daher nun den Religionswechsel im ganzen Land, zumindest was den öffentlichen Kult angeht. Damit man den wahren Gott immer und überall ehren könne, sollen die heidnischen Kultstätten umgewidmet werden und die verbrieften Rechte der heidnischen Priester an den kirchlichen Klerus übergehen: ,der tempel wirde sî gelegen / und werde grôz der kirchen reht‘ (S 2236-2237) - alles als Zeichen, dass der Kaiser allein Gott dienen wolle. Die Versammelten aber geraten in

147 Der Zusammenhang der Basilika Alt St. Peter und der Kirche im Lateran mit dem Wirken Konstantins ist historisch belegt, in der narrativen Fiktion wird er unmittelbar mit seiner persönlichen Bekehrung verknüpft. 
einen großen Aufruhr und fordern gar, dass ,verderben müezen alle die / Jêsu Kriste widersagen / und im niht holdes herze tragen“ (S 2264-2266). Mehrere Stunden fordert die Menge lautstark noch deutlichere Repressionen gegen das Heidentum: swer Krist niht üeben wolte dâ, / daz im der keiser trüge sâ / vil offenliche vientschaft (S 22812283), der heidnische Götterkult solle verboten, die Heiden aus der Stadt vertrieben werden (S 2302-2306). Konstantin - der keiser edel unde balt (S 2308) - aber besänftigt hier nun die Menge und gemahnt an die Freiwilligkeit des Glaubens; dieser lasse sich nicht durch Herrschaftsmaßnahmen erzwingen:

\author{
,der liute dienest unde gotes \\ ûf erden ist gescheiden sô \\ daz mit betwungenlîcher drô \\ der liute dienest hie geschehe \\ und daz man gote dienen sehe \\ mit willeclichem muote.' (S 2314-2319)
}

Und es folgt die theologische Erklärung: Weil Gott in freier Entscheidung verehrt werden und den sündesiechen (S 2335) die Möglichkeit der Besserung geben wolle, lasse er sie leben: ,ir schulde wil er in vergeben / ob si bekêren sich' (S 2336-2337). Unschwer lässt sich das auf die Heidenproblematik hin Formulierte auf die Existenz des Menschen in der Welt überhaupt und die Notwendigkeit beständiger innerer conversio beziehen. Konstantin begründet bei Konrad seine eigene Haltung mit der Entscheidung Gottes, ,daz er mit argen dingen / niemen wil betwingen / daz er im undertænic sî (S 2343-2345). Weil also auch Gott niemanden zum Glauben zwinge, so kann auch er es nicht tun, nur, mit senften worten' und, mit liebe si gebiten / daz si bekêren gerne sich‘ (S 2355 und 2352-2353).

Doch ist diese den Untertanen zugestandene Freiheit in Glaubensdingen nicht ohne Widersprüche: Einerseits besteht kein Zwang zur Konversion, noch trifft diejenigen, die Heiden bleiben, eine Strafe - kaiserliche Gunst aber erwerben sich alle, die sich bekehren und taufen lassen, so verspricht Konstantin (S 2362-2368). Und der kaiserliche Großmut gründet offenbar darauf, dass der Gegensatz zum Heidentum ein temporaler ist, dass also die Taufe nicht ewig abgelehnt werden wird, sondern Aussicht auf Bekehrung besteht:

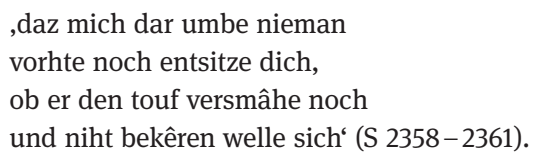

In der Legenda aurea, die das Heidentum ja erst am Ende der Silvesterlegende mit dem Drachenbann überwunden sieht und Konstantin ohnehin insgesamt eine untergeordnete Rolle zuweist, erübrigen sich solche Feinheiten im Hinblick auf die Etablierung einer christlichen Herrschaft: Der Heilige erweist seine Wundermacht und bestätigt damit den Triumph des Christentums, eine große Menge bekehrt sich und mehr 
braucht es nicht, um die Bedeutung des heiligen Papstes herauszustellen. Das gilt auch für das Passional, immerhin wird hier aber angedeutet, dass mit der Massenbekehrung die Konversion der Heiden zum Christentum noch nicht abgeschlossen ist, mithin die innere Bekehrung ein längerer Prozess ist: Die Römer griffen chriftenlichen an, / fwaz Silvefter der gute man / von Crifto gutes larte (P 92, 15-17) und ihr tugendsames Streben wird als das Aufgehen reicher Frucht beschrieben, deren Same Petrus mit seinem Martyrium in den Boden Roms gelegt habe (P 92, 23-35).

\subsubsection{Adversus Judaeos - Die Aushandlung des religiösen Gegensatzes zum Judentum}

Mit der Taufe Konstantins durch Silvester ist auch in Konrads Chronologie der Ereignisse der religiöse Gegensatz zum Heidentum überwunden: Auch wenn noch nicht alle Heiden getauft sind, hat das Christentum gesiegt und sich in der Mission erfolgreich ausgebreitet. Dieser Zustand idealer christlicher Herrschaft wird erst durch die Kaiserinmutter Helena gestört, die dem jüdischen Glauben anhängt und daher ihren Sohn zwar ob seiner Abkehr von den heidnischen Götzen lobt, für seine Bekehrung zum Christentum aber gleichzeitig heftig tadelt: nû bistû zeinem orden komen / der noch zwîrent boeser ist (S 2486-2487). Der christliche Glauben erscheint ihr als neue und noch viel schlimmere Form von Aberglauben, und dieser Vorwurf gründet in dem, was Judentum und Christentum theologisch trennt, nämlich der Glaube an Jesus Christus als Sohn Gottes:

,sît dû von den touben

abgöten bist getreten,

war umbe wiltû danne beten

an Jêsum Krist ûf erden?‘ (S 2516-2519)

Damit ist nicht nur der äußere Anlass, sondern auch das zentrale inhaltliche Thema des nun folgenden Glaubensdisputs mit den Juden genannt, der neben der Bekehrung des Kaisers zum erzählerischen Kern der Silvesterlegende gehört und in ihr einen breiten Raum einnimmt. Seine Relevanz ergibt sich aus dem spezifischen Charakter des religiösen Gegensatzes zum Judentum, denn dieses stellt sich letztlich als eine Sonderform des Unglaubens dar, die zum christlichen Glauben in einer besonderen Beziehung steht.

Konstitutiv für diese Beziehung ist der Umstand, dass sich das Christentum aus dem Judentum heraus entwickelt und sich schließlich von diesem ablöst, ohne dass die gemeinsame Wurzel je ganz vergessen werden könnte. Damit spielt das Judentum eine entscheidende Rolle für das christliche Selbstbild und zwar in doppelter Weise, insofern es einerseits eine Abgrenzung verlangt, die die Abkehr vom alten Glauben markiert, der, aus christlicher Sicht, durch Christus ,erfüllt‘ und mit dem Glauben an ihn überwunden ist; andererseits aufgrund der gemeinsamen religiösen Wurzeln eine 
gewisse Kontinuität zu ihm als dem Ursprung des Christentums gewahrt werden muss. Die Juden sind damit das religiöse Eigene wie das Fremde, genauer: das religiös Fremd-Gewordene zugleich. Sie erschienen entweder als Zeugen der mit den Christen geteilten Wahrheit oder als verstockte Unvernünftige und ,Blinde‘, die die Erfüllung und Ablösung ihres Glaubens durch Christus verkennen und ablehnen.

Aus dieser paradoxen Konstellation rührt die spezifische Funktion der Aushandlung des religiösen Gegensatzes zum Judentum, die häufig in der Form von Religionsdisputen literarisch inszeniert wird, die von der frühchristlichen Apologetik bis in die hochmittelalterlichen Traktate tradiert werden, dabei auch immer wieder in legendarischen Texten eine narrative Einbindung und Ausgestaltung erfahren. Mit Blick auf die wechselseitigen schriftlichen Polemiken zwischen Judentum und Christentum hat der jüdische Historiker und Kulturwissenschaftler Amos Funkenstein pointiert:

Judentum und Christentum waren und blieben Konfrontationskulturen im genauen Sinne des Wortes. Die bewußte und stete Ablehnung von Werten und Ansprüchen des anderen war und blieb ein konstitutives Moment für den fortlaufenden Aufbau der eigenen Identität beider Kulturen. ${ }^{148}$

Die ,intensive Doppelbeziehung von Faszination und Aversion, Anziehung und Abstoßung“ und die „erstaunliche Symmetrie der ambivalenten Einstellungen“ ließen „sich nicht etwa als notwendige Folge dessen erklären, daß hier zwei monotheistische Religionen, beide mit absolutem Wahrheitsanspruch, in einem Orte zusammenwohnten“; Hunderten jüdisch-christlicher Polemik stünden nur wenige jüdisch-islamische gegenüber: „Judentum und Islam betrachteten sich gegenseitig mit einer Gleichgültigkeit, die an Verachtung grenzte. Sie waren eben keine Konfrontationskulturen." ${ }^{49}$ Der Grund für die wechselseitige Konfrontation von Judentum und Christentum liege weniger in der theologischen Dimension, denn zwischen den Dogmen beider Religionen ließen sich leicht Äquivalenzen finden und „[k]ein Gesetz der schriftlichen oder mündlichen Überlieferung verböte einem streng orthodoxen Juden auch heute, von der Messianität Jesu überzeugt zu sein“. ${ }^{150}$

Daher sei die Konfrontation beider Religionen „eine historische eher denn eine ideologisch-dogmatische““. ${ }^{151}$ Damit zielt er auf die Genese des Christentums aus dem Judentum als jüdisch-apokalyptische Sekte, die bald den Anspruch erhebt, das wahre Israel zu sein, während das übrige verdammt sei. Mit der Ausbreitung des Christentum über das Judentum hinaus habe sich diese legitimatorische Abgrenzung zum Hass auf

148 Amos Funkenstein: Juden, Christen und Muslime. Religiöse Polemik im Mittelalter. In: Die Juden in der europäischen Geschichte. Sieben Vorlesungen. Hrsg. von Wolfgang Beck. München 1992, S. 33-49, hier S. 33.

149 Ebd.

150 Ebd., S. 34.

151 Ebd. 
das Judentum allgemein verwandeln können, da nun beide Religionen um die Bekehrung der Heiden konkurrierten, was noch durch die Rivalität zwischen Judenchristen und Heidenchristen innerhalb der Kirche verstärkt worden sei. ${ }^{152}$ Aber auch über die Etablierung des Christentums als Staatsreligion, mit der vom Judentum kaum mehr eine akute Gefahr und konkrete Konkurrenz für die Christen ausgehen kann, hinaus erfüllt die christliche antijüdische Polemik eine wichtige Funktion, und vielleicht gerade dann.

Dabei habe die Polemik schon seit Ende des zweiten Jahrhunderts, also noch vor den Konstantinischen Wende, kaum mehr eine „lebendige Auseinandersetzung“ reflektiert, vielmehr handele es sich um eine „stereotype Wiederholung überkommener topoi, insbesondere um die Aufzählung der vermeintlichen Hinweise im Alten Testament auf die Wahrheit des Neuen Testaments““. ${ }^{153}$ Der ,Sitz im Leben“ der christlichen Polemik gegen das Judentum hätte sich damit schon zu einem sehr frühen Zeitpunkt auf interne Zwecke der Selbstvergewisserung verschoben, angesichts der Weiterexistenz des Judentums, das doch mit Christus eigentlich hätte überholt sein müssen. Insofern stellt diese Polemik eine Form der Problembewältigung dar, die das religiöse Selbstverständnis der Kirche betrifft:

Gerade weil es der Kirche mißlang, die Juden zur nova lex zu bekehren, wurde deren Existenz zu einem theologischen Paradox, zu einem Skandalon sondergleichen, welches erklärt werden mußte. Juden und Judentum waren und blieben ein mysterium tremendum et fascinosum, und als solches von beträchtlicher Anziehungskraft für eine Kultur, in der alles Alte ehrwürdig war und alles Neue verdächtig - während die Christen, sozusagen nach eigenem Bekenntnis, homines rerum novarum cupidi waren. ${ }^{154}$

Dieses Legitimationsproblem wird typologisch gelöst mit der Vorstellung, „daß der Status des ausgewählten Volkes vom ,Israel im Fleische` auf ,Israel im Geiste` verlagert worden war“, was sich in der Möglichkeit zur Erkenntnis der göttlichen Wahrheit konkretisiere: „Demnach konnten Juden ihre Schriften nur im wortwörtlichen Sinne verstehen. Ihnen fehlte das tiefere Schriftverständnis, die spiritualis intelligentia, und sie galten deshalb als ,blind“." "155 Weil sie den neuen, christlichen Glauben nicht annehmen, erscheinen die Juden als „lebender Anachronismus“, gerade daher aber können sie als „ewiges Zeugnis“ für die Wahrheit der heiligen Schriften und damit des

152 Ebd., S. 34-35.

153 Ebd., S. 35.

154 Ebd., S. 35-36. Geradezu spiegelbildlich Entsprechendes lässt sich auch für die jüdischen antichristlichen Polemiken herausarbeiten: „Such polemical arguments had no utility in direct encounter with Christians, but they fortified the resolve of European Jews physically to survive and culturally to flourish in the face of condemnation and attack." Jeremy Cohen: Towards a Functional Classification of Jewish anti-Christian Polemic in the High Middle Ages. In: Religionsgespräche im Mittelalter. Vorträge, gehalten anläßlich des 25. Wolfenbütteler Symposions vom 11. bis 15. Juni 1989 in der Herzog August Bibliothek. Hrsg. von Bernard Lewis, Friedrich Niewöhner. Wiesbaden 1992 (Wolfenbütteler MittelalterStudien. 4), S. 93-114, hier S. 99.

155 Funkenstein, Juden, Christen und Muslime, S. 36. 
Christentums dienen: Sie sind der lebende Beweis, dass mit Christus die Erwählung von Israel auf die Kirche übergegangen ist. ${ }^{156}$

Die Loslösung des Christentums aus dem Judentum führt also zwangsläufig zur Wahrheitsfrage, die mittels der Substitutionstheologie gelöst wird: Die allegorische Ausdeutung der antitypisch verstandenen Bundestheologie - das Christentum als triumphierende ecclesia, das Judentum als blinde und gebrochene synagoga - versinnbildlicht den alleinigen Anspruch der christlichen Kirche auf Heilsvermittlung, von der alle Ungläubigen, Juden und Heiden gleichermaßen, ausgeschlossen sind, wenn sie sich nicht bekehren. Allerdings kommt den Juden dabei eine besondere Funktion zu, weil ihre Blindheit schon von Paulus als gottgewollt verstanden wird. Im Römerbrief betont er, dass der Alte Bund, den Gott einst mit Abraham geschlossen habe, sowie die Tora unwiderruflich Bestand hätten (Röm 9, 4), und bekennt sich entschieden $\mathrm{zu}$ seinem eigenen Judentum: nam et ego Israhelita sum, ex semine Abraham tribu Benjamin (Röm 11, 1). ${ }^{157}$ Wenn ein Teil der Juden nicht an Jesus Christus als den Messias und seine Auferstehung glauben, dann weil Gott selbst sie verstockt habe, auf dass auch die Heiden die Möglichkeit bekommen, das christliche Heil zu erlangen - erst dann solle das Volk Israel gerettet werden (Röm 11, 11 und 25-32).

Die den Juden zugeschriebene heilsgeschichtliche Funktion begründet ihre prinzipielle Duldung als Andersgläubige innerhalb der mittelalterlichen christianitas. Anders als die Heiden, die die christliche Botschaft schlichtweg noch nicht gehört haben und daher völlig unschuldig für ihren Unglauben sind, verstünden es die Juden nicht besser, könnten also etwas für ihren Unglauben, aber immerhin nur wenig. Man dürfe sie daher, wie auch die Heiden, nicht zum Glauben zwingen, dessen Annahme aus freien Stücken erfolgen müsse. ${ }^{158}$ Dennoch bleibt das christliche Verhältnis zum Judentum von einer grundlegenden Ambivalenz bestimmt, denn weil „das Christentum die Juden einerseits als Zeugen der Wahrheit der christlichen Lehre anerkannte, aber zugleich das Festhalten am ,alten Gesetz' in nachmessianischen Zeiten als ständige Provokation empfinden musste“ ${ }^{\text {159 }}$, konnte die Duldung rasch in Verfolgung umschlagen.

Ein gegenüber der typologischen und zeugnistheologischen Deutung des Judentums „grundlegender und dauerhafter Wandel der christlichen Sichtweise der Juden“ lässt sich aber erst im 12. Jahrhundert feststellen, als „[e]in neues Klischee der Juden als Bedrohung und Geheimnisträger entstand“, und diese neuen Vorurteile basierten bezeichnenderweise „nicht auf Unwissenheit, sondern im Gegenteil auf einer besse-

156 Vgl. ebd.

157 „Denn auch ich bin ein Israelit, vom Geschlecht Abrahams, aus dem Stamm Benjamin.“

158 Vgl. dazu auch oben in Kap. 2.2.1 Heidentum als dynamischer Gegenbegriff.

159 Vgl. Marcel Müllerburg, Britta Müller-Schauenburg, Henrik Wels: „Und warum glaubst du dann nicht?" Zur ambivalenten Funktion der Vernunft in Religionsdialogen des 12. Jahrhunderts. In: Integration und Desintegration der Kulturen im europäischen Mittelalter. Hrsg. von Michael Borgolte [u. a.]. Berlin 2011 (Europa im Mittelalter. 18), S. 261-324, hier S. 264. 
ren Kenntnis der nachbiblischen jüdischen Literatur““. ${ }^{160}$ Mit Petrus Venerabilis (1092/ 94-1156), Abt von Cluny, der durch seine Schriften und die in seinem Auftrag entstandene ersten Koran-Übersetzung auch die theologische Auseinandersetzung mit dem Islam maßgeblich prägt, setzt eine christliche Polemik gegen den Talmud ein, der als ketzerisch gebrandmarkt wird. Die genauere Kenntnis des zeitgenössischen Judentums liefert dabei den Beweis, dass die Juden die Bibel keineswegs wortwörtlich auslegen, und einem eigenen, von Menschen geschaffenen Gesetz folgen, das das biblische ersetzt habe: „Das Judentum galt nicht länger als eine anachronistische, vielleicht sogar lächerliche, aber in jedem Fall verständliche und durchsichtige Religion: jetzt erschien es als ein Sammelbecken geheimnisvoller, teuflischer Traditionen. “161 Auf dieser Argumentation basiert dann die „Entmenschlichung und Dämonisierung“162 des Judentums, die über die polemischen Traktate hinaus auch die populären Vorstellungen bestimmen wird, wie sie zum Beispiel in den Ritualmordlegenden des 12. und vor allem 13. Jahrhunderts Gestalt gewinnen. ${ }^{163}$

Der christliche Diskurs über das Judentum, der zunächst vom Ordnungsmodus ,transzendenter Ganzheit‘ bestimmt ist, bei dem die Juden als die religiös Fremden als ,Resonanzboden von Eigenheit' fungieren, wandelt sich und wird nun bestimmt vom Modus ,perfekter Vollkommenheit‘, der die Juden zum ,Gegenbild“ und zur ,Negation der Eigenheit' macht und das in besonders drastischer Weise, nämlich im Sinne einer teuflischen Entstellung der eigenen, christlichen Wahrheit. Die christliche antijüdische Polemik wäre also ein prägnantes Beispiel dafür, dass bessere Kenntnis nicht zwangsläufig - und, zumindest unter vorneuzeitlichen Bedingungen, wahrscheinlich sogar recht selten - zu mehr ,Toleranz' gegenüber Andersgläubigen führt, sondern Nähe die Erfahrung von Fremdheit intensiviert und die eigene Identität herausfordert. $^{164}$

In einem anderen Beitrag hat Funkenstein seinen historischen Abriss der christlich-jüdischen Auseinandersetzung stärker typisiert und vier Grundformen christlicher antijüdischer Polemik herausgearbeitet, von denen hier drei interessieren: ${ }^{165}$ Zunächst die bereits erwähnte stereotype Aufzählung von alttestamentlichen Beweisen für die Wahrheit des Christentums, die freilich davon ausgeht, dass das Judentum

160 Funkenstein, Juden, Christen und Muslime, S. 36-37.

161 Ebd., S. 37.

162 Ebd.

163 Dem steht später, bei den Humanisten und Renaissancephilosophen, freilich eine aus der religiösen Fremdheit gespeiste Faszination für die jüdische Exegese des Talmud und die Geheimlehre der Kabbala gegenüber. Vgl. ebd., S. 38.

164 Vgl. dazu sowie zu den ,Modi des Fremderlebens‘ nach Schäffter oben in Kap. 2.2.2 Heidentum als Erfahrung des religiös Fremden, S. 54-57.

165 Amos Funkenstein: Basic Types of Christian Anti-Jewish Polemics in the Later Middle Ages. In: Viator. Medieval and Renaissance Studies 2 (1971), S. 373-382. Die vierte Form, nämlich der Versuch, schließlich mit dem Talmud zu beweisen, „that even postbiblical Jewish literature, especially the Midrash, contains explicit hints of the veracity of the Christian dogma“ (S. 374), ist im Zusammenhang der religiösen Auseinandersetzungen des 13. Jahrhunderts nicht relevant. 
sich seit Entstehung des Christentums nicht geändert habe. Im 12. Jahrhundert vollzieht sich demgegenüber ein Wandel von Inhalt und Funktion der Polemiken, der sozio-ökonomische Gründe wie theologische hat und sich in zwei Formen konkretisiert. ${ }^{166}$ Zum einen, auf der Grundlage eines allgemeinen Rationalisierungsprozesses in der christlichen Theologie, in einer Rationalisierung der religiösen Polemik, die auf philosophischer Grundlage die Wahrheit der christlichen Dogmen beweisen will. Gerade diese Rationalisierung des Glaubensdiskurses beziehungsweise des Diskurses um die Ungläubigen liefere aber - eben weil sie auf der Ebene der Vernunft argumentiert, die allen Menschen gemeinsam sei, und daher allgemeine Verbindlichkeit einfordern zu können meint - eine neue, universelle Begründung von Intoleranz. Beispielhaft dafür ist der Syllogismus des Petrus Venerabilis, wonach, wenn erstens gelte, dass der Mensch ein animal rationale sei, und zweitens die Juden der Vernunft nicht folgten, sie schließlich Tiere seien. Gemeint ist dabei natürlich die von der Vernunft gebotene Anerkennung der christlichen Wahrheit, die die Juden weiterhin ,blind“ verweigern. Auf diese Weise führt gerade Vernunft zur Intoleranz, die Option rationaler Toleranz, also von der Vernunft gebotener Anerkennung religiöse Gegensätze, wird hingegen selten realisiert. ${ }^{167}$ Die Juden werden auf diese Weise von Ungläubigen im Sinne des Heidenbegriffs zu Un-Menschen, von religiöse Fremden zu schlichtweg Anderen, die gar nicht mehr in die eigenen menschlichen Kategorien vermittelt werden müssen.

Zum anderen konkretisiert sich der Wandel der Polemiken in der Auseinandersetzung mit der nachbiblischen jüdischen Literatur, die die Erkenntnis mit sich bringt, dass sich das Judentum seither verändert hat. ${ }^{168}$ Auf dieser Grundlage entwickelt sich dann im 13. Jahrhundert eine neue ideologische Perspektive gegenüber den zeitgenössischen Juden, „that having broken with their own heritage they had no rightful place in a properly ordered Christian society“169, und diese Perspektive führt dazu, dass Juden erstmals und mit ganz eigener Dringlichkeit als Ziel kirchlicher Mission und Gegner in realen Religionsdisputen erscheinen:

\footnotetext{
For the first time in medieval Europe ecclesiastical authorities took concerted steps to proselytize among the Jews en masse, persecuting the Talmud [...], exploiting inquisitorial jurisdiction to harass entire Jewish communities, invading synagogues to preach to Jewish worshippers, and coercing leading rabbis to participate in public, officially sanctioned disputations. ${ }^{170}$
}

Diese neue Unduldsamkeit gegenüber den Juden, die die rein theologisch-gelehrte Ebene weit übersteigt und sich in konkreten lebensweltlichen Phänomenen niederschlägt, ist auch vor dem Hintergrund einer tatsächlichen Judenfeindschaft zu sehen,

166 Vgl. ebd., S. 377.

167 Vgl. ebd., S. 378.

168 Vgl. ebd., S. 379.

169 Cohen, Towards a Functional Classification of Jewish anti-Christian Polemic, S. 104.

170 Ebd. 
die sich im Kontext der ersten Kreuzzüge im 11. Jahrhundert ausprägt und popularisiert. Denn mit der kriegerischen Aushandlung des religiösen Gegensatzes zu den Heiden an den Grenzen der christianitas rücken auch die Juden als Ungläubige im Inneren neu in den Blick; die äußere Expansion der lateinischen Christenheit steht auch und gerade hier in enger Wechselwirkung mit ihrer inneren Homogenisierung. Explizit wird das ebenfalls bei Petrus Venerabilis, der in einem Brief an den französischen König Ludwig VII. anlässlich des Zweiten Kreuzzuges ausführt:

Sed quid proderit inimicos Christianæ spei, in exteris aut remotis finibus insequi, ac persequi, si nequam, blasphemi, longeque Sarracenis deteriores Judæi, non longe a nobis, sed in medio nostri, tam libere, tam audacter, Christum cunctaque Christiana sacramenta impune blasphemaverint, conculcaverint, deturpaverint? Quomodo zelus Dei comedet filios Dei, si sic prorsus intacti evaserint, summi Christi ac Christianorum inimici Judæi? ${ }^{171}$

Was nützt es aber, die Feinde des christlichen Glaubens in fernen Landen aufzusuchen und zu bekämpfen, wenn die liederlichen und lästernden Juden, die weitaus übler als die Sarazenen sind, nicht in fernen Landen, sondern (hier) in unserer Mitte so ungehemmt und verwegen Christentum und alle christlichen Sakramente ungestraft schmähen, mit den Füßen treten, verächtlich machen? Wie soll Gottes Eifer die Kinder Gottes beseelen, wenn die Juden, diese schlimmsten Feinde Christi und der Christen, so ganz ungeschoren davonkommen?

Freilich geht er nicht so weit zu fordern, dass die Juden getötet werden müssten oder dürften, sondern empfiehlt, sie zur Finanzierung des Kreuzzuges heranzuziehen, aber es lässt sich natürlich darin eine Rechtfertigung physischer Gewalt und gar organisierter Pogrome sehen, wie sie die jüdischen Gemeinden im Rheinland im Vorfeld des Ersten Kreuzzuges im Frühjahr 1096 ja bereits tatsächlich hatten erleiden müssen.

In der Forschung hat sich für die Entwicklung der christlich-jüdischen Auseinandersetzung im Laufe des Mittelalters ein lineares Modell zunehmender Verschärfung etabliert, demzufolge ,die relativ kleinen jüdischen Gemeinden auf dem Gebiete des späteren Deutschen Reiches seit den letzten Tagen der Römerherrschaft bis in das 11. Jahrhundert relativ ungestört und unbehelligt leben konnten““. ${ }^{172}$ Erst seit dem 11. und 12. Jahrhundert habe sich dann eine wechselseitige Auseinandersetzung von Judentum und Christentum auf Grundlage des Talmuds entwickelt, ${ }^{173}$ die durch die

171 Petrus Venerabilis: Epistulae 4, Epistula 36. In: Patrologiae cursus completus. Series Latina, Bd. 189. Hrsg. von Jacque-Paul Migne. Paris 1890, Sp. 366-368, hier Sp. 366-367. Übersetzung nach Bernhard Blumenkranz: Patristik und Frühmittelalter. Die Entwicklung im Westen zwischen 200 und 1200. In: Kirche und Synagoge. Handbuch zur Geschichte von Christen und Juden. Darstellung mit Quellen, Bd.1. Hrsg. von Karl Heinrich Rengstorf, Siegfried von Kortzfleisch. Stuttgart 1968, S. 84-135, S. 120.

172 Vgl. Winfried Frey: Gottesmörder und Menschenfeinde. Zum Judenbild in der deutschen Literatur des Mittelalters. In: Die Juden in ihrer mittelalterlichen Umwelt. Hrsg. von Alfred Ebenbauer, Klaus Zatloukal. Wien/Köln 1991, S. 35-51, hier S. 36.

173 Vgl. dazu Kurt Schubert: Das christlich-jüdische Religionsgespräch im 12. und 13. Jahrhundert. In: Die Juden in ihrer mittelalterlichen Umwelt. Hrsg. von Alfred Ebenbauer, Klaus Zatloukal. Wien/Köln 1991, S. 223-250. 
missionarischen Bestrebungen der Bettelorden im 13. Jahrhundert schließlich einen neuen Schub bekommen hätten. So fasst der Historiker Michael Borgolte die gängige Darstellung der Entwicklung jüdisch-christlicher Religionsgespräche zusammen:

Trotz des unbefriedigenden Kenntnisstandes glaubte die Forschung urteilen zu können, daß die christlich-jüdischen Gespräche im Laufe des elften Jahrhunderts zugenommen hatten und vorerst in moderatem Ton verliefen. Erst der Aufschwung der Gelehrsamkeit, besonders im Zeichen der (Früh-)Scholastik, habe die Christen ermutigt, sich dem Religionsgespräch mit den traditionell schriftkundigen und oft hochgebildeten Juden auszusetzen. Im dreizehnten Jahrhundert habe sich der Ton verschärft, insbesondere die Angehörigen des Dominikaner- und des Franziskanerordens hätten die Juden neben Zwangspredigten auch durch Zwangsdisputationen bedrängt, also den Druck zur Konversion erhöht. ${ }^{174}$

Der alten ,Meistererzählung‘ einer sich vom Früh- zum Hochmittelalter herausbildenden ,persecuting society“ wäre in Bezug auf die christliche Auseinandersetzung mit den Juden - trotz aller gewaltsamen Übergriffe und Unduldsamkeit, die es fraglos gegeben hat - aber zumindest die traditionelle Pflicht der Herrscher zu deren Schutz entgegenzuhalten, die sich in Privilegien für jüdische Gemeinden ausdrückt oder darin, dass im Zuge von Pogromen zwangsgetauften Juden die Rückkehr zu ihrem alten Glauben zugestanden wird. ${ }^{175}$

Und entgegen der ,angeblichen Linearität eines geistes- oder theologiegeschichtlichen Prozesses [...], der große Räume und soziale Einheiten, etwa den christlichen europäischen Westen oder die römische Christenheit, kennzeichnen sollte“, hat Borgolte im Zeichen des ,spatial turn' in den Geschichtswissenschaften gefordert, im Sinne einer ,Gleichzeitigkeit des Ungleichzeitigen` die konkreten kommunikativen Zusammenhänge und damit verbundenen unterschiedlichen Zielsetzungen von Religionsgesprächen zu beachten: „Sie konnten der bloßen Präsentation der für sicher gehaltenen Wahrheit dienen, der klärenden Absicherung des Eigenen in der Auseinandersetzung mit den Anderen, ein echtes Interesse am Fremden befriedigen oder auch unmißverständlich auf Konversion angelegt sein." ${ }^{176}$ Eine Geschichtswissenschaft, „die sich für die Lage der Menschen in ihrer Welt“ interessiere, müsse sich mit „den konkreten Lebensräumen“ beschäftigen, um „Rückschlüsse auf das Zusammenleben religiöser Mehrheiten mit Minderheiten der eigenen Gemeinschaft oder anderer Bekenntnisse beziehungsweise Kulte“177 ziehen zu können.

Aus literaturwissenschaftlicher Perspektive ist in diesem Zusammenhang zudem die Literarizität der Quellen zu betonen, die die religiösen Auseinandersetzungen ja nie einfach nur wiedergeben, sondern immer schon reflektieren und in ihren Insze-

174 Michael Borgolte: Christen und Juden im Disput. Mittelalterliche Religionsgespräche im ,spatial turn'. In: HZ 286 (2008), S. 359-402, hier S. 365-366, der sich damit auf die These von Jeremy Cohen: The Friars and the Jews. The Evolution of Medieval Anti-Judaism. Ithaca/London 1982 bezieht.

175 Vgl. ebd., S. 368-371. Der Begriff geht zurück auf Robert Ian Moore: The Formation of a Persecuting Society. Power and Deviance in Western Europe, 950 -1250. Oxford/New York 1987.

176 Borgolte, Christen und Juden im Disput, S. 400.

177 Ebd., S. 401. 
nierungsformen verschiedenen Gattungen und Stofftraditionen verpflichtet sind. Die Aushandlung des religiösen Gegensatzes zum Judentum gehört dabei ,in einer historisch-genetischen und eschatologischen Dimension ganz wesentlich zum eigenen religiösen Selbstverständnis; als Baustein der eigenen religiösen Identität““. ${ }^{178}$ Als Konfrontationskulturen bilden Judentum und Christentum ihre Identität in Abgrenzung von der jeweils anderen heraus. Das ändert sich auch nicht mit der Etablierung und Durchsetzung des Christentums, sondern gewinnt gerade hier an Bedeutung für das christliche Selbstverständnis, weil die heilsgeschichtlich eigentlich überholte Weiterexistenz des Judentums nun erst recht den Wahrheitsanspruch des Christentums in Frage stellt und bearbeitet werden muss. Das geschieht nun gerade in der Form von Religionsdialogen, also der literarischen Darstellung von persönlichen Glaubensgesprächen oder öffentlichen Disputen zwischen Juden und Christen.

Dass die Aushandlung des religiösen Gegensatzes zum Judentum im lateinischen Mittelalter in ganz unterschiedlichen literarischen Formen durchgängig von Bedeutung ist, bezeugt das kaum überschaubare Korpus von sogenannten Adversus-Judaeos-Texten, das Heinz Schreckenberg in zwei umfangreichen Bänden dokumentiert hat. ${ }^{179}$ Deutlich wird in dieser Zusammenstellung, dass die hochmittelalterlichen Adversus-Judaeos-Schriften an frühchristlich-spätantike Vorbilder anknüpfen können, so wie andererseits auch Motive, Themen und Argumentationen der frühchristlichen apologetischen Literatur über die lateinische Legendenliteratur bis ins hohe Mittelalter überliefert werden und dort dann Eingang in die volkssprachige Literatur finden. ${ }^{180}$

In der Gestaltung religiöser Auseinandersetzungen in Form von Glaubensdisputen mit den Heiden spiegeln die mittelalterlichen Legenden daher „eine Zeit, in der sich das Christentum noch mit polytheistischen und anderen antiken Religionen konfrontiert sah" ${ }^{181}$ Der Anachronismus steht dabei im Dienst christlicher Identitätsbildung, denn solche Erzählungen, „die aus dem ,heroic age‘ der Kirche berich-

178 Jana Pacyna: Juden und Christen im Mittelalter. Zwischen Verfolgung und ,Judenrecht‘. In: Der Umgang mit Andersdenkenden und Andersgläubigen in der Christentumsgeschichte. Hrsg. von Mariano Delgado, Volker Leppin, David Neuhold. Fribourg 2012 (Studien zur christlichen Religions- und Kulturgeschichte. 17), S. 31-49, hier S. 36.

179 Die christlichen Adversus-Judaeos-Texte und ihr literarisches und historisches Umfeld (1.-11. Jh.). Frankfurt a. M. 1982 (Europäische Hochschulschriften, Reihe 23 Theologie. 172) und Die christlichen Adversus-Judaeos-Texte und ihr literarisches und historisches Umfeld (13.-20. Jh.). Frankfurt a. M./ Bern 1994 (Europäische Hochschulschriften, Reihe 23 Theologie. 497).

180 Vgl. Elisabeth Schenkheld: Die Religionsgespräche der deutschen erzählenden Dichtung bis zum Ausgang des 13. Jahrhunderts. Borna/Leipzig 1930, S. 117.

181 Burghart Wachinger: Religionsgespräche in Erzählungen des Mittelalters. In: Die Aktualität der Vormoderne. Epochenentwürfe zwischen Alterität und Kontinuität. Hrsg. von Klaus Ridder, Steffen Patzold. Berlin 2013 (Europa im Mittelalter. Abhandlungen und Beiträge zur historischen Komparatistik. 23), S. 295-316, hier S. 298. Das gilt freilich nicht nur für Legenden im engeren Sinn, sondern für volkssprachige Erzählungen überhaupt, zu denken wäre beispielsweise an die ,Religionsgespräche“ im Willehalm. 
teten, dienten im hohen Mittelalter zweifellos der eindrucksvollen Demonstration der Heiligkeit der himmlischen Fürsprecher und der Selbstvergewisserung im Glauben“. ${ }^{182}$ Während das antike Heidentum keine konkrete Entsprechung in der mittelalterlichen Lebenswelt hat, die Iteration seiner Überwindung also eine primär erinnernde Funktion im Sinne eines Gründungsmythos der Kirche hat sowie davon ausgehend eine spirituelle Dimension, die die Gläubigen an die Notwendigkeit der inneren conversio gemahnt, bleibt die Auseinandersetzung mit dem jüdischen Glauben aktuell: „Mit Juden konnte man im Alltag in Kontakt kommen, und für die Theologie blieb die christologische Deutung des Alten Testaments ein zentrales Thema." 183

Aber auch wenn ein unmittelbarer lebensweltlicher Bezug nahezuliegen scheint, steht die symbolisch-typologische Funktion des Judentums, wie sie die christliche antijüdische Polemik seit ihren Anfängen maßgeblich bestimmt und der christliche Identitätsbildung gedient hat, im Zentrum der Adversus-Judaeos-Literatur. Daher lässt sich inhaltlich keine unmittelbare Verbindung vom theologischen Antijudaismus dieser Schriften zur religiös motivierten Gewalt gegenüber den Juden im Mittelalter ziehen, beispielsweise zur „vulgärtheologisch begründeten Judenfeindschaft der Prediger des Kreuzzugs und eines Teil der Kreuzfahrer“, wie überhaupt die antijüdischen Ausschreitungen des Ersten Kreuzzuges „nicht regulären Abteilungen ritterlicher Kreuzfahrer, sondern eher den spontan sich bald nach Urbans Rede bildenden irregulären Heerhaufen“ zuzuschreiben seien. ${ }^{184}$ Insgesamt lässt sich zeigen, dass diese Schriften

trotz der Wiederaufnahme zahlreicher antijudaistischer Stereotypen doch in der Regel unterhalb des Vorwurfs des Gottesmordes bleiben und nie die Basis der offiziellen hochkirchlichen Theologie im Sinne der paulinisch-augustinischen Lehre verlassen, welche die Existenz der Juden heilsgeschichtlich begründet. ${ }^{185}$

Die theologische Auseinandersetzung mit dem Judentum meint erst einmal nicht die zeitgenössischen Juden, sondern die historischen beziehungsweise typologischen der christlichen Apologetik. Deren Anfänge liegen im 2. und 3. Jahrhundert, also in der Zeit, in der sich das Christentum noch als Minderheit einer gleichgültig neutralen bis offen ablehnenden heidnischen Mehrheitsgesellschaft gegenübersieht. In diesem Zusammenhang stellt sich die apologetische Literatur als diskursive Form der Identitätsbildung dar, in Ergänzung zur narrativen der Märtyrerlegenden und Konversionserzählungen. Ihre Aufgabe besteht in der vernunftmäßigen und systematischen

182 Ebd., S. 304.

183 Ebd.

184 Friedrich Lotter: „Tod oder Taufe“. Das Problem der Zwangstaufen während des Ersten Kreuzzugs. In: Juden und Christen zur Zeit der Kreuzzüge. Hrsg. von Alfred Haverkamp. Sigmaringen 1999 (Vorträge und Forschungen. 47), S. 107-152, hier S. 110 u. 124.

185 Ebd., S. 124. 
Rechtfertigung des christlichen Glaubens gegenüber dem Heidentum, vor allem in der Form, dass sie seine Inhalte als logische und erfüllende Fortführung der überkommenen Philosophie darstellt, andererseits die Unzulänglichkeiten der anderen Glaubensvorstellungen angreift. Insofern sind Apologetik und Polemik, Verteidigung und Angriff, kaum trennscharf zu unterscheiden.

In der Dialogform liegt dabei eine prägnante Steigerung der Apologetik, weil sie nicht nur die christlichen Glaubensinhalte darstellen, sondern die heidnischen zugleich widerlegen, ${ }^{186}$ ja mehr noch: die diskursive Überwindung des Heidentums durch das Christentum in actu umsetzen kann. Das gilt natürlich umso mehr, wenn Glaubensgespräche mit erfolgreichen Konversionen erzählerisch verknüpft werden, die diskursive Aushandlung des religiösen Gegensatzes also narrativ eingebettet und beglaubigt wird, denn damit werden zwei entscheidende Formen der christlichen Identitätsbildung wirkungsvoll miteinander kombiniert.

Der apologetische Ursprung von Religionsdialogen macht deutlich, dass es sich hierbei um fiktive Dialoge handelt, die einen „realistischen Kern“ nur insofern haben, als sie „die religiösen Konfliktlinien und Auseinandersetzungen ihrer Zeitalters“187 widerspiegeln. Die Rede von ,Dialogen“ ist dabei anachronistisch, wenn sie sich nicht auf die Beschreibung der literarischen Gestaltung als Wechselrede beschränkt, denn „[d]er Begriff ,Dialog‘ beschreibt in seiner heutigen Verwendung [...] nicht nur das bloße Faktum der Kommunikation zwischen einer Anzahl von Interlokutoren, sondern führt einen evaluativen Anteil mit sich, der ihn als eine Form der Toleranz und damit als ethisch geboten aufweist" ${ }^{188}$ Von einer solch emphatischen Toleranz und gleichberechtigten gemeinsamen Wahrheitssuche kann im Zusammenhang vorneuzeitlicher Religionsdialoge aber kaum die Rede sein. Selbst Ramon Llulls Vision einer friedlichen Bekehrung aller Ungläubigen im dialogischen Einvernehmen, auf die ich weiter oben schon einmal eingegangen bin, bleibt eine von der absoluten Wahrheit des christlichen Glaubens bestimmte Missionsmethode und ist kein philosophischer Selbstzweck. ${ }^{189}$ Zwar vollzieht sich seit dem 11. Jahrhundert „eine systematisch äußerst folgenreiche Wende von der hermeneutisch-exegetischen zur philosophischen Apologetik“, die „die philosophische Vernunft als Medium des Dialogs zwischen den

186 Vgl. David A. Wells: Christliche Apologetik, die mittelhochdeutsche Silvesterlegende, Wolframs von Eschenbach Willehalm und die Toleranz gegenüber Andersgläubigen im Mittelalter. In: Mediaevistik. Internationale Zeitschrift für interdisziplinäre Mittelalterforschung 14 (2001), S. 179-224, hier S. 179-180.

187 Mathias Hildebrandt: Mittelalterliche Religionsdialoge. Auf der Suche nach einer interreligiösen Hermeneutik. In: Friedensstiftende Religionen? Religion und die Deeskalation politischer Konflikte. Hrsg. von Manfred Brocker, Mathias Hildebrandt. Wiesbaden 2008 (Politik und Religion. 5), S. 29-70, hier S. 30.

188 Müllerburg, Müller-Schauenburg, Wels, Zur ambivalenten Funktion der Vernunft, S. 261.

189 Vgl. dazu oben in Kap. 2.3.2 Das Verhältnis von Kreuzzug und Mission, S. 85. Zur Problematik des heutigen Toleranzbegriffs zur Beschreibung mittelalterlicher Phänomene vgl. oben in Kap. 2.3.1 Formen religiösen Kulturkontakts. 
Religionen erprobt“ “. ${ }^{190}$ Und auf dieser Grundlage entwirft Ramon Llull in seinem Llibre del gentil e dels tres savis (Buch vom Heiden und den drei Weisen) tatsächlich

eine Art offener und kontinuierlicher Diskurs, der auf ein permanentes Forum der Religionen hinausläuft, in dem Diskussionen nicht mit partikularen Kompromissen enden sollten, sondern so lange fortgeführt werden müssen, bis die verschiedenen Wahrheitsansprüche im Licht eines generell akzeptierten rationalen Verfahrens [...] entschieden sind und so eine vollkommene Schlussübereinkunft unter den Teilnehmenden erreicht worden ist. ${ }^{191}$

Das Potential von Religionsdialogen mag dabei darin liegen, dass die szenische Fiktion gegenüber dem systematischen theologischen Urteil Freiräume gewährt. ${ }^{192}$ Dabei muss man nicht zwangsläufig davon ausgehen, dass im Fall eines auf rationale Verständigung angelegten Religionsdialoges „[d]ie von moralischen Diskriminierungen bestimmte Grenze [...] schon Erosionen erfahren haben“, vielmehr sollte man verschiedene Situationen und Konstellationen in Betracht ziehen, denn „die literarischen Fiktionen [sind] auch ihrerseits Theorie, abgehoben von ganz anderer interreligiöser Realität“ ${ }^{193}$ In den Religionsdialogen und Missionstraktaten Ramon Llulls zeichnet sich jedenfalls letztlich ein Wandel vom Dialog im emphatischen Sinne zum Disput und Streitgespräch, von der Apologie zur Polemik ab: „In dieser auffallenden Verhaltensänderung Lulls den Andersgläubigen gegenüber handelt es sich um nichts anderes als um die ganze Dialektik von Theorie und Praxis bzw. von Selbst- und Zwiegespräch." ${ }^{194}$ Unter dem Eindruck des Scheiterns einer friedlichen Mission im realen Gespräch mit den Muslimen beginnt er, so jedenfalls die biographische Lesart, eine Verbindung von Kreuzzug und Mission, wie er sie zuvor abgelehnt hatte, zu unterstützen - wenn man nicht allein schon die Situationsgebundenheit und Eigenlogik der jeweiligen Schriften für ausschlaggebend hält.

In den Religionsdialogen, wie sie sich innerhalb von Legenden finden, ist die Wahrheitsfrage jedenfalls immer schon entschieden: „Man disputiert also nicht, um in gemeinsamer Arbeit in dialektischen Erörterungen die Wahrheit zu finden, sondern man streitet, um die für einen selbst schon feststehende Wahrheit zu demonstrieren

190 Alexander Fidora: Das philosophische Religionsgespräch im Mittelalter. Von Gilbert Crispin und Peter Abaelard zu Ramon Llull. In: Religiöse Toleranz im Spiegel der Literatur. Eine Idee und ihre ästhetische Gestaltung. Hrsg. von Bernd F. W. Springer, Alexander Fidora. Wien/Berlin 2009 (Literatur. 18), S. 71-81, hier S. 73.

191 Ebd., S. 76-77.

192 Vgl. Hans Zirker: Grenzüberschreitungen. Möglichkeiten und Bedingungen einer Theologie interreligiösen Gesprächs. In: Ethik im Konflikt der Überzeugungen. Hrsg. von Andreas Lob-Hüdepohl. Fribourg 2004 (Studien zur theologischen Ethik. 105), S. 80-94, hier S. 85.

193 Ebd.

194 Eusebio Colomer: Raimund Lulls Stellung zu den Andersgläubigen. Zwischen Zwie- und Streitgespräch. In: Religionsgespräche im Mittelalter. Vorträge, gehalten anläßlich des 25 . Wolfenbütteler Symposions vom 11. bis 15. Juni 1989 in der Herzog August Bibliothek. Hrsg. von Bernard Lewis, Friedrich Niewöhner. Wiesbaden 1992 (Wolfenbütteler Mittelalter-Studien. 4), S. 217-236, hier S. 232. 
oder gegen die Unwahrheit zu schützen. “195 Dahinter steht, zumal bei den christlichjüdischen Religionsdialogen, die Überzeugung, „daß man das Christentum durch ratio und scriptura als die wahre Religion dartun kann“"196, soll heißen: durch vernunftgemäße Argumentation und Beweise aus der Heiligen Schrift, die im Fall der Juden und des Alten Testaments ja auch eine gemeinsame Autorität ist. Die Funktion dieser Religionsdialoge liegt in der religiösen Selbstvergewisserung und theologischen Belehrung eines christlichen Publikums. So entspricht die komplette Übernahme des umfangreichen Disputs mit den Juden in Konrads Silvester den

im Prolog geäußerten pädagogischen Intentionen, denn der Begriff bezzerunge (25) zielt sowohl auf den Heiligen als das Vorbild im religiös-sittlichen Sinne als auch auf die dogmatische Festigung und Belehrung, die der Leser aus der Disputation gewinnen kann; denn im Grunde ist der Dialog doch ein von kurzen Fragen und Einwürfen durchsetzter Monolog Silvesters, der weniger dazu dienen soll, die Juden zu belehren als vielmehr die Christen zu erbauen und zu stärken. ${ }^{197}$

Religionsdialoge stellen sich in diesem Zusammenhang vor allem dar als literarische Tradition innerchristlicher Erbauung, wobei seit der frühchristlichen Apologetik die dialogische Form charakteristisch für die Auseinandersetzung mit dem Judentum ist, während gegen das Heidentum Monologe genügen:

Während man sich den Heiden gegenüber in der Regel damit begnügen kann, das Christentum in seiner Gesamtheit als die wahre Religion hinzustellen (gelegentlich auch Angriffe auf die Reinheit des Christentums abzuweisen), was am besten in einer langen Lehrrede geschieht, muß man sich. mit dem jüdischen Gegner mehr auf Einzelheiten einlassen. ${ }^{198}$

Dieser Unterschied von antijüdischem und antiheidnischem Disput zeigt sich auch im Vergleich der mittelalterlichen Legenden von Silvester sowie Barlaam und Josaphat: Mit den Juden müssen einzelne Dogmen diskutiert werden und das geschieht in der Form immer wieder einsetzender Angriffe seitens der Juden und deren darauffolgender Widerlegung durch die Christen. Auf diese Weise wird die historische Ablösung des Judentums durch das Christentum dialogisch durchgespielt, während der heidnische Vorwurf, das Christentum sei eine Irrlehre, mit einer Darlegung der christlichen Glaubensinhalte abgewehrt werden kann. ${ }^{199}$

Die Auffassung, dass die Adversus-Judaeos-Texte seit dem 12. Jahrhundert insgesamt als Ausdruck christlicher Missionsbemühungen gegenüber den Juden zu verstehen seien, übersieht also die Ursprünge und die Funktionszusammenhänge der verschiedenen Texte und Gattungen, die von der Aufzeichnung mündlicher Disputationen über theoretische Traktate bis hin zu Predigten und eben Legenden rei-

195 Schenkheld, Die Religionsgespräche der deutschen erzählenden Dichtung, S. 39.

196 Ebd., S. 45.

197 Brinker, Formen der Heiligkeit, S. 188.

198 Schenkheld, Die Religionsgespräche der deutschen erzählenden Dichtung, S. 116.

199 Vgl. ebd., S. 116-117. 
chen. ${ }^{200}$ Zweifelhaft bleibt aber auch, ob die Zielrichtung der christlich-jüdischen Religionsgespräche des 13. Jahrhunderts wirklich eine missionarische war. Zwar spielten bei den Disputationen 1240 in Paris und 1263 in Barcelona sowie einer zweiten in Paris 1271 oder 1272 „Gelehrte aus den Mendikantenorden eine führende Rolle“, sodass sie wohl „im Rahmen der Missionsoffensive zu sehen [sind], die von Vertretern dieser Orden innerhalb und außerhalb der christlichen Welt durchgeführt wurde“. ${ }^{201}$

Doch scheint hier wiederum das apologetische und binnenchristlich-missionarische Motiv bestimmend gewesen zu sein, also das der religiösen Selbstvergewisserung angesichts der bleibenden Herausforderung durch das Judentum, das der inneren Homogenisierung der christianitas als religiöser Fremdkörper im Eigenen entgegenstand. Denn im Mittelpunkt dieser Disputationen steht jeweils der Talmud: 1240 in Paris wird er als gefährliche Quelle des Irrglaubens diffamiert, sodass der vorhersehbare Sieg des Christentums vier Jahres später in der Verbrennung ganzer Wagenladungen der Schrift gipfelt. 1263 in Barcelona und bei der zweiten Disputation in Paris soll der Talmud hingegen gerade die Wahrheit des christlichen Glaubens bezeugen, indem gezeigt wird, dass mit den nachbiblischen jüdischen Schriften sehr wohl die christliche Auffassung bewiesen werden kann, dass der Messias bereits erschienen und die Inkarnation Gottes ist. ${ }^{202}$ Die Juden erscheinen dabei kaum als Adressaten tatsächlicher Missionsbemühungen, sondern haben - wenn man den schriftlichen Aufzeichnungen folgt, die zwar fraglos Inszenierungen darstellen, dabei aber doch die Paradigmen solcher Disputationen offenbaren - eine Funktion im Sinne der christlichen Identitätsbildung: „In both these disputations, while flesh and blood Jews take an active role, the Jews themselves are hermeneutical in the sense that while they are seen through their authoritative texts, their personalities and beliefs are not important or of interest.“203

Der Zweck aller drei Disputationen kann demnach nicht primär in der Konversion der Juden gesehen werden, sondern in der Bestätigung und Festigung der Wahrheit des christlichen Glaubens ausgehend von den jüdischen, biblischen und nachbiblischen, Schriften. Dazu passt, dass diese Disputationen zwar jeweils öffentliche Auseinandersetzungen unter königlichem Vorsitz und unter Anwesenheit kirchlicher Amtsträger sind, bezeichnenderweise aber von zwei zum Christentum konvertierten Juden, die im Zuge ihrer Konversion in den Dominikaner- beziehungsweise Franziskanerorden eingetreten waren, angestoßen werden. So mag auch für die tatsächlichen Religionsgespräche gelten, was für die literarischen Religionsdialoge offensichtlich

200 Vgl. Harvey J. Hames: Truly Seeking Conversion? The Mendicants, Ramon Llull and Alfonso de Valladolid. In: Morgen-Glantz. Zeitschrift der Christian-Knorr-von-Rosenroth-Gesellschaft 20 (2010), S. 41-62, hier S. 42.

201 Ora Limor: Art. Religionsgespräche III. Jüdisch-christlich. In: TRE 28 (1997), S. 649-654, hier S. 649.

202 Vgl. Hames, Truly Seeking Conversion?, S. 46.

203 Ebd. S. 43. 
ist, dass sie nämlich ,eigentlich christliche Selbstgespräche sind, die in der Auseinandersetzung mit dem Judentum, dem Islam und der Philosophie immer der Selbstvergewisserung des eigenen Glaubens dienen“204, also vor allem apologetischen Charakter haben und einen teilweise sich darin niederschlagenden missionarischen Anspruch nicht einlösen können.

\subsubsection{Glaubensdisput und Demonstration des Heils im Stierwunder}

Der Glaubensdisput der Silvesterlegende ist also im Kontext christlicher Selbstvergewisserung zu sehen, wie er sich in der breiten Tradition der Adversus-JudaeosSchriften manifestiert. Im Zusammenhang meiner Frage nach Konversion als Form der Aushandlung des religiösen Gegensatzes zum Heidentum - in diesem Fall in der besonderen Gestalt des Judentums - interessiert nun weniger die theologische Argumentation des Disputs, die auch und gerade bei Konrad in ausführlicher Breite wiedergegeben wird und damit das narrativ Notwendige weit überschreitet; ihre Funktion findet sie ganz offensichtlich in der Darstellung christlichen Heilswissens für das Legendenpublikum. Interessant ist hier vor allem, auf welche Weise der Disput mit dem nachfolgenden Stierwunder verknüpft und wie dabei Konversion narrativiert wird.

Denn die Silvesterlegende bietet dafür zwei Modelle: Im ersten Teil der Legende mit der Heilung und Taufe Konstantins geht es um eine ,Bekehrung als Wunder', also das Problem der Darstellung eines inneren Konversionsgeschehens, das mit einem individuellen, zeugenlosen Moment der Gotteserkenntnis einsetzt und dessen Motivierung und Plausibilisierung in der äußeren, intersubjektiven. Dieses Problem wird gelöst durch die explizite diskursive Vermittlung des von Konstantin innerlich Erlebten und Vollzogenen durch Silvester, andererseits durch die zeichenhafte Realisierung des Heilsgeschehens durch den Zusammenfall von Taufe und wundersamer Heilung. Im zweiten Teil der Legende geht es bei der Überwindung des Judentums um eine ,Bekehrung durch Wunder‘, denn nicht die rationale Argumentation, so überzeugend sie sein mag, kann die Glaubensentscheidung herbeiführen, sondern nur der zeichenhafte Durchbruch des Heiligen.

Das berührt das dem legendarischen Erzählen innewohnende Problem der Evidenz und Darstellbarkeit des Glaubens, also der Narrativierung des Einbruchs der Transzendenz in die Immanenz: Denn Glaubenswahrheiten können weder in der persönlichen Unterweisung noch im öffentlichen Disput tatsächlich bewiesen werden. Die Erfahrung des Heils, die das Konversionsgeschehen, zumindest in der entsprechenden christlichen Inszenierung, letztlich ausmachen soll, muss sich erweisen und gläubig angenommen werden. Daher wird Konversion als kognitiv nicht zu plausibilisierender Umschlag narrativiert, sei er nun durch eine innere Krise oder die

204 Hildebrandt, Mittelalterliche Religionsdialoge, S. 67. 
äußere Demonstration göttlicher Macht angestoßen. Disput und Unterweisung können diesen Umschwung nur vor- beziehungsweise nachbereiten, nicht aber garantieren - an diese Stelle tritt das Wunder.

Die Disputation wird von Konstantin aber gerade als Tribunal einberufen, das den wahren Glauben mit Vernunftgründen beweisen und seine Mutter damit zur Konversion bewegen soll:

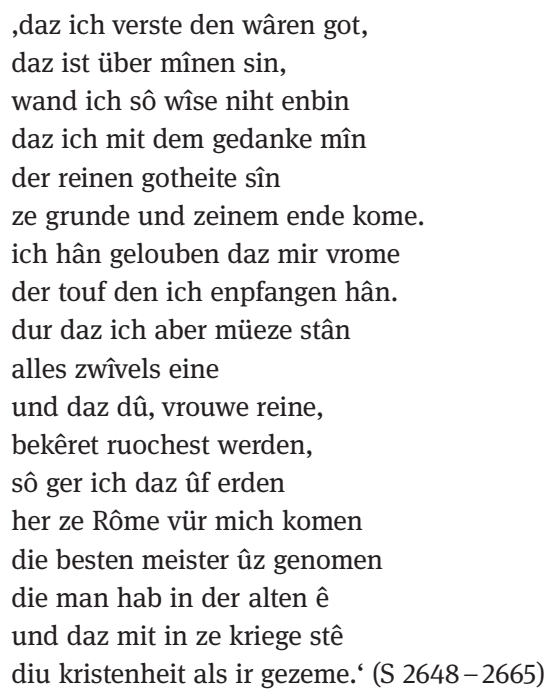

Dabei zielt Konstantins Argumentation nicht allein auf eine Apologie des christlichen Glaubens, sondern zumindest theoretisch auf eine Wahrheitsfindung im Wettstreit der beiden Religionen: Er als Kaiser habe ,zem besten [...] pfliht' und wolle , an die rehten wârheit‘ glauben (S 2639 und 2645). Die anberaumte Disputation wird entsprechend als wechselseitiges Streitgespräch angekündigt, das endgültig und verbindlich das Heil für alle Menschen erweisen soll:

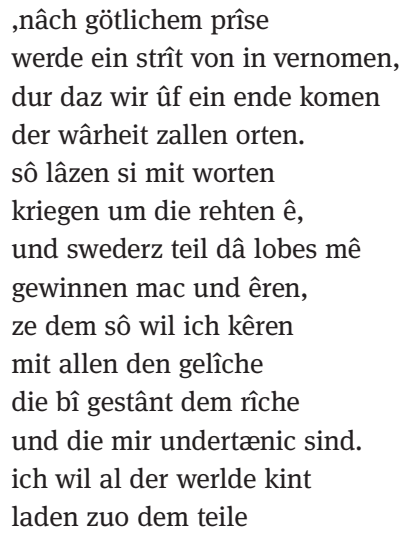


daz mit lobes heile

von dem kriege scheiden sol.' (S 2670-2685)

An die heilsgeschichtliche Entscheidung zwischen Heidentum und Christentum im ersten Teil der Legende schließt sich mit dem Disput also eine zweite an, die erzählerisch zunächst weitgehend neutral eingeführt wird. Bei Konrad ist nun Konstantin selbst der Schiedsrichter, während in der Legenda aurea zwei Heiden, die ja in dieser Fassung der Silvesterlegende noch nicht völlig überwunden sind, als gerechte, weil unparteiische Schiedsrichter über den christlich-jüdischen Disput eingesetzt werden. Das entscheidende Kriterium für ihre Wahl ist ihre Weisheit beziehungsweise Vernunft, so heißt es nach dem ersten Wortwechsel, in dem es um die Trinität geht: ,Constat Abiathar a Silvestro superatum. Nam et ratio hoc docet, quia, si deus non esset et se deum dixisset, conferre vitam mortuis non valeret.' (LA 274) ${ }^{205}$ Im Folgenden werden die einzelnen Kontroversen der Disputation hingegen nur noch durch lakonische Erzählerkommentare entschieden, nach dem Muster: Isto superato tertius [...] accedens ait (LA 274). ${ }^{206}$ Bald übernimmt aber auch hier Konstantin die Schiedsrichterrolle: Wenn der betreffende jüdische Meister nichts mehr zu sagen wüsste, was freilich stets rhetorisch bleibt, sei er überwunden. Damit bekommt die Disputation mehr und mehr den Charakter einer „Zwangspredigt für die Juden, bei der die Andersgläubigen nur die Stichworte liefern, die aber gleichzeitig dazu dient, die Gläubigen in den eigenen Reihen zu erbauen und zu stärken“ ${ }^{207}$ Andererseits aber wird die theologische Auseinandersetzung zwischen Judentum und Christentum eben nicht nur in ihren Inhalten dargestellt, sondern dialogisch inszeniert. ${ }^{208}$

205 „,Abiathar ist eindeutig von Silvester geschlagen, denn auch die Vernunft lehrt, daß er, wäre er nicht Gott und hätte sich Gott genannt, nicht Toten hätten zum Leben verhelfen können.““

206 „Als dieser geschlagen war, trat der dritte auf [...] und sagte““.

207 Miklautsch, Der Antijudaismus in den mittelalterlichen Legenden, S. 179. Gerade wegen dieser symbolischen Funktion der Juden bleibt es zumindest kurzschlüssig, solche Religionsdialoge als Ausdruck eines zeitgenössischen Antijudaismus verstehen zu wollen, wie es in der Forschung für die Silvesterlegende immer wieder getan worden ist. So beispielsweise bei Vera Milde: si entrunnen alle scentlîchen dannen. Christlich-jüdischer Disput in der Silvesterlegende der Kaiserchronik. In: Juden in der deutschen Literatur des Mittelalters. Religiöse Konzepte, Feindbilder, Rechtfertigungen. Hrsg. von Ursula Schulze. Tübingen 2002, S. 13-34, die ein negatives Bild der Juden konstatiert, die sich trotz zwingender ,rationaler' Schriftbeweise der Bekehrung verweigern, und darin einen Reflex des frühscholastischen Rationalitätsbegriffs sieht - obwohl sie am Ende selbst einräumt, dass die Disputation in der Stofftradition vorgegeben und ein direkter Einfluss scholastischer Argumentation nicht nachweisbar ist. Mit Blick auf die Tradition der Adversus-Judaeos-Schriften wird man eher von einem Arsenal antijüdischer Topoi ausgehen können, die zunächst einmal der christlichen Selbstvergewisserung dienen.

208 Vgl. Christiane Witthöft: Zwischen Wahrheitssuche und Wunderglauben. Die christlich-jüdische Disputation der Silvesterlegende in der Kaiserchronik. In: Disputatio, 1200-1800. Form, Funktion und Wirkung eines Leitmediums universitärer Wissenskultur. Hrsg. von Marion Gindhart, Ursula Kundert. Berlin/New York 2010, S. 291-310, hier S. 295. 
Für die beiden volkssprachigen Bearbeitungen, im Passional und bei Konrad, lässt sich dabei von so etwas wie ,Lebendigkeit‘ sprechen, die durch häufigere Sprecherwechsel erzeugt wird, während die Legenda aurea „es bei einem nüchternen Verlaufsbericht belässt, bei dem die exegetischen Feinheiten in der Argumentation des Heiligen zentral sind“209 - wie in der lateinischen Fassung ohnehin allerlei theologische Fragen verhandelt werden, die für ein volkssprachiges Laienpublikum von untergeordnetem Interesse gewesen sein dürften, so die angebliche Auseinandersetzung Silvesters mit der Ostkirche, bei der die Griechen schließlich den Vorrang Roms anerkennen. ${ }^{210}$ Der Disput mit den Juden samt Stierwunder nimmt hier mindestens die Hälfte der Erzählung ein, wobei das Wunder von dieser Hälfte höchstens ein Fünftel ausmacht. Die gelehrten theologischen Erörterungen Silvesters, die zumindest teilweise mit expliziten Schriftbeweisen durchsetzt sind, nehmen also breiten Raum ein und umfassen die im Hinblick auf die Auseinandersetzung mit dem Judentum zentralen Punkte der christlichen Dogmatik: Nach der Trinität geht es um die Relevanz der Beschneidung, die Göttlichkeit Jesu trotz seiner Kreuzigung, die Frage, ob die alttestamentlichen Schriften auf Jesus bezogen sind, sodann die Taufe Christi, die Jungfrauengeburt, die Versuchung Christi, seine Geburt und sein Leiden.

All das findet sich auch in Konrads Silvester, allerdings wird die Disputation hier auf über 2000 Versen, knapp die Hälfte der Erzählung, ausgebaut und ihre situative Einbindung lebendiger gestaltet. Der Triumph der Christen über die Juden erscheint dabei als eine „Integrationsleistung“, denn der „binäre Antagonismus des EntwederOder auf jüdischer Seite“ wir durch Silvester ,in der Dialektik des figuralen Denkens aufgehoben“. ${ }^{211}$ Die Argumentation soll nicht einfach zeigen, dass die Juden Unrecht und die Christen Recht haben, sondern ganz im Sinne der tradierten typologischen Deutung ausgehend vom jüdischen die Wahrheit der heiligen Schriften und damit des christlichen Glaubens beweisen - der gesamte Disput wird damit ,von einer rhetorischen zu einer hermeneutischen Veranstaltung“. ${ }^{212}$

Interessant ist dabei die zentrale Rolle, die Silvester als heiligem Papst und Glaubensstreiter zugewiesen wird, wenn er in einer asymmetrischen Konstellation den zwölf besten jüdischen Meistern gegenübersteht. Die Ebene der diskursiven Verhandlung von theologischen Wahrheiten wird dabei von Anfang mit einer weiteren überblendet, die für den Sieg Silvesters und der Christen letztlich entscheidend sein wird: die der geistlichen Haltung. Nicht durch menschliche Gelehrsamkeit, auf die sich die Juden voreilig verlassen, wird die Disputation gewonnen, sondern im Vertrauen auf die Gnade Gottes, der in seinem Glaubenszeugen und durch ihn wirkt. Dieser geistliche Diskurs steht am Beginn der Disputation, wenn die Kontrahenten vorgestellt werden: Namentlich werden die einzelnen jüdischen Gelehrten mit ihrem

209 Hammer, Erzählen vom Heiligen, S. 418.

210 Vgl. LA 267, Anm. 11.

211 Bleumer, Metalegendarisches Erzählen, S. 256.

212 Ebd. $\mathrm{Zu}$ diesem typologischen Verfahren vgl. oben in Kap. 5.2.2 Adversus Judaeos - Die Aushandlung des religiösen Gegensatzes zum Judentum, S. 309. 
witze (S 2758), ihrer kunst (S 2762) und wîsheit (S 2766) eingeführt. Besonders auf dem zwölften, Zambri, ruht die Zuversicht der Juden, denn

der truoc, als ich geschriben las,

ob in allen hôhen prîs

und was sô gar unmâzen wîs

von der schrifte, sô man giht (S 2770-2773).

Daher hoffen sie ûf sîne kunst vil meisterlich (S 2777) und auf seine witzen über al (S 2783), doch macht der Erzähler von vornherein klar, dass diese Hoffnung vergeblich ist:

des wart in ein strengen val

diu starke zuoversiht gelet

die si zuo der menscheit

truogen mit ir valschen ger. (S 2784-2787)

\section{Ganz anders natürlich die Christen:}

der bâbest vrôn Silvester

hæte sich an got verlân

und truoc ze sîner helfe wân;

dâ von sîn trôst dâ niht verdarp,

wand er die sigenunft erwarp

an sînen widersachen hie. (S 2788-2793)

Als die Juden nun die Christen auffordern, ihrerseits zwölf Disputanten zu benennen, tritt Silvester ihnen allein entgegen und benennt die unterschiedliche Haltung und Zuversicht der beiden Parteien:

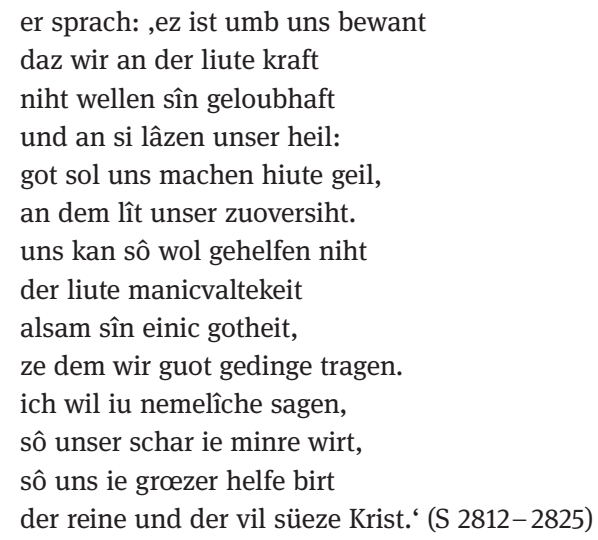

Die Herausforderung zur Disputation nimmt Silvester an als die zu einem geistlichen Kampf, indem sich angesichts göttlicher Unterstützung irdische Macht und zahlen- 
mäßige Stärke als äußerer Schein und daher nichtig erweisen müssen, so die paradoxale Logik der Inversion von Gegensätzen, wie sie das legendarische Erzählen besonders im Fall der Märtyrerlegenden bestimmt. ${ }^{213}$ Gerade in der immanenten Schwäche der Christenheit kann und muss sich die transzendente Macht Gottes zeigen, während sub specie aeternitatis die rein menschliche Gelehrsamkeit hinfällig wird. Es geht dabei auch um die hermeneutische Frage, wie die heiligen Schriften zu verstehen seien, denn die Juden bezweifeln ja im Disput auf der Grundlage des Alten Testaments die christlichen Heilswahrheiten, weil sie mit ihrer Auslegung des Neuen Testaments nicht über den Literalsinn, den sensus historicus hinauskommen. Silvester aber vermag den vermeintlichen Widerspruch zwischen Altem und Neuen Testament im Lichte der christlichen Offenbarung figural aufzulösen: Im sensus typologicus kann die jüdische Auslegung des Alten Testaments der christlichen nicht widersprechen, weil sie diese „als Implikation schon enthält“.214

Der entsprechende Diskurs um die menschliche Klugheit der jüdischen Gelehrten und das Gottvertrauen der Christen, um die Grenzen menschlichen Erkenntnisvermögens und die Notwendigkeit göttlicher Offenbarung, findet sich auch im Passional. Hier wird aber die Rolle Silvesters nicht extra betont: Er ist Anführer, steht aber zugleich in geistlicher Gemeinschaft mit den finen $(\mathrm{P} 73,17)$, mit denen er gemeinsam um die Hilfe Gottes bittet, weil der Disput ein gemeinsamer Kampf der Christenheit ist (P 73, 18-25). Und im Folgenden scheint Gott als der eigentliche Akteur, der durch seinen Heiligen spricht: wand gotes geift im vurte / fin herze in wife antwurte (P 78, 38 - 39 und inhaltlich entsprechend P 80, 64-67), während er die Juden ratlos verstummen lässt:

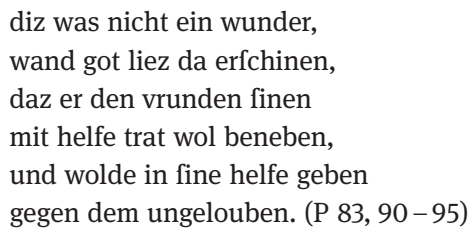

Bei Konrad aber ist Silvester als die zentrale Figur Glaubensstreit herausgearbeitet, wenn er sich selbst als „der erwählte Sprecher der gesamten Christenheit“215 positioniert:

,ich eine sol bî dirre vrist

antwürte vür uns alle geben

und den zwelfen widerstreben

die gegen uns hie wellent stân` (S 2826-2829).

213 Vgl. oben in 3.2.1 Die Zeichenhaftigkeit des Martyriums: Margareta.

214 Bleumer, Metalegendarisches Erzählen, S. 257.

215 Brinker, Formen der Heiligkeit, S. 188. 
Damit erscheint er insgesamt als heiliger Glaubensstreiter, der in einer Art Gottesurteil für die Christen spricht, das die Wahrheit des christlichen Glaubens nach außen gegenüber den Ungläubigen erweisen, gleichzeitig aber ein Glaubenszeichen nach innen zu Bestärkung der christlichen Gläubigen geben soll. Diese Doppelfunktion des Heiligen in der religiösen Konfrontation mit den Ungläubigen wird später noch besonders im Stierwunder deutlich, das den Disput entscheidet: Die Ankündigung des letzten jüdischen Meisters Zambri, den Stier durch den ihm ins Ohr geflüsterten Namen Gottes zu töten und damit die Wahrheit seines Gottes zu erweisen, versetzt die versammelten Christen in Schrecken, denn ihr Glaube ist noch nicht gefestigt. Ihre conversio steht erst noch am Anfang und daher stehen sie in Gefahr, sich vom Teufel versuchen zu lassen und in den alten Unglauben zurückzufallen:

Der rede erschrac diu kristenheit:

si was ir âne mazen leit

und dûhte si vil strenge.

der kristen anegenge

sich êrst erhaben hæte,

dâ von si niht so stæte

an dem gelouben wâren,

sine müesten dô gebâren

zwîvellichen under in.

versuochet wart ir blœeder sin

von dem tiufel unde ir muot. (S 4799-4809)

Ganz anders hingegen reagiert Silvester:

der bâbest heilic unde guot

stuont aber âne vorhte,

dô der gar verworhte

jüde warf die rede vür.

im wart nâch sines herzen kür

erloubet unde erteilet sâ

daz er bewæren solte dâ

swaz er gelobet hæte. (S 4810 - 4817)

Auch wenn die letzten Verse sich hier wohl darauf beziehen, dass er von Konstantin und dem versammelten Tribunal aufgefordert wird, zu handeln, also wie angekündigt den Stier wieder zum Leben zu erwecken, klingt dabei auch seine Berufung dazu durch Gott selbst an: Er ist sein Stellvertreter und Werkzeug seines Wunderhandelns in der Welt. Jedenfalls ist es ein eigenständiger Akzent Konrads, Silvester solcherart herauszustellen und im Gegensatz $\mathrm{zu}$ den vorherigen Begebenheiten bewusst $\mathrm{zu}$ isolieren: „Er steht nicht nur allein den Juden gegenüber, sondern er ist auch der einzige, der die durch Zambris Herausforderung gestellte Bewährungsprobe vollkommen besteht. “216

216 Ebd., S. 189. 
Hier wird intradiegetisch deutlich, inwiefern Heiligkeit ihr Identifikations- und Integrationspotential als ,Distanzkategorie‘ entfaltet. ${ }^{217}$ Als von göttlicher Kraft und Einsicht erfüllte Ausnahmegestalt hebt sich der Heilige von der christlichen Masse ab, ist insofern eine Exklusionsfigur. Andererseits markiert er damit einen identifikatorischen Maximalpunkt, der auch den Juden und Heiden gilt. Weil er das christliche Eigene übersteigt, kann er - als Figur eines Dritten, die in der Transzendenz verankert ist - zur Integrationsfigur gegenüber dem heidnischen Fremden werden: Alle Menschen gleichermaßen bedürfen der Erlösung und, auf dem Weg zu dieser, der Konversion zu Gott, die nicht durch Worte bewirkt werden kann, sondern durch eine Gotteserfahrung, die hier durch das Wunderwirken des Heiligen vermittelt wird. Denn ein Grundproblem der narrativen Inszenierung von Religionsdialogen liegt darin, dass die in ihnen verhandelten rationalen Argumente und Schriftbeweise nicht verfangen müssen, weil diesen keine Evidenz per se zukommt: Sie können angenommen werden oder eben auch nicht. Als innere und subjektive Erfahrungen sind Bekehrungen aber kaum plausibel darstellbar. Daher werden Konversionsgeschehen meist überdeterminiert und als Transzendenzerweis narrativiert:

Doch begnügt man sich meistens nicht mit der Überwindung mit Worten. Zwar ist durch eine Besiegung mit diesen rationalen Mitteln die Wahrheit des Christentums klar erwiesen, doch kann der Feind verstockt sein, er kann nicht glauben wollen. Da tritt das Wunder ein. Das Wunder hat eine ungeheure Beweiskraft, es redet deutlicher als alle Worte. ${ }^{218}$

Wo also die diskursive Vermittlung von Glaubenswahrheiten an ihre immanenten Grenzen stößt, bedarf es eines performativen Aktes, der in der Silvesterlegende im Stierwunder besteht, „welches das vorab diskutierte Wunderverständnis in actu umsetzt und einen Evidenzbeweis in reiner Form umsetzt“". ${ }^{219}$ Wie im Martyrium die verbale Auseinandersetzung zwischen Christentum und Heidentum um die Wahrheit des Glaubens zeichenhaft an Leib und Leben des Märtyrers fortgesetzt wird, an dem sich die göttliche Macht erweist, so erfolgt hier in Tötung und Auferweckung des Stieres eine „Fortführung des Gesprächs mit anderen Mitteln“. ${ }^{220}$ Interessanterweise ist es gerade dieses Wunder, das in der kultischen Rezeption der Silvesterlegende formgebend wird, wenn der Stier pars pro toto zum Heiligenattribut Silvesters wird, neben dem Drachen, der für die Überwindung des Heidentums steht, und dem Olivenzweig als Zeichen des mit dem Ende der Christenverfolgungen erreichten Friedens. 221

217 Vgl. oben in Kap. 2.1.2 Heiligkeit zwischen Distanz und Teilhabe, S. 36.

218 Schenkheld, Die Religionsgespräche der deutschen erzählenden Dichtung, S. 52.

219 Witthöft, Zwischen Wahrheitssuche und Wunderglauben, S. 292.

220 Ebd., S. 305. Zum Martyrium als ,Glaubensdisput mit anderen Mitteln` vgl. oben die Einleitung zu Kap. 3.2 Das Martyrium als Glaubenszeugnis in Wort und Zeichen, S. 112.

221 Vgl. ebd., S. 292, Anm. 6. 
Auf der Handlungsebene ist das Stierwunder aber nicht als logische Konsequenz von Silvesters Verkündigung im Disput, sondern als Störung und Infragestellung der Diskursregeln durch den letzten jüdischen Meister inszeniert, der sich nicht mit der drohenden Niederlage der Juden abfinden will. Die anderen Meister hat Silvester bereits mühelos überwunden, wobei sich ein immer deutlicheres Einvernehmen zwischen ihm und dem Kaiser einstellt, der die jüdischen Kontrahenten jeweils als überwunden erklärt und Silvester in den einzelnen Kontroversen immer deutlicher den Sieg zuspricht: ,reht unde redelichen gar / antwürte gît der bâbest nû́ (S 36463647). Der elfte jüdische Meister, Zeleon, setzt schon gar nicht mehr zum Angriff an, sondern huldigt Silvester: ,dû redest als der reden sol / der kunst hât unde liste (S 4320 - 4321) und bittet ihn um eine Unterweisung, die zur Bekehrung der Juden führen soll:

,durch daz wir alle noch mit dir

an in geloubic werden

und iemer ûf der erden

den namen sîn hie prîsen` (S 4336-4339).

Das Streitgespräch verwandelt sich damit plötzlich in ein einvernehmliches Bekehrungsgespräch, in dem der Heilige die christliche Lehre nicht mehr gegen die Angriffe der Juden verteidigen muss, sondern allen Versammelten wie in einer Predigt vermitteln kann: ,ich sol gemeinlîche noch / entsliezen al der werlte heil` (S 4360 - 4361). Silvester legt ihnen dazu in Form eines kommentierten Glaubensbekenntnisses, das die typologische Integration des Judentums in das Christentum vollzieht, ausführlich die gesamte Heilgeschichte dar. Zeleon antwortet:

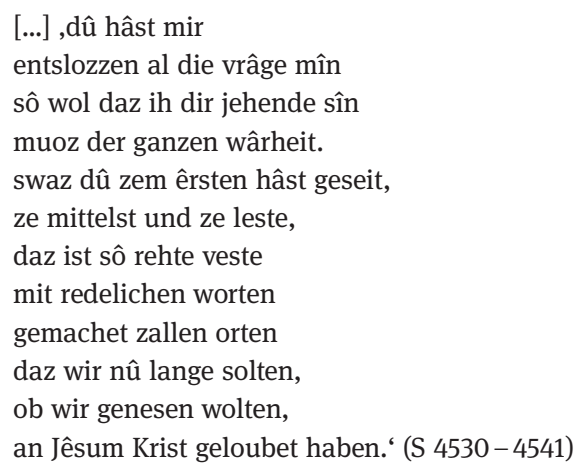

Allein die jüdische Eigenart - und hier ist einem Juden selbst die Erkenntnis seiner eigenen Verstocktheit und der seines Volkes als Erkenntnis in den Mund gelegt verhindert ihre Bekehrung:

,nû sîn wir leider sô begraben

in jüdeschlicher unkust

daz unser valscher muotgelust 
ie mit zwîvellicher maht

wider unserm heile vaht.' (S 4542-4546)

Dem De-facto-Bekenntnis zur Wahrheit der christlichen Lehre und zu Christus als ihrem Kern fehlt allein noch die innere Dimension des Glaubens - damit läuft, aus christlicher Sicht, alles auf ein Wunder hinaus, das diese Wahrheit zeichenhaft bezeugt und zur endgültigen Konversion der Juden führt. Die Apostasie seiner Glaubensgenossen erzürnt nun aber Zambri, der es nicht länger hinnehmen will, dass Silvester ,unser veterlichen $\hat{e}^{`}$ (S 4550) zerstört und dazu ,mit sînen worten [...] / der sinne uns wil berouben '(S 4553-4553). Er fordert Taten statt Worte und bringt den Stier ins Spiel, an dem er nun seinerseits die Wahrheit und Macht des jüdischen Glaubens zeigen will:

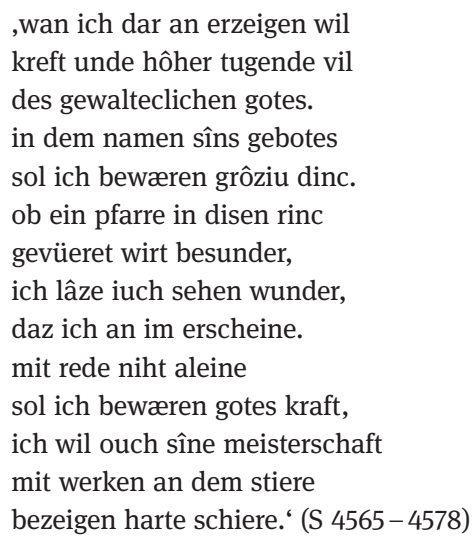

Er wisse ,einen gotes namen, / der ist sô heilic und sô starc' (S 4614-4615), dass er den gewaltigen und bösartigen Stier, der auf seinen Vorschlag hin in den kaiserlichen Saal geführt wird, töten werde. Schon in alttestamentlichen Zeiten habe man die Opfertiere getötet, indem man ihnen den Namen Gottes ins Ohr geflüstert habe (S 4618-4634), wie er es nun an diesem Stier tun wolle. Auf die zeichenhafte Kraft von Taten gegenüber der mangelnden Evidenz von Worten beruft er sich später noch explizit, wenn er erreichen möchte, dass Silvester nicht weitersprechen darf, weil er mit der Tötung des Stiers doch bereits gesiegt habe: ,ir wizzent und erkennent wol / daz werc sint besser danne wort.' (S 4934-4935)

Noch deutlicher wird die theologische Problematik der Vermittlung von Heil durch Worte im Kontrast zur Evidenz von Zeichen in der Legenda aurea benannt, wenn Zambri dort gleich zu Beginn spricht: „Miror vos sapientissimos iudices verborum ambagibus credere et die omnipotentiam existimare humana ratione concludi. Sed iam cessent verba et veniamus ad facta.“ (LA 282) ${ }^{222}$ Damit wird nicht weniger als die 
Relevanz des Disputes in Bezug auf den Beweis von Glaubensfragen überhaupt in Frage gestellt: ratio und Glaube treten hier hinsichtlich der Gotteserkenntnis völlig auseinander. Die Funktion des Disputs liegt allein in der Darstellung von Heilswissen für ein christliches Publikum, sodass die Aushandlung des religiösen Gegensatzes zum Judentum holzschnittartig bleibt und vor allem die Bedingungen von Konversionen nicht weiter ausgeleuchtet werden. Im Passional hingegen ist die Problematik, dass Worte im Blick auf die Gotteserkenntnis immer zwivilliche (P 86, 14) bleiben müssen, noch deutlicher herausgearbeitet, wenn Zambri zu den Richtern und der Menge spricht:

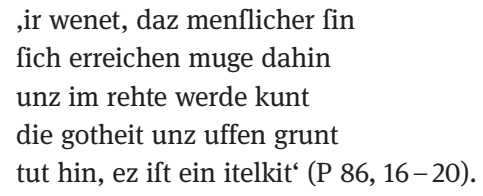

Das entspricht dem Diskurs um das Verhältnis von Wissen und Glaubenskraft, nur ist es hier der gelehrteste jüdische Meister selbst, der diese Erkenntnis formuliert, die dem von den Juden bis dahin verkörperten Selbstverständnis doch gerade entgegensteht. Die volkssprachige Vermittlung des Passionals legt damit den Akzent auf den geistlichen Nutzen, den ein christliches Publikum aus der zeichenhaften Vergegenwärtigung göttlichen Heilshandelns insgesamt ziehen kann, in der inneren conversio vom immanenten menfliche[n] fin hin zur transzendenten Wahrheit der gotheit, die sich im Wunder gnadenhaft ereignet - aber, anders als Zambri denkt, nicht in der Tötung, sondern der Auferweckung des Stieres.

Parallel zur Fortführung des Glaubensdisputes ,mit anderen Mitteln“ im Martyrium soll die Wahrheit des christlichen Glaubens also nicht mehr diskursiv verhandelt werden, sondern die Macht Gottes sich im Stierwunder zeichenhaft erweisen. Ein zeichenhaftes Handeln ist dabei allerdings nicht selbstevident, sondern zunächst einmal doppeldeutig, weil es auch den Heiden offensteht. Dann aber ist es im christlichen Sinn kein Wunder, das vom allein wahren und lebendigen Gott bewirkt wird, sondern ein dämonischer Zauber. Das Zeichen, das der Heilige in göttlichem Auftrag wirkt, muss daher auch als ein solches wahrgenommen und verstanden werden, es bedarf also gerade der diskursiven Einbindung, die die richtige Deutung des Geschehens festigt: „Das Erzählen über das Sehen und Erkennen von Wundern, die durch ihre Narrativierung auch für andere sichtbar gemacht werden sollen, ist eine der wichtigsten Aufgaben der Legende.“223

Gottes Allmacht lasse sich mit menschlichem Verstand fassen. Doch wollen wir jetzt das Reden lassen und zu Taten schreiten.““

223 Nine Miedema: Wunder sehen - Wunder erkennen - Wunder erzählen. In: Sehen und Sichtbarkeit in der deutschen Literatur des Mittelalters. XXI. Anglo-German Colloquium. London 2009. Hrsg. von Ricarda Bauschke, Sebastian Coxon, Martin H. Jones. Berlin 2011, S. 331-347, hier S. 334. 
Diese Deutung wird vorbereitet durch die Inszenierung der beiden Kontrahenten, in denen sich Gott und Teufel gegenüberstehen. ${ }^{224}$ Während Zambrî der zouberære (S 4766) den Stier mit magischen Kräften tötet, was die versammelten Christen in Angst versetzt und die Juden in voreiliger Siegesgewissheit Silvester schmähen lässt, vertraut der gotes knehte (S 4846) auf Gott und bittet ihn, daz er geruochte im an der vrist / trôst unde helfe senden (S 4858-4859). So tritt der Heilige vor die versammelte Menge und beruft sich auf die Macht Christi, der Blinde sehend gemacht und die Menschen vom Teufel befreit habe und weiterhin ,vil wunder schicket“ (S 4895). Ein solches kündigt er nun mit der Erweckung des Stieres an, die zugleich beweisen soll, dass es nicht Gottes Name war, der den Stier getötet hat, sondern der des Teufels, denn Christus töte nicht, sondern mache lebendig:

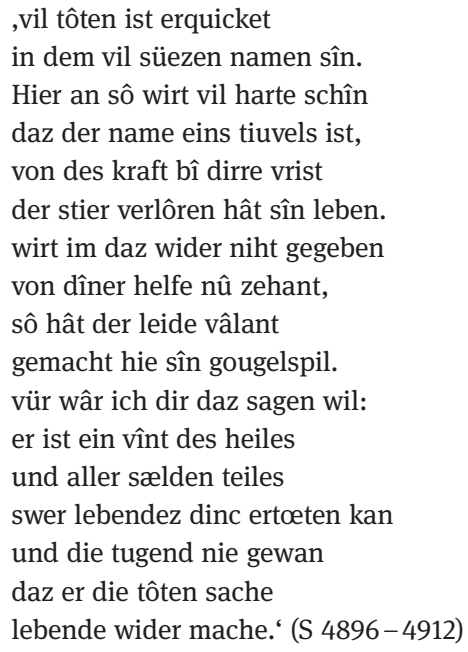

Damit ist Zambri als Teufelsdiener entlarvt und sein ,Wunder' als Beweis seiner dämonischen Verstrickungen gegen ihn und die Juden gekehrt. Die folgende tatsächliche Wundertat durch Silvester ist hingegen zu verstehen als Symbol der Erlösung und der Auferweckung der Toten, die in der Auferstehung Christi präfiguriert ist. Als Zambri abermals Taten statt weitere Worte einfordert, erklärt Konstantin als Richter des Disputs das versprochene Wunder zum unmissverständlichen Heilszeichen, in dem sich die Macht Gottes erweisen muss:

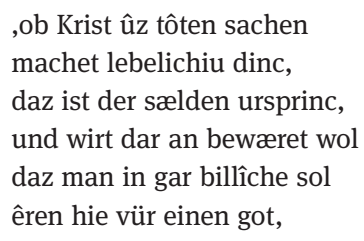

224 Vgl. Witthöft, Zwischen Wahrheitssuche und Wunderglauben, S. 308. 
des gewalt und des gebot

himel, mer und erden

und elliu dinc hiez werden. (S 5032-5040)

Zambri verspricht daraufhin, dass die Juden sich bekehren, sollte Silvester den Stier tatsächlich auferwecken können. Ihre Konversion wird also allein an die Evidenz des Glaubens im Wunder gebunden, allein in ihr ist die Umkehr der Juden aus ihrer Verstocktheit möglich: Das Zeichen erlöst sie aus ihrer Blindheit.

Mit dieser charakteristischen Nachordnung von Disput und Wunder inszeniert die Silvesterlegende die Mission der Juden als einen religiösen Zweikampf, wie er charakteristisch ist für die Mission des frühen Mittelalters ist. Denn deren Erfolg konnte nicht in dogmatischen Erörterungen gründen, sondern allein im Erweis der Macht und Nützlichkeit des christlichen Glaubens gegenüber den heidnischen Glaubenssystemen, die Religion nicht in den Kategorien persönlicher Erlösung und transzendenten Heils verstanden, sondern in denen eines immanenten Nutzens für den Kultverband. ${ }^{225}$ Mit seinem Zeichenhandeln aber übersteigt der Silvester die Immanenz und wird zum Transzendenzvermittler nicht nur für seine intradiegetischen Adressaten, sondern ebenso für sein christliches Legendenpublikum: Das Wunder ergänzt nicht nur die Überwindung des Judentums im Wort, sondern setzt die Argumentation auf höherer Ebene fort, indem es das im Disput Erörterte zeichenhaft bekräftigt. In ty-

225 Vgl. Lutz E. von Padberg: Religiöse Zweikämpfe in der Missionsgeschichte des Frühmittelalters. In: Runica, Germanica, Mediaevalia. Gewidmet Klaus Düwel. Hrsg. von Wilhelm Heizmann, Astrid van Nahl. Berlin [u. a.] 2003 (Ergänzungsbände zum Reallexikon der germanischen Altertumskunde. 37), S. 509-552, hier S. 539. Ähnlich auch in Ders.: Missionierendes Christentum und nicht-christliche Religionen im Mittelalter. In: Schwierige Toleranz. Der Umgang mit Andersdenkenden und Andersgläubigen in der Christentumsgeschichte. Hrsg. von Mariano Delgado, Volker Leppin, David Neuhold. Fribourg 2012 (Studien zur christlichen Religions- und Kulturgeschichte. 17), S. 169-180, und grundlegend in Ders.: Die Inszenierung religiöser Konfrontationen. Theorie und Praxis der Missionspredigt im frühen Mittelalter. Stuttgart 2003 (Monographien zur Geschichte des Mittelalters. 51). Grundlegend sind in diesem Zusammenhang auch die Arbeiten von Hans-Dietrich Kahl, der in seinen ,Bausteinen für eine Phänomenologie des missionsgeschichtlichen Mittelalters‘ zwischen ,Universalreligion` und ,Gentilreligion' unterscheidet und davon ausgehend darstellt, dass sich der christliche Missionar im Mittelalter „immer wieder zuerst vor die Aufgabe gestellt [sieht], den Nachweis zu führen, daß der von ihm verkündete Gott wirklich auch für das Land und das Volk zuständig und wirkmächtig ist, an das seine Botschaft herangetragen werden soll; daß dieser Gott die Fähigkeit und die Macht besitzt, auch hier fördernden Schutz zu gewähren oder aber unter Umständen zornig zu schaden. Es ist dieser Nachweis, in dem für diese Periode die entscheidende Bedeutung jener immer wieder geübten Zerstörung heidnischer Kultstätten und Kultbilder liegt, dieses so treffend als ,Tatmission charakterisierten Verfahrens“. Die ersten Jahrhunderte des missionsgeschichtlichen Mittelalters. Bausteine für eine Phänomenologie bis ca. 1050. In: Ders.: Heidenfrage und Slawenfrage im deutschen Mittelalter. Ausgewählte Studien 1953-2008. Leiden/Boston 2011 (East Central and Eastern Europe in the Middle Ages 550 - 1450.4), S. 271-342, hier S. 293. In diesem Zusammenhang unterscheidet Kahl (ebd., S. 298) auch zwischen ,positiver‘ und ,negativer' Missionsarbeit, zwischen ,Christianisierung' und ,Entpaganisierung`.Vgl. dazu auch Adolf Martin Ritter: Das Mittelalter als Zeitalter der Missionsgeschichte. In: Zeitschrift für Missionswissenschaft und Religionswissenschaft 79, 2 (1995), S. 97-110, hier S. 104. 
pologischer Überbietung des jüdischen Unglaubens geraten die Worte, die Silvester im Gegensatz zum notwendigerweise heimlich gesprochenen, tödlichen Wort Zambris - mit lûter stimme (S 5092) spricht, zur Heilsverkündigung. Diese bezieht sich im historisch-typologischen Sinn wie in der konkreten Situation auf den Unglauben der Juden und ihre Ablehnung des christlichen Heilandes:

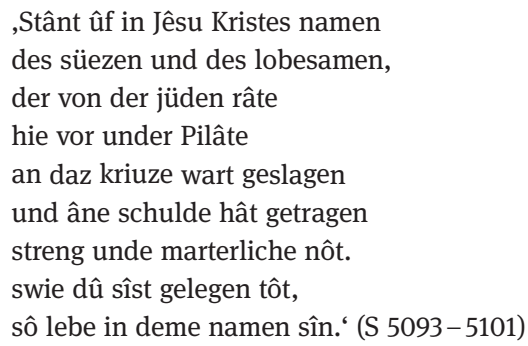

In Legenda aurea und Passional geht dem ein regelrechter Exorzismus voran, der den dämonischen Zauber Zambris aufhebt, indem er den tödlichen Namen austreibt:

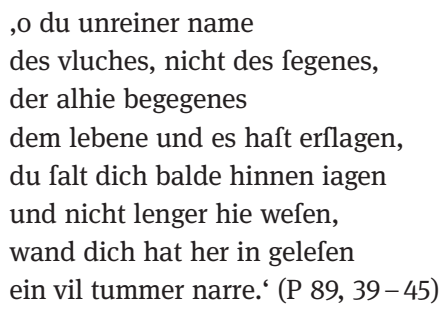

Bei Konrad hingegen sind es vor allem die in einer Credo-ähnlichen Formel zusammengefassten zentralen Elemente des christlichen Glaubens, die sich in der Auferweckung des Stieres konkretisieren und damit „den Wahrheitsgehalt des zuvor nur diskursiv (in der Disputation) Vermittelten nun ereignishaft offenbaren - die vergangenen Ereignisse zeigen ihre Wirksamkeit für die Gegenwart“. ${ }^{226}$ Wie einst Christus selbst vom Tode auferstanden ist, so macht er im von der Silvesterlegende verbürgten historischen Geschehen einen toten Stier wieder lebendig und vermag daher noch in der Gegenwart des Legendenerzählers und seines Publikums, die im Erzählen und Hören diese Stationen der Heilsgeschichte vergegenwärtigen, seine Macht zu erweisen.

Die Wirksamkeit eines Glaubensbeweises durch heilspräsentische Evidenz, wie sie das Stierwunder darstellt, erweist sich aber bereits intradiegetisch in der Bekehrung der Juden, für die im Passional stellvertretend Helena spricht, die nun bekennt, Silvester habe in allem die Wahrheit gesagt: ,diz groze wunder hie von dir, / daz ift ein veftenunge mir / der vorbenanten rede gar` (P 89, 76-78). Nicht Überredungskünste 
oder dialektische Finessen der Argumentation, und sei sie noch so rational im Sinne des christlichen Glaubens, können die Konversion bewirken, sondern erst das Wunder, das die Verkündigung Silvesters bestätigt und Glaubenswissen begründet. Im Vollzug der Konversion formuliert Helena ihr Bekenntnis zu Christus als dem Sohn Gottes, was letztlich das zentrale Dogma ist, das im jüdisch-christlichen Disput verhandelt worden ist: ,ich weiz nu wol funder fpot, / daz der gute Iefus Crift / war got und menfche ift ${ }^{\star}(\mathrm{P}$ 89, 83-85).

Damit ist auch der Diskurs um die Erkenntnismöglichkeiten des menschlichen Verstandes in Bezug auf Glaubenswahrheiten zu einem endgültigen Abschluss gekommen: „Das Wunder wird zum Medium der Erkenntnis und ist in seiner klaren, sichtbaren Aussage wie geschaffen für den Abschluss einer Glaubensdisputation, in der die göttliche Offenbarung letztlich doch über dem menschlichen Wissen steht. “227 In ihrer charakteristischen Verknüpfung des Glaubensdisputs mit dem Stierwunder reflektiert die Silvesterlegende die Bedingungen und Möglichkeiten von Konversion überhaupt. Die Geltung religiöser Wahrheitsansprüche erscheint hier zwischen menschlichem, immanentem Begreifen und der Erfahrung von Transzendenz verortet, die durch ersteres nicht eingeholt, nur vermittelt werden kann. Das Stierwunder hat daher nicht nur eine apologetische und identitätssftiftende Funktion in der Abgrenzung vom Judentum, sondern verhandelt christlich-selbstreflexiv das Problem der ,Sichtbarkeit von Erkenntnis‘. ${ }^{228}$ Damit kann es heilsvermittlend auf das christliche Legendenpublikum wirken, das sich schließlich in der Konversion Helenas zum Glauben an Christus auf seinem inneren Weg der conversio wiederfinden soll.

\subsection{Bekehrung durch Unterweisung: Barlaam und Josaphat}

\subsubsection{Die Buddhageschichte als höfische Konversionslegende}

Die Legende von Barlaam und Josaphat ist, was Verbreitung und volkssprachige Rezeption betrifft, einer der großen Erzählstoffe der westlichen Christenheit. Das mag erstaunlich scheinen angesichts der Tatsache, dass es sich um eine Bearbeitung der Buddhageschichte handelt. 229 Der genaue Weg der Übertragung in den christlichen Kulturbereich ist dabei bis heute ungeklärt, vor allem hinsichtlich der Frage, ob sie mit Johannes von Damaskus (um 650 bis 750) und damit der Autorität eines Kirchenvaters verknüpft werden kann. Dieser galt traditionell als Urheber der griechischen Fassung, die ab dem 12. Jahrhundert über eine Vulgata-Fassung Eingang in die lateinische Literatur und die Volkssprachen des abendländischen Mittelalters fand. Für ihre Bekanntheit und Bedeutung spricht ihre Aufnahme in Legendensammlungen wie die

227 Witthöft, Zwischen Wahrheitssuche und Wunderglauben, S. 307.

228 Ebd., S. 309.

229 Zur Buddhalegende vgl. Günter Grönbold: Art. Buddha. In: EM 2 (1979), Sp. 987-998, hier Sp. $988-992$. 
Legenda aurea - allerdings fehlt sie im Passional - und enzyklopädische Werke wie das Speculum Historiale des Vinzenz von Beauvais. ${ }^{230}$ In der Forschung scheint sich mittlerweile, entgegen der möglichen Urheberschaft des Johannes von Damaskus, weitgehend die Überzeugung durchgesetzt zu haben, dass die griechische Fassung auf den heiligen Euthymios (ca. 955-1028) zurückgeht, der als Abt des georgischen Klosters Iviron auf dem Berg Athos eine umfangreiche Übersetzungstätigkeit aus dem Georgischen ins Griechische entfaltete. Der zwischen dem 9. und 10. Jahrhundert entstandene georgische Balavariani wiederum ist die älteste christliche Fassung des Stoffes. ${ }^{231}$

Die Vermittlung der Buddhageschichte von Ost nach West und die damit einhergehende christlich-legendarische Transformation vollziehen sich also in jedem Fall über das byzantinische, wahrscheinlich sogar athonitische Mönchtum und stehen daher im Zeichen der Propagierung eines entsprechenden Anachorese- und Askeseideals - ein Reflex dieser Tendenz findet sich noch in der Barlaam-und-JosaphatLegende der Legenda aurea, wenn gleich zu Beginn die Christenverfolgung durch den heidnischen Königs Avenier als Kampf gegen ein blühendes Mönchtum dargestellt wird: Etenim cum universa India christianis et monachis plena esset, surrexit quidam praepotens nomine Avennir, qui christianos et praecipue monachus plurimum persequebatur. (LA 2322) ${ }^{232}$ Die Anschlussfähigkeit der Buddhageschichte für die christlichmonastische Rezeption erweist sich dabei in ihrer Reduktion auf die grundlegende Lehre, dass alles Irdische vergänglich und das wahre Leben daher nur in der asketischen Abkehr vom Weltlichen zu erreichen ist. ${ }^{233}$

Zwar mag die Konzentration auf Askese und Weltflucht eine einseitige Verkürzung des buddhistischen Gehalts der Erzählung darstellen, die sich durch manichäistische Einflüsse bei der Verbreitung des Stoffes erklären lässt, ${ }^{234}$ von Struktur und Inhalt her liegt eine solche Uminterpretation unter den entsprechenden Vorzeichen aber nahe.

230 Für einen Überblick über die weit ausgreifende Verbreitung und intensive Rezeption des Stoffes in Mittel- und Westeuropa vgl. Albrecht Classen: Kulturelle und religiöse Kontakte zwischen dem christlichen Europa und dem buddhistischen Indien im Mittelalter. Rudolfs von Ems Barlaam und Josaphat im europäischen Kontext. In: Fabula 41, 3/4 (2000), S. 203-228, hier S. 209-214.

231 Vgl. David Marshall Lang: St. Euthymius the Georgian and the Barlaam and Ioasaph Romance. In: Bulletin of the School of Oriental and African Studies 17, 2 (1995), S. 306-325, außerdem Philip Almond: The Buddha of the Christendom. A Review of the Legend of Barlaam and Josaphat. In: Religious Studies 23, 3 (1987), S. 391-406, hier S. 400 - 402 und Constanza Cordoni: Barlaam und Josaphat in der europäischen Literatur des Mittelalters. Darstellung der Stofftraditionen - Bibliographie - Studien. Berlin 2014, S. 43.

232 „Als nämlich schon ganz Indien voll von Christen und Mönchen war, bestieg ein überaus mächtiger König namens Avennir den Thron, der die Christen und vor allem die Mönche schwer verfolgte.“

233 Vgl. Almond, The Buddha of the Christendom, S. 399. Ebenso: Jürgen Tubach: Das Bild vom idealen Christen. Askese im Barlaam-Roman. In: Sprache, Mythen, Mythizismen. Festschrift für Walter Beltz zum 65. Geburtstag am 25. April 2000. 3. Hrsg. von Armenuhi Drostabgarjan, Jürgen Tubach. Halle 2004, S. 759-782, hier S. 765.

234 Vgl. ebd. 1987, S. 404-405. 
Denn zur Kontrafaktur bedarf es letztlich nur einer kleinen, aber theologisch entscheidenden narrativen Transformation: An die Stelle eines Erkenntnisprozesses durch Meditation, die in der Erleuchtung unter dem Baum gipfelt und den Menschen aus der Verhaftung im Irdischen befreit, ${ }^{235}$ treten göttliches Gnadenhandeln und vor allem die Unterweisung im christlichen Glauben, die zur Konversion des heidnischen Prinzen Josaphat führen. Das zentrale Moment des buddhistischen Konversionsnarrativs bleibt dabei erhalten, nämlich die durch eine krisenhafte Erfahrung vermittelte Einsicht in die Vergänglichkeit der Welt, die nun aber den Boden für die Erlösung durch den christlichen Glauben bereitet. ${ }^{236}$ Die buddhistischen ,vier Zeichen' in Gestalt eines Alten, eines Kranken, eines Toten und eines Asketen, in denen der Fürstensohn dem Leid der Welt sowie der Möglichkeit zu dessen Überwindung begegnet, werden zur christlichen Mahnung an die Vergänglichkeit des Irdischen und die daraus resultierende Notwendigkeit der Abkehr von der Welt.

In das Muster einer Anachoretenlegende sind dabei mit der Konversion und dem Bekennertypus zwei weitere Erzählschemata eingebunden: Durch das Vorbild und die Unterweisung Barlaams bekehrt sich Josaphat zum christlichen Glauben, bekennt ihn allen Anfeindungen zum Trotz und verhilft ihm schließlich in seiner Rolle als Herrscher zum Sieg. Josaphats Konversion zum Christentum, erscheint dabei als folgerichtiger Schritt: Von Geburt an führt er ein sündenfreies Leben und als er, ausgelöst durch die krisenhafte Erfahrung menschlicher Vergänglichkeit, nach der höchsten Wahrheit fragt, bietet ihm Barlaam den ,Generalschlüssel für die Wirklichkeit “, ${ }^{237}$ den er von Anfang an gesucht hat. Der neue Glaube bietet Josaphat aber kein bloß verstandesmäßiges Sinnsystem, sondern verlangt einen existentiellen Vollzug: Barlaam ist nicht nur Prediger und Lehrer, sondern ein konkretes Vorbild eremitischen Lebens, dem Josaphat folgen wird. Der eigentliche Umschlag besteht mithin weniger in Josaphats Abkehr vom Heidentum, dem er zuvor schon kaum aktiv angehangen hatte, als darin, dass er dem Weltleben entsagt und sich für ein asketisches und anachoretisches Dasein entscheidet, das sich als logische Konsequenz der Annahme des Christentums darstellt. ${ }^{238}$

Daher erklärt sich auch das Fehlen charakteristischer Wunder, in denen sich die Heiligkeit der Protagonisten erweisen würde: Göttliches Handeln wird nur im Zusammenhang der Bekehrung Josaphats erwähnt, ohne deren eigentlicher Auslöser zu sein, sowie bei der des heidnischen Zauberers Nachor unmittelbar vor dem groß an-

235 Vgl. Grönbold, Art. Buddha, Sp. 990.

236 Vgl. Graeme MacQueen: Rejecting enligthenment? The medieval Christian transformation of the Buddha-legend in Jacobus de Voragine's Barlaam and Josaphat. In: Studies in Religion / Sciences Religieuses 30, 2 (2001), S. 151-165, hier S. 152.

237 Vgl. oben in Kap. 5.1.1 Konversion als Grundmuster christlicher Identitätsbildung, S. 270.

238 Im Gegensatz zur Buddhageschichte heiratet der Fürstensohn Josaphat nicht, bevor er die Welt flieht, was seine Stilisierung zum Asketen und Anachoreten noch steigert. Eine Konversion im Sinne der Bekehrung aus der Gottesferne hin zu einem christlich-heiligmäßigem Leben vollzieht hingegen sein Vater. 
gelegten Religionsdisput, der die Wahrheit des christlichen Glaubens diskursiv beweisen soll. Konversion erscheint insgesamt weniger als ein durch den Einbruch von Transzendenz bewirktes Umschlagsmoment, sondern vollzieht sich „through a calm and deliberate process of self-analysis and self-discipline“. ${ }^{239}$ In einem inneren Erkenntnisprozess findet Josaphat zur Einsicht in die wahre Natur der Dinge, die Unterweisung im christlichen Glauben sowie das gelebte asketische Vorbild Barlaams befördern diesen Prozess und geben ihm ein konkretes äußeres Ziel.

Insofern also die durch die Unterweisung und das Vorbild Barlaams bewirkte Bekehrung Josaphats das zentrale Thema der Erzählung ist, kann es nicht verwundern, dass in ihr lehrhafte Passagen mit der Darstellung und Vermittlung des christlichen Glaubens in seinen Inhalten und einer entsprechenden asketischen Lebensform einigen Platz einnehmen. Sie werden aber, zumal in der um 1220 bis 1225 entstandenen mittelhochdeutschen Fassung Rudolfs von Ems in einer Breite auserzählt, die das Maß des narrativ Notwendigen deutlich übersteigt: Zwar muss Josaphat den christlichen Glauben erlernen, bevor er ihn annehmen und verbreiten kann, doch würden dafür, wie in anderen Konversionserzählungen, einige grundlegenden Elemente genügen. Das Übergewicht der Vermittlung christlicher Lehre gegenüber der Darstellung eines Heiligenlebens ist offenkundig ein Effekt der Genese des Stoffes: In der Transformation der buddhistischen Legende hin zur christlichen Erzählung verschiebt sich der Akzent hin zur Darstellung des Sieges des Christentums über das Heidentum in der Mission. ${ }^{240}$ Gemäß dieser Tendenz räumt schon der griechische Verfasser der theologischen Dialektik breiten Raum ein: „Barlaams katechetische Unterweisung, seine Erklärung der christlichen Dogmen in seinen Gesprächen mit dem Prinzen ist, in all ihrer theologisch-abstrakten Trockenheit, aufs gründlichste ausgearbeitet, ohne Rücksicht auf die Ökonomie der Erzählung“. 241

Die Barlaam-und-Josaphat-Erzählung erwächst also nicht aus dem christlichen Heiligenkult, sondern ist als zunächst rein monastisch-intellektueller Lehrtext und Exempel konzipiert. ${ }^{242}$ Ihr Potential erschöpft sich dabei aber keineswegs in einer

239 Vgl. Almond, The Buddha of the Christendom, S. 399.

240 Vgl. Hiram Peri: Der Religionsdisput der Barlaam-Legende. Ein Motiv abendländischer Dichtung. Untersuchung, ungedruckte Texte, Bibliographie der Legende. Salamanca 1959 (Acta Salmanticensia. Filosofía y Letras. XIV, 3), S. 26.

241 Peri, Der Religionsdisput der Barlaam-Legende, S. 27.

242 Vgl. Wyss, Theorie der mittelhochdeutschen Legendenepik, S. 192. Das kann man auch als Folge der fehlenden paraliturgischen Funktion der Erzählung im Kontext der Heiligenverehrung sehen: „Die fehlende kultische und liturgische Einbindung resultiert in einer medialen Komplexitätsreduktion: Hier steht der Legendentext für sich selbst ein. Wo es keine Lesung, kein Evangelium, keine Predigt im Umfeld gibt, werden diese virtuell erzeugt. Er generiert daher sein heilsgeschichtliches Umfeld und tut es in den integrierten Lehren“, so Volker Mertens: Langweilige Heilige - heilige Langeweile? In: Barlaam und Josaphat. Neue Perspektiven auf ein europäisches Phänomen. Hrsg. von Matthias Meyer, Constanza Cordoni. Berlin/München/Boston 2015, S. 247-270, hier S. 249. In den Ostkirchen scheint die Verehrung Barlaams und Josaphats weiter verbreitet als im römisch-katholischen Bereich, wo sie auch nicht kanonisiert und erst 1583 in das offizielle Martyrologium Romanum aufgenommen werden. 
bloßen narrativen „Einkleidung für die Darstellung christlicher Dogmatik und Katechese“"243, vielmehr bieten die als Redeszenen fingierten Lehrgespräche die Möglichkeit einer ,wirklichkeitsnahen“ Darstellungsweise, weil Glaubensvermittlung als sprachliche Interaktionen nicht nur berichtet, sondern in den Sprechrollen aktualisiert wird, und dadurch vom Hörer oder Leser einfacher an Alltagserfahrungen rückgeschlossen werden kann. ${ }^{244}$ Die lehrhaften Abschnitte sind dabei narrativ eingebunden, sodass die Vermittlung christlicher Lehre in ihrem Vollzug und ihrer Wirkung darstellbar wird. Die Wahrheit der dogmatischen und katechetischen Inhalte erscheint auf diese Weise nicht nur durch die Autorität des Stoffes und seines Bearbeiters verbürgt, sondern narrativ eingelöst.

Glaubenslehre und Erzählung durchdringen sich aber auch insofern, als mit dem legendarischen Gerüst und den zahlreichen eingeschobenen Parabeln, mit denen Barlaam Josaphat für den christlichen Glauben gewinnt, zwei spezifische exemplarische Erzählweisen miteinander verknüpft werden. Die Legende, verstanden als Muster christlich-heiligmäßigen Lebens, ist an sich schon ein Exempel, das auf Erbauung und Nachahmung zielt. Exemplarisches Erzählen ist aber nicht auf sie beschränkt, sondern findet in ihr nur eine seiner möglichen Ausformungen. Der Begriff des Exempels bezeichnet dabei allgemein eine bestimmte Art von kurzen Erzählungen, die auf Grund ihrer Vielgestaltigkeit und Polyfunktionalität weniger als eigene literarische Gattung gelten kann denn als ein allgemeines narratives beziehungsweise rhetorisches Verfahren. Die Grundzüge dieser aus der antiken Tradition der Gerichtsrede hervorgegangene Argumentationstechnik lassen sich fassen als die einer

narrative[n] Minimalform [...], die einen abstrakten, theoretischen oder thesenhaften Textsinn konkret beleuchtet (illustrare), die in diesem enthaltene Aussage induktiv beweist (demonstrare) und damit sowohl eine dogmatische oder didaktische Interpretationshilfe schafft als auch [...] mit moralisierender Implikation zur Belehrung, Erbauung oder Unterhaltung des Rezipienten [...] beiträgt (delectare). Ziel des Exempelgebrauchs ist die auf seiner Überzeugungskraft (persuasio) beruhende Aufforderung, sich am beispielhaften Vorbild zu orientieren (imitatio). ${ }^{245}$

Auf Grund dieser didaktischen und persuasiven Möglichkeiten zeigen die verschiedenen Formen der Vermittlung besonders religiöser Lehre eine starke Affinität zum exemplarischen Erzählen. Gerade die Predigt arbeitet gern mit exempla, deren Blütezeit im 13. und 14. Jahrhundert liegt, als sie von den Predigern vor allem der Bet-

Vgl. Almond, The Buddha of the Christendom, S. 394. In der neuesten Ausgabe des Martyrologium Romanum von 2001/2004 sind sie hingegen nicht mehr verzeichnet.

243 Christine Stöllinger-Löser: Art. Barlaam und Josaphat. In: ${ }^{2}$ VL 11 (2004), Sp. 215-219, hier Sp. 215. 244 Vgl. Hannes Kästner: Mittelalterliche Lehrgespräche. Textlinguistische Analysen, Studien zur poetischen Funktion und pädagogischen Intention. Berlin 1978 (Philologische Studien und Quellen. 94), S. 224.

245 Christoph Daxelmüller: Art. Exemplum. In: EM 4 (1984), Sp. 627-649, hier Sp. 627. Vgl. dazu auch Markus Schürer: Das Beispiel im Begriff. Aspekte einer begriffsgeschichtlichen Erschließung exemplarischen Erzählens im Mittelalter. In: Mittellateinisches Jahrbuch 38 (2003), S. 199-237, hier S. 201. 
telorden als geeignetes Mittel der Verkündigung an Laien breit genutzt und in umfangreichen Sammlungen als Vorlage schriftlich festgehalten werden. Im Prolog einer dieser Exempelsammlungen, De dono timoris des Dominikaners Humberts von Romans (1190/1200 - 1277), wird der Modus exemplarischen Redens und dessen Eignung für Predigten wie persönliche Gespräche unter anderem mit der Figur Barlaams belegt, der den heidnischen Königssohn Josaphat per parabolas et exempla pulcherrima zum perfectissimus heremita bekehrt habe. ${ }^{246}$

Das aber meint nicht nur die vielen in den Lehrgesprächen genutzten biblischen Gleichnisse, sondern vor allem die für den Barlaam-und-Josaphat-Stoff charakteristische Gruppe von vanitas-Parabeln, die vorchristliches Erzählgut darstellen, das eng mit der Genese und Tradierung des Stoffes verbunden ist. ${ }^{247}$ Ihr Potential zur erzählerischen Ausgestaltung unabhängig von diesem Stoff aber dürfte einer der Gründe für dessen weite Verbreitung in den mittelalterlichen Volkssprachen sein. Einzelbearbeitungen finden sich schon vor den volkssprachigen Bearbeitungen der ganzen Legende und bis um 1250 waren die einzelnen Barlaam-Parabeln sogar bekannter als die Erzählung insgesamt. ${ }^{248}$ Ihr gemeinsames Grundthema, die Nichtigkeit der Welt beziehungsweise die Problematik von Schein und Sein, ${ }^{249}$ ist ein wesentliches Element der Konversion Josaphats, stellt aber gleichzeitig einen Kern mittelalterlicher religiöser Lehre dar. Folglich finden sich diese Parabeln für den monastischen Gebrauch oder als Predigtexempla in den großen Sammlungen des 13. Jahrhunderts wieder, ${ }^{250}$ und in diesem Zusammenhang ist auch Barlaam-und-Josaphat-Legende der Legenda aurea zu sehen.

Die eigentliche Erzählung ist, wie üblich in diesem Legendar, knapp gefasst, was nicht ganz einfach ist, insofern sie aus den üblichen Legendenschemata herausfällt. Im Vergleich zu den ausführlich wiedergegeben Lehr- und Disputszenen ist der nar-

246 Zitiert nach: Humbert de Romans: Le Don de crainte ou L'Abandonce des exemples. Traduit du latin et présenté par Christine Boyer. Lyon 2003 (Collection d'histoire et d'archéologie médiévales. 11). Vgl. dazu auch Schürer, Das Beispiel im Begriff, S. 87.

247 Es handelt sich also nicht um spätere Zusätze, denn schon die griechische Legende im 12. Jahrhundert enthält vollständig alle diese Erzählungen. Vgl. Marianne Derron: Des Strickers ernsthafter König. Ein poetischer Lachtraktat des Mittelalters. Eine motivgeschichtliche Studie zur ersten BarlaamParabel. Frankfurt a. M. 2008 (Kultur, Wissenschaft, Literatur. Beiträge zur Mittelalterforschung. 19), S. 57.

248 Vgl. ebd., S. 67.

249 Vgl. ebd., S. 68.

250 So beim Zisterzienser Caesarius von Heisterbach wie den Predigern Jakob von Vitry und Odo von Cheriton sowie dem Dominikaner Stefan von Bourbon. Wie hoch ihre exemplarische und emblematische Wirkung gewesen sein muss, lässt sich am deutlichsten für die Parabel vom Mann im Abgrund nachverfolgen, die besonders häufig eigenständig überliefert wird, als Bildformel in verschiedenen Kontexten erscheint und sich in der außerhandschriftlichen Ikonografie, vor allem in kirchlicher Plastik und Freskomalerei, verselbstständigt. Vgl. Norbert H. Ott: Art. Barlaam und Josaphat. In: Katalog der deutschsprachigen illustrierten Handschriften des Mittelalters, Bd. 2, 1/2. Hrsg. von der Kommission für Deutsche Literatur des Mittelalters der Bayerischen Akademie der Wissenschaften. München 1993, S. 5-21, hier S. 6. 
rative Rahmen an vielen Stellen auf das Nötigste konzentriert. Dem gelehrt-klerikalen Interesse entsprechend, das den Funktionszusammenhang der Legenda aurea bestimmt, sind gerade die vanitas-Parabeln breit auserzählt, ohne über Wechselreden zwischen Lehrer und Schüler sowie intradiegetisch explizite Auslegungen in die Handlung integriert zu werden. Die biblischen Gleichnisse, die im klerikalen Zusammenhang als bekannt vorausgesetzt werden können, fehlen hingegen und die breite Darstellung der Heilsgeschichte ist auf ihren Kern reduziert: Berichtet wird nur, dass Barlaam lange über die Erschaffung der Welt, den Sündenfall, Fleischwerdung, Leiden und Auferstehung Christi predigt und multa von der Belohnung der Guten und der Bestrafung der Bösen darlegt (LA 2330), nicht wie er das tut und welche intradiegetisch Wirkung es entfaltet.

Rudolf von Ems hingegen nutzt gerade das narrative Potential einer bewussten inszenatorischen Verknüpfung, in der sich das in den Exempeln Antizipierte in der folgenden Handlung verwirklichen und damit seine Relevanz für die Rezipienten des Textes entfalten kann. ${ }^{251}$ Legendarische Muster und gleichnishafte Geschichten werden so auf das Grundanliegen der Vermittlung von Lehre hin integriert: „Es ist ein kunstvolles Gebilde: eine Legende, die belehren soll, in die selbst Lehren eingefügt sind, die ihrerseits wieder durch Legenden, Gleichnisse und Geschichten illustriert werden.“252 Daraus ergibt sich ein komplexes Gefüge der Wirkungsebenen von lêre,

251 Die Einbindung von gleichnishaften Erzählungen in eine Legende, wie sie den Barlaam-undJosaphat-Stoff auszeichnet, lässt sich mit Peter von Moos: Geschichte als Topik. Das rhetorische Exemplum von der Antike bis zu Neuzeit und die historiae im Policratius Johannes von Salisbury. Hildesheim 1988 (Ordo. Studien zur Literatur und Gesellschaft des Mittelalters und der frühen Neuzeit. 2) systematisch fassen, insofern sich in diesen beiden exemplarischen Erzählweisen ,zwei Grundformen des spezifisch-christlichen Beispiels“ darstellen: auf der einen Seite das „hagiographische Exemplum des herausragenden, besonders begnadeten Einzelnen“ oder „hierarchische Persönlichkeits-Exemplum“ (ebd., S.100), auf der anderen das „didaktisch-paränetische oder volkspredigthafte Exemplum“ (ebd., S. 118), dessen Handlungsträger unbekannt und namenlos ist als ein „die ganze Menschheit repräsentierende[r] anonyme[r] quidam“ (S. 115). Während die erste Form argumentationslogisch induktiv funktioniert und als „primär eschatologischer Präzedenzfall“ zur ,admirativen Identifikation des Rezipienten mit dem exemplarisch Vorgestellten“ auffordert, dient zweitere auf deduktive Weise „der Illustration von christlichen Tugenden oder göttlichen Gesetzen“ und „thematisiert Formen religiösen Wohlverhaltens, die prinzipiell für jeden Menschen in eigener Handlung nachvollziehbar sind“, so Schürer, Das Beispiel im Begriff, S. 205. Das steht aber nicht im Widerspruch zum Geflecht von Rezeptionspotentialen im legendarischen Erzählen selbst: Die Zuordnung der Wirkungsabsichten und Identifikationsweisen von admiratio und imitatio auf hagiographisches und didaktisch-paränetisches Exemplum ist vor allem typologisch zu verstehen, weniger als eindeutiger Befund, der sich in der mittelalterlichen exempla-Literatur verfolgen ließe. So können sich induktive und deduktive beziehungsweise illustrative Verwendung bei ein und demselben Beispiel je nach der gewünschten argumentativen Einbindung fallweise abwechseln. Vgl. von Moos, Geschichte als Topik, S. 121. In der Legende, die immer in einem heilsgeschichtlichen Rahmen steht und das Vorbild der Heiligen als Ausdruck der für alle verbindlichen imitatio Christi permanent verfügbar macht, durchdringen sich die Perspektiven. Vgl. Schürer, Das Beispiel im Begriff, S. 219.

252 Heinz Rupp: Rudolfs von Ems Barlaam und Josaphat. In: Dienendes Wort. Eine Festgabe für Ernst Bender zum 70. Geburtstag. Hrsg. von Walter Franke. Karlsruhe 1959, S. 11- 37, hier S. 36. 
das nicht nur bewusst inszeniert, sondern musterhaft ausgestellt wird: Der Erzähler als göttlich inspirierter Vermittler von lêre, wie er im für volkssprachige Legendendichtungen typischen Prolog entworfen wird, lässt sie auf der Figurenebene vermitteln, wobei die Lehren narrativ eingebunden sind und in ihnen selbst wieder kleine gleichnishafte und exemplarische Erzählungen genutzt werden, und stellt sie in ihrer Verwirklichung in der Konversion und dem beispielhaften Vorbild seiner Protagonisten dar. Auf diese Weise öffnet sich das Dargestellte auf die extradiegetische Welt hin, denn lêre wird sowohl im als auch durch den Text vermittelt und soll auf diese Weise die innere conversio eines christlichen Legendenpublikums befördern.

Für ein höfisches Publikum stellt die verchristlichten Buddhalegende dabei einen durchaus spannungsreichen Stoff dar, wenn sich darin ein Königssohn in der Erkenntnis der Vergänglichkeit alles Weltlichen zum christlichen Glauben bekehrt, der gleichbedeutend ist mit Askese und Anachorese, sodass er nach der Mission seines Volkes der Herrschaft entsagt und in der Wüste die Heiligkeit erringt. Die im Zusammenhang mit dem Barlaam und Josaphat Rudolfs von Ems üblichen Gattungszuschreibungen von ,höfischer Legende' oder ,Legendenroman“ betonen die Diskrepanz von geistlicher Thematik und weltlichem Wertehorizont beziehungsweise legendarischem und romanhaftem Erzählen, lassen dabei allerdings keinen Zweifel daran, dass es sich grundlegend um einen Legendenstoff handelt, der, wie auch immer, erfolgreich an ein höfisches Publikum vermittelt wird. Die damit verbundenen Spannungen lässt Rudolf seinen Erzähler im Epilog auch ausdrücklich benennen:

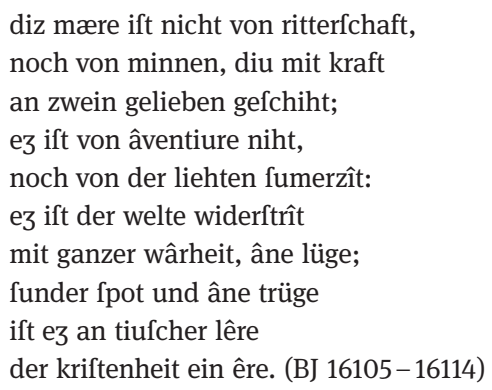

Wenn diese Erzählung aber als eine programmatische Absage an die Welt ritterlicher âventiure und höfischer Weltfreude gilt, stellt sich die Frage nach Art und Intention ihrer Vermittlung an einen entsprechenden Rezipientenkreis. Denn für einen solchen müsste sich die Geschichte von der radikalen Weltabkehr eines Fürstensohnes als höchst problematisch erweisen, wenn man ihren Zweck allein in der Propagierung des vom Protagonisten verkörperten Lebensmodells aufgehen sähe.

Die Forschung hat sich daher gerade an der Frage abgearbeitet, wie der Abschied Josaphats aus der Welt zu begreifen sei und in welchem Verhältnis seine Anachorese zu seinem Wirken als christlicher Herrscher stehe: ${ }^{253}$ Der Barlaam und Josaphat stehe 
entweder, als Ausdruck einer persönlichen religiösen Krise des Autors, im Zeichen des contemptus mundi, ${ }^{254}$ oder aber der ,Dichter' distanziere sich in seinen Kommentaren von der Handlung und „den Idealen seines Helden““. ${ }^{255}$ Gemeinsam ist diesen Beiträgen das Bestreben, das breite und vielgestaltige Werk Rudolfs einer schlüssigen Gesamtinterpretation zuzuführen, was sich schon insofern als problematisch erweist, als der Zusammenhang über die aus den Texten selbst rekonstruierte Persönlichkeit und Biographie des Autors hergestellt werden soll. Die vermeintlichen Selbstaussagen des Autors gerade im Prolog des Barlaam und Josaphat sind aber unverkennbar topischer Natur: Das Bekenntnis des Erzählers, die Leute mit trügelîchen mæren (BJ 153) belogen zu haben, nun aber er diese wahre Geschichte ze trôfte uns fündæren (BJ 154) dichten zu wollen, damit auch jeder, der sie lese, fich bezzernde wefe (BJ 158) und seiner vor Gott gedenke, sind Teil der Inszenierung einer Erzählerrolle, die auf den Stoff angepasst ist - eine Legende eben, und hier zumal eine, die von Konversion erzählt.

Die einseitige Fokussierung auf die Vorbildlichkeit des Protagonisten und die Weltabkehr unterschneidet aber auch die deutlich vielschichtigeren Entstehungs- und Rezeptionszusammenhänge volkssprachiger Legenden: Wenn eine lateinische Vorlage auf monastisch-klerikaler Veranlassung hin in mittelhochdeutsche Verse übertragen wird, zur didaktischen Unterweisung und moralischen Besserung - daz fich die liute bezzern mite (BJ 132) - eines adlig-laikalen und dezidiert höfischen Publikums, wie es Rudolf in Prolog und Epilog bewusst inszeniert, sind die Rezeptionspotentiale deutlich breiter anzusetzen. ${ }^{256}$ Die Eigenständigkeit von Rudolfs Bearbeitung des

Erzählschluß. Untersuchungen zu Kaiserchronik, König Rother, Orendel, Barlaam und Josaphat, ProsaLancelot. Stuttgart 2004, S. 85-88.

254 Vgl. Helmut de Boor: Geschichte der deutschen Literatur. Von den Anfängen bis zur Gegenwart, Bd. 2: Die höfische Literatur. Vorbereitung, Blüte, Ausklang. 1170 -1250. München 1953, S. 180-181. 255 Rupp, Rudolfs von Ems Barlaam und Josaphat, S. 29. Diesem Ansatz folgt Rüdiger Schnell, Studien zur inneren Einheit seines Gesamtwerkes. Bern 1969 (Basler Studien zur deutschen Sprache und Literatur. 41), der ein „gottesfürchtige[s] Dasein inmitten dieser Welt“ (S. 94) als Zielpunkt aller Werke Rudolfs ausmacht, und letztlich auch Xenja von Ertzdorff, Rudolf von Ems. Untersuchungen zum höfischen Roman im 13. Jahrhundert. München 1967, die anknüpfend an Rupp eine bewusste höfische Überformung für ein entsprechendes Publikum betont, in der sie Rudolfs Bestreben sieht, „die starre Unnachgiebigkeit und Konsequenz des heiligen Josaphat“ (S. 216) in der Askese zu Gunsten der Darstellung der Bekehrung der Heiden abzumildern.

256 Die genaue Vorlage Rudolfs von Ems ist nicht bekannt, jedenfalls ist sie nicht einfach identisch mit der lateinischen Vulgata-Fassung, die selbst in über 90 Handschriften überliefert ist. Vgl. Cordoni, Barlaam und Josaphat in der europäischen Literatur des Mittelalters, S. 71-73. Die Vulgata-Fassung wurde im 16. Jahrhundert unter dem Titel Ioan. Damasceni Historia duorum Christi militum e Graeco in Latinum versa in einer Gesamtausgabe Johannis Damasceni opera in Basel gedruckt. Die beiden bisherigen Untersuchungen, die Rudolfs Text vor dem Hintergrund der lateinischen Stofftradition untersuchen, nehmen diese Fassung als Grundlage. Vgl. Hannah Czizek: Rudolfs von Ems Barlaam und Josaphat und seine lateinische Vorlage. Diss. masch. Wien 1931, S. 22 außerdem Charlotte Nägler: Studien zu Barlaam und Josaphat von Rudolf von Ems. Diss. masch. Karlsruhe 1972, S. 162, die ge- 
Stoffes im Kontext der höfischen Literatur hebt sich dabei auch vor dem Hintergrund der beiden anderen mittelhochdeutschen Fassungen ab, dem unikal überlieferten, um oder vor 1200 entstandenen Laubacher Barlaam Bischof Ottos II. von Freising (1184-1220) sowie dem nur in zwei Fragmenten derselben Handschriften aus dem 13. Jahrhundert überlieferten Zürcher Barlaam, die jeweils eine deutlich enger an die lateinische Vorlage angelehnte Übertragung bieten. ${ }^{257}$ Von einem breiteren Rezeptionsrahmen ist nicht zuletzt auch wegen der Besonderheiten des zugrundeliegenden Stoffes auszugehen, der eben keine genuin christliche Heiligenlegende darstellt und dessen Übernahme in nahezu alle europäischen Volkssprachen immer wieder mit seiner lehrhaften Tendenz begründet worden ist: „Verbreitung und Einfluß verdankt das Buch seiner die christliche Glaubenslehre bildhaft darstellenden und veranschaulichenden Struktur“. ${ }^{258}$ Die Bekehrung des Prinzen in einem ausführlichen und mit etlichen Beispielerzählungen durchsetzten Lehrgespräch, die Auseinandersetzung mit dem Heidentum, sowie schließlich Josaphats Wirken als christlicher Herrscher vor seinem Lebensende als Wüstenheiliger lassen viel Raum für die Darstellung von Glaubensinhalten und Unterweisungen zum entsprechenden Lebensvollzug.

Diesen Schlüssel zum Verständnis seiner Erzählung bietet Rudolf im Zusammenhang mit der welte widerftrît selbst, wenn es nach der Absage an die höfischen Themen von Minne und Ritterschaft über den Gegenstand dieses mære heißt: funder fpot und âne trüge / ift ez an tiufcher lêre / der kriftenheit ein êre. (BJ 16112-16114) Dass der lehrhafte Zug des Stoffes ein grundlegendes Element darstellt, das in dieser mittelhochdeutschen Fassung gar „zum durchgehenden Gestaltungsprinzip“259 aufgewertet wird, sodass ihm in seiner besonderen Akzentuierung und Reflexion eine poetologische Funktion zukommt, erweist sich auch mit Blick auf den Begriff der lêre. Dieser erscheint im Text in unüberschaubarer Fülle und wird immer wieder in neuen

genüber Czizek herausarbeitet, dass Rudolfs Vorlage nicht in allem mit der lateinischen Historia übereinstimmt. Eine kritische Ausgabe der Vulgata liegt erst seit 2001 vor, vgl. VB.

257 Zum Laubacher Barlaam vgl. Ulrich Wyss: Art. Otto II. von Freising. In: ${ }^{2}$ VL 7 (1989), Sp. 223-225, hier Sp. 224, außerdem Christian Seebald: Erzählstrategien und literarischer Ort des Laubacher Barlaam. In: Barlaam und Josaphat. Neue Perspektiven auf ein europäisches Phänomen. Hrsg. von Matthias Meyer, Constanza Cordoni. Berlin/München/Boston 2015, S. 343-364, der zeigt, dass sich diese Adaption der lateinischen Barlaam-Vulgata an den Mustern frühmittelhochdeutscher Erzähltraditionen orientiert und mit entsprechenden eigenen stilistischen Schwerpunkten an einer anderen Stelle im Literatursystem seiner Zeit zu verorten ist. Zu vermuten ist eine primäre Rezeption im persönlichen Umfeld des Bischofs oder in einem Kloster, vgl. ebd., S. 363-364. Ähnliches ließe sich wohl auch für den Zürcher Barlaam sagen, wenn die 432 erhaltenen Reimpaarverse eine solche Einschätzung überhaupt erlauben. Vgl. Cordoni, Barlaam und Josaphat in der europäischen Literatur des Mittelalters, S. $199-200$.

258 Irmgard Lackner: Art. Barlaam und Josaphat. In: EM 1 (1977), Sp. 1243-1252, hier Sp. 1244.

259 Françoise Salvan-Renucci: Heidentum und christliche Theologie im Barlaam und Josaphat Rudolfs von Ems. In: Orient und Okzident in der Kultur des Mittelalters. Monde oriental et monde occidental dans la culture médiévale. XXXI. Jahrestagung des Arbeitskreises „Deutsche Literatur des Mittelalters“. Greifswald 1997 (Wodan. 68, Serie 3, Tagungsbände und Sammelschriften, Vol. 39), S. 125-135, hier S. 125. 
bedeutungsstiftenden Zusammenhängen verdichtet: lêre kommt von Gott, wird in der Erzählung weitergegeben und durch diese an den Rezipienten vermittelt. ${ }^{260}$ Es verwundert daher, dass der Aspekt der Vermittlung von religiöser Lehre in der Erzählung und durch sie sowie die Bedeutung dieses Zusammenhangs für die Interpretation von Rudolfs Barlaam und Josaphat bisher kaum fruchtbar gemacht worden ist. ${ }^{261}$ Dabei ist offensichtlich, dass lêre hier nicht nur das Exempel der Heiligen umfasst, denn die dargelegten Lehrinhalte sind zwar narrativ eingebunden, übersteigen aber zugleich die Erzählung und wirken über diese hinaus. Ihre Adressaten sind nicht nur die Figuren auf der Handlungsebene, die sie exemplarisch mitvollziehen und in der Konversion verwirklichen, sondern zugleich die Rezipienten, die ihrerseits belehrt werden sollen:

\author{
[...] diz mære gît \\ den liuten ze etlîcher zît \\ an kriftenlîcher êre \\ vorbilde in guoter lêre (BJ 137-140).
}

260 Die mittelhochdeutsche Begriffsdatenbank verzeichnet für den Barlaam und Josaphat bei 16164 Gesamtversen insgesamt 330 Belegstellen für den Begriff lêre, weitere 110 für die Formen von lêren und 13 für das Substantiv lêrer. http://mhdbdb.sbg.ac.at:8000/mhdbdb/App?action=TextQueryModule\&string=lere\&filter=\&texts=BAR-\&startButton=Suche + starten\&contextSelectListSize $=1 \&$ contextUnit=1\&verticalDetail=3\&maxTableSize=100\&horizontalDetail=3\&nrTextLines=3 [Zugriff: 02.02.2021]. 261 Zwar hat schon Helmut Brackert: Rudolf von Ems. Dichtung und Geschichte. Heidelberg 1968 (Germanische Bibliothek, Dritte Reihe, Untersuchungen und Einzeldarstellungen) gegenüber der Frage nach einem persönlich-individuellen Bekenntnis Rudolfs in seiner Legende deren Einheit in der lêre herausgestellt, die er als „Einheit von Leben in der Welt und Weltabkehr“ (S. 216) versteht. Es müsse primär von der Gattung her geurteilt werden und diese verlange die konsequente Darstellung einer exemplarischen Möglichkeit mittelalterlichen Weltverhaltens, an dem sich die lêre manifestiere und das in diesem Fall im Zeichen des contemptus mundi stehe. Allerdings verabsolutiert er dabei wiederum einseitig Gattungscharakteristika und vernachlässigt, indem er das umfangreiche Gesamtwerk Rudolfs unter einer diesem als Dichter eigenen Konzeption von Wahrheit und Geschichte zusammenfasst, die konkreten Inhalte der im Barlaam und Josaphat vermittelten lêre zu Gunsten einer Leerformel. Zwar erkennt Brackert ganz richtig, dass sich die Gültigkeit des aufgestellten Exempels „nicht an einer persönlichen existentiellen Entscheidung des Autors für dieses Lebensideal“ beweist, um dann aber seinerseits zu konstatieren, dieser distanziere sich vom entworfenen Ideal: „die Lösung ist, wie so oft bei Rudolf, ganz und gar formalistisch, die Ebene der bloßen Darstellung wird nicht zugunsten eines persönlichen Bekenntnisses verlassen“ (S. 218). Die lêre sieht er also nicht nur unabhängig vom ohnehin fragwürdigen Konstrukt der Dichterpersönlichkeit, sondern letztlich auch vom konkreten Bezug auf ein Publikum, und bleibt damit bei einer rein textimmanenten Interpretation, die nicht weiter nach Rezeptionspotentialen und Identifikationspunkten fragt, die über das, dann zumal äußerst abstrakte, Vorbild Josaphats hinausreichen. Biesterfeldt nimmt Brackerts These als Ausgangspunkt, um zu zeigen, dass die „Ebene der bloßen Darstellung“ im Text eine weitaus positivere Wertschätzung erfährt. Die inhaltliche und funktionale Breite von lêre berücksichtigt sie aber nur einseitig, da es ihr um die Einordnung der moniage Josaphats in eine literarische Reihe solcher Erzählschlüsse geht, stellt aber überzeugend dar, wie diese über diese Erzählung für jeden Rezipienten, ob geistlichen oder weltlichen Standes, imitativ oder affirmativ, mitvollzogen werden kann. Vgl. Biesterfeldt, Moniage, S. 97-108. 
Der Begriff der lêre umfasst thematisch den Inhalt christlicher Lehre ebenso wie den Modus ihrer Vermittlung, und bezeichnet dabei situativ sowohl die Glaubensunterweisungen Barlaams an Josaphat, deren Thema die persönliche Bekehrung, Buße und Askese des einzelnen ist, als auch den großen Religionsdisput, in dem sich die universale dogmatische Geltung des Christentums erweist, und die sich daran anschließende Bekehrung des ganzen Reiches - in beiden Fällen geht es auf signifikante Weise um die Narrativierung von Konversion beziehungsweise Mission. Diesen Verständnisrahmen einer Konversions- und Missionslegende, die christliche lêre „in einem Reflexionsprozeß auf den Modus ihrer Vermittlung“262 rezipierbar macht, öffnet der Erzähler, wenn er nach einem umfangreichen Eingangsgebet mit Gottespreis und Glaubensbekenntnis zur materia überleitet, indem er Gott um Inspiration bittet: ${ }^{263}$

\author{
durch die gnâde bite ich dich, \\ daz dû geruocheft hœren mich \\ und mir in mîne finne \\ des heilegen geiftes minne \\ ze lêre geruocheft fenden, \\ daz ich wol müge verenden, \\ des ich mit kranken finnen \\ alhie wil beginnen \\ ze fprechenne von einem man, \\ wie des lêre dir gewan \\ vil der heidenifchen diet, \\ wie er von ungelouben fchiet \\ mit dîner lêre liute, lant
}

262 Hans-Joachim Ziegeler: Art. Rudolf von Ems. In: Deutsche Dichter. Leben und Werk deutschsprachiger Autoren, Bd. 1: Mittelalter. Hrsg. von Gunter E. Grimm, Frank Rainer Max. Stuttgart 1989, S. 264-281, hier S. 270.

263 Damit ist die Rolle eines göttlich inspirierten Erzählers entworfen, die Walter Haug: Wolframs Willehalm-Prolog als Paradigma für das Selbstverständnis der Legendenautoren im 13. Jahrhundert. Rudolfs Barlaam und Josaphat als Musterbeispiel. In: Ders.: Literaturtheorie im deutschen Mittelalter. Von den Anfängen bis zum Ende des 13. Jahrhunderts. Sonderausgabe, unveränderter Nachdruck der 2. Aufl. 1992. Darmstadt 2009, S. 316-328, vor dem Paradigma des Willehalm-Prologs interpretiert hat, auf den Rudolf unzweifelhaft zurückgreift und der seinerseits eine auf die folgende Erzählung - und die in ihr aufscheinende Frage nach der Gottesgeschöpflichkeit der Heiden sowie ihre vielschichtige Sinnstiftung - bezogene literarische Situation und Erzählerrolle gestaltet. Gegenüber Wolframs Vorrede, wo die Fähigkeiten des Dichters als ein unmittelbarer Ausfluss des Heiligen Geistes inszeniert werden, was eng verknüpft ist mit den Gedanken der Gotteskindschaft und Gottes Wirken in der Natur, sieht Walter Haug bei Rudolf von Ems einen „Rückgriff auf das traditionelle Konzept des Legendenprologes“ mit seinen Topoi. Denn hier handele es sich um die „Frage des göttlichen Beistands in der traditionellen Form der religiösen Wahrheitsvermittlung“, die eng verknüpft ist mit der Thematik des Barlaam und Josaphat, in dem es um „die Lehrbarkeit des Glaubens“ geht, „darum, zu demonstrieren, wie die christliche Glaubenswahrheit in ihrer Überzeugungskraft sich selbst darzustellen und durchzusetzen vermag“ (ebd., S. 326). Der Geist Gottes wirkt dabei nicht unmittelbar im Dichter, sondern im menschlichen Vermögen, allen voran der wîsheit (BJ 76), womit er zum Werkzeug göttlicher Unterweisung und Offenbarung wird, er „,ist der Belehrte, der Lehre weitervermittelt“ (ebd.). 
und den gelouben tet erkant

in dînem namen, füezer Krift. (BJ 103-117)

Es geht in der folgenden Erzählung also um die Konversion eines ganzen Landes durch christliche lêre, mithin die Überwindung des Heidentums durch die Unterweisung im christlichen Glauben, ganz so wie es bei der Apostelaussendung imaginiert wird: euntes ergo docete omnes gentes baptizantes eos [...] docentes eos servare omnia quaecumque mandavi vobis (Mt 28, 19-20). ${ }^{264}$ Allein die Verkündigung im Wort soll den Gegensatz zwischen heidnischem Unglauben und wahrem Glauben offenbar machen und zur Konversion der Heiden führen. Unklar bleibt, von welchem eine[ $n]$ man hier genau die Rede ist, denn beiden heiligen Protagonisten kann dieses Bekehrungswerk zugeschrieben werden; Josaphat ganz unmittelbar und Barlaam zumindest indirekt, insofern er mit der Konversion Josaphats die Grundlage für dessen Mission seiner Untertanen legt.

Gleichzeitig wird in der Inspirationsbitte die Rolle des Erzählers auf komplexe Weise auf die folgende Erzählung hin entworfen, seine Legitimation und Autorität bewusst mit der materia verknüpft: ${ }^{265}$ Der Erzähler bittet um die lêre Gottes durch den Heiligen Geist, die ihm helfen soll, die Erzählung zu vollenden, deren Protagonist durch seine lêre, die nichts anderes ist als die lêre Gottes, die von ihm handelt und aus ihm entspringt, die Heiden bekehren konnte. Sie soll sich aber nicht nur intradiegetisch in ihrer Wirksamkeit erweisen, sondern vermittelt durch die Erzählung in der extradiegetischen Welt des im religiösen Mitvollzug des Legendengeschehens mit dem Erzähler verbundenen Publikums. Dass dabei mit dem Abt Wido des Zisterzienserklosters Cappel eine historisch verbürgte und dem Publikum wohl bekannte lebende geistliche Autorität angeführt wird (BJ 144-147) mag ,die situativ evidente kirchliche Beauftragung des Prädikanten“266 ersetzen und der Legitimation des Erzählers dienen, wenn er gleich einem geistlichen Prediger über Glaubensdinge spricht.

Allerdings wird Wido an keiner Stelle als direkter Auftraggeber genannt, ${ }^{267}$ sondern als Vermittler des Stoffes in tiufchiu lant (BJ 144). Der eigentliche funktionale Zusammenhang dieser Figur wird erst in den Ausführungen des Epilogs deutlich, die ihn samt seinem Konvent zum Garanten des geistlichen Nutzens der Legende machen:

von Kapelle der abbet riet

und al diu famenunge mir

264 Vgl. dazu oben in Kap. 3.1.2 Das Martyrium als Praxis der Differenz, S. 101.

265 Zur im Prolog entworfenen Erzählerrolle beziehungsweise der Konstruktion von Autorschaft vgl. insgesamt Coxon, The presentation of authorship, S. 44-58.

266 Volker Mertens: Sprechen mit Gott - Sprechen über Gott. Predigt und Legendendichtung im frühen 13. Jahrhundert (Rudolf von Ems, Barlaam und Josaphat). In: Sprechen mit Gott. Redeszenen in mittelalterlicher Bibeldichtung und Legende. Hrsg. von Nine Miedema, Angela Schrott, Monika Unzeitig. Berlin 2012 (Historische Dialogforschung. 2). S. 269-284, hier S. 277.

267 Vgl. Cieslik, Die Legenden Rudolfs von Ems und Konrads von Würzburg, S. 193-194. Ebenso von Ertzdorff, Rudolf von Ems, S. 81-82. 


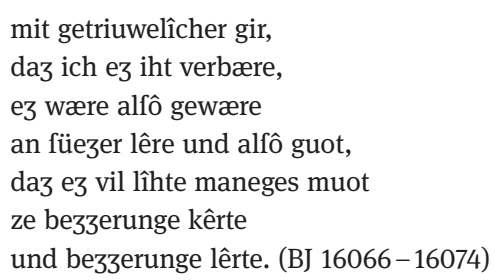

Mit dieser Beglaubigung durch eine monastische Gemeinschaft als den ,Spezialisten“ geistlichen Lebens ist die Aufgabe des Autors und Erzählers als die der Vermittlung von Lehre in der Erzählung und durch sie wiederum auf den Mitvollzug durch ein breites Laienpublikum bezogen. Das wird auch darin deutlich, dass sich diese Verse des Epilogs inhaltlich an die Verehrung der heiligen Protagonisten und die Tradierung ihrer Lebensgeschichte anschließen, wie sie auf der Handlungsebene geschildert werden, wo Josaphats Nachfolger für beides sorgt. Die Erzählung öffnet sich damit auf die legendarischen Funktionsstellen von außerliterarischen Verbürgtheit und Wirksamkeit des beziehungsweise der beiden Heiligen, deren Bekehrung $\mathrm{zu}$ Gott und daraus entspringende Mission die Gläubigen in ihrer inneren conversio bestärken soll.

\subsubsection{Bekehrung als Erkenntnisprozess: Josaphats Konversion zur Askese}

Die Glaubensunterweisung Josaphats durch Barlaam bildet den ersten großen und gemessen am Gesamtumfang umfangreichsten Teil der Erzählung. Inszeniert ist sie als ein großes Lehrgespräch, dessen Situationen und Stationen narrativ integriert sind, denn Josaphats Konversion ist ein durch eine krisenhafte Erfahrung ausgelöster persönlicher Glaubensprozess, in dem die christliche Weltdeutung, die Barlaam ihm vermittelt, die gesuchten Antworten bietet. Der erste Anstoß zu Josaphats Suche liegt allerdings schon vor der eigentlichen Krise, denn obwohl er aufgrund der Prophezeiung, er werde sich einst zum Christentum bekehren und der Krone entsagen, abgeschirmt von jedem Kontakt zur christlichen Lehre aufwächst und eine rein höfischweltliche Erziehung erhält (BJ 867-908), stellt er sich irgendwann von ganz allein die Frage nach dem Schöpfer der Welt. Diese gründet im ,epistemologischen Staunen ${ }^{268}$ angesichts der Schöpfung:

\footnotetext{
dâ bî begunde er denken fô:

wer mit fô rîchem werde

des himels und der erde

fô gewaltic möhte fîn,

daz der liehten funnen fchîn

tages fchîne und nahtes niht.
}

268 Vgl. dazu oben in Kap. 5.1.3 Die Narrativierung von Konversion zwischen Ereignis und Prozess, S. $286-287$. 
in dûhte ein wunderlîch gefchiht,

wâ von diu vinfter trüebe (BJ 990-997).

Diese Erwägungen legt er seinen Lehrer vor als

wîfe vrâge in vremeder kür,

ob der gefchephede orden

wær von im felben worden,

oder ob ez wære gemachet fô (BJ 1004-1007).

Von einem seiner Lehrer erfährt Josaphat daraufhin von der Prophezeiung und dem christlichen Schöpferglauben. Der grundsätzlichen Erkenntnisfähigkeit jedes Menschen, die in seiner Gottesgeschöpflichkeit gründet und daher auch dem Heiden eignet, antwortet auch hier die göttliche Gnade, die in der typischen zirkulären Struktur der Bewegungsrichtungen Ursache wie Ziel der Konversion ist, die damit im Letzten ein innerer, unerklärlicher Vorgang bleibt: ${ }^{269}$

Do began der junkherre

gedenken harte verre

nâch wâne in fînen finnen

ze kriftenlîcher minnen.

got tet an im genâde fchîn:

er fante im in daz herze fîn

des heilegen geiftes güete

fô gar, daz fîn gemüete

beleip in reiner ftætekeit,

als iu wirt her nâch gefeit. (BJ 1071-1080)

Die Konversion ist damit innerlich schon vollzogen, sie bedarf aber noch der diskursiven Vermittlung und Konkretion in der intradiegetisch äußeren, intersubjektiven Welt, zumal der Konvertit in diesem Fall mit der christlichen Lehre noch keineswegs vertraut ist, also erklärt bekommen muss, wozu er sich nun eigentlich bekehrt.

Dieser diskursiven Vermittlung wie der narrativen Plausibilisierung des Konversionsgeschehens dient der Ausritt Josaphats, auf dem er mit der Vergänglichkeit und

269 Das ist, wie ich oben in Kap. 5.1.3 Die Narrativierung von Konversion zwischen Ereignis und Prozess, S. 280 - 281 dargestellt habe, ein Grundproblem der narrativen Darstellung von Konversion: Das Ziel ist immer schon die Voraussetzung, nämlich Heilsteilhabe, die letztlich nicht plausibilisierbar und als solche darstellbar ist. Daher geht es zu weit, wie Constanze Geisthardt: Nichts als Worte. Die Problematik sprachlicher Vermittlung von Heil in Rudolfs von Ems Barlaam und Josaphat. In: Barlaam und Josaphat. Neue Perspektiven auf ein europäisches Phänomen. Hrsg. von Matthias Meyer, Constanza Cordoni. Berlin/München/Boston 2015, S. 101-139, in den intradiegetischen Lehrsituationen des Barlaam und Josaphat ,jeweils das Scheitern der sprachlichen Vermittlung von Heil vorgeführt“ (ebd., S. 106) zu sehen, wohl aber treten dabei „Bedingungen und Möglichkeiten des richtigen Verstehens [...] gegenüber den eigentlichen Inhalten in den Vordergrund“ (ebd., S. 132). 
dem Leid des irdischen Daseins konfrontiert wird. Dadurch gerät er in eine veritable Lebenskrise und in seiner Verzweiflung über die Frage, was nach dem Tode komme, wird er wiederum auf den Christenglauben verwiesen (BJ 1350 -1373). An dieser Stelle erscheint nun Gott als der eigentliche Handelnde, der uns vil armen / gefchuof unde werden hiez (BJ 1380 -1381) und niemanden abweist, der ihn demütig sucht, und sich daher auch Josaphats erbarmt und ihm finen boten (BJ 1388) schickt. Als Kaufmann verkleidet gelangt Barlaam zu Josaphat in den Palast und es folgt eine ausführliche Darstellung christlicher Lehre in der Form eines Lehrer-Schüler-Gesprächs. Die dialogische Struktur fingiert dabei eine lebensnahe Gesprächssituation, wie sie der altkirchlichen Praxis von Unterweisung der Katechumenen vor der Taufe und anschließender Ermahnung der Getauften widerspiegelt. ${ }^{270}$ Sie ermöglicht es zudem, den Erkenntnisprozess Josaphats darzustellen, in der der ihm von Barlaam angebotene neue Deutungsschlüssel diskursiv umgesetzt wird in immer wieder neuen Anläufen der Unterscheidung der falschen heidnischen und weltlichen Gesinnung vom wahren christlichen Glauben und einem entsprechenden existentiellen Vollzug.

Auf Josaphats Frage nach Barlaams Herrn verknüpft dieser sein Glaubensbekenntnis mit einer Darlegung der Heilsgeschichte von den Anfängen bis zur Situation des Glaubensgespräches, indem sich die beiden befinden (BJ 1947-3124): Ausgehend vom in Christus menschgewordenen Gott, der der Herr der Schöpfung ist, erzählt er von der Entstehung des Bösen, der Schaffung des Menschen, vom Paradies und dem Sündenfall, Kain und Abel, der Sintflut, Abraham, von Mose und dem Auszug aus Ägypten, im Überblick von den Königen des Alten Testaments, der babylonischen Gefangenschaft, nennt schließlich die Propheten, von denen Bileam und seine als Ankündigung auf die Geburt Christi verstandene Prophezeiung zitiert werden (BJ 2445-2452). Die Menschwerdung Gottes zur Erlösung des Menschen, die Verkündigung an Maria und weitere Prophetien auf Jesu Geburt bilden dann den Übergang zum neutestamentlichen Teil, der von Jesu Taufe, seiner Lehre und seinen Wundern berichtet, seiner Passion und Kreuzigung, und schließlich über Auferstehung, Himmelfahrt, Pfingsten und die Aussendung der Apostel den Bogen zum Gespräch Barlaams mit Josaphat schließt. Denn die lêre, die Barlââm mit wîsheit / [...] hâte vollefeit (BJ 3125-3126) gründet in der Verkündigung und dem Vorbild Christi (BJ 2744-2754), sie wird von den Aposteln und Evangelisten verbreitet und fordert nun Josaphat zum Vollzug auf (BJ 3039-3097). Die umfassende Vermittlung christlichen Heilswissens bildet aber erst die Grundlage für die folgenden, weit umfangreicheren Unterweisungen im religiösen Vollzug, denn Josaphats drängende und mehrfach wiederholte Frage ist die nach der Verwirklichung der lêre:

270 Das entspricht freilich nicht mehr der Praxis von Bekehrungen und Taufe im lateinischen Hochmittelalter, doch ist diese Struktur im Stoff vorgegeben und dürfte im Kontext der mendikantischen Neubelebung der Verkündigung an die Laien und der laikalen religiösen Bewegungen im 13. Jahrhundert von Interesse gewesen sein. 


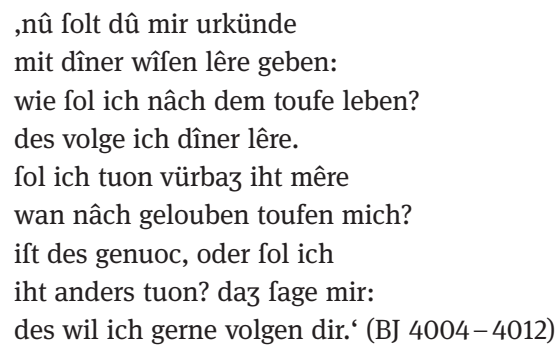

Weil die Konversion aus christlicher Sicht nicht im äußeren Religionswechsel aufgeht, sondern eine innere Umkehr umfasst, kann die Taufe nicht nur ein formaler Akt sein. Dementsprechend meint lêre hier kein abstraktes Heilswissen, das zur persönlichen Erlösung einfach nur verstandesmäßig angenommen werden müsste, sondern fordert zum existentiellen Vollzug auf, zur Umsetzung in der eigenen Lebensweise. Dafür wird dem Schüler der Lehrer zum Vorbild, ihm und seiner Lehre will er folgen. Diese Verknüpfung von diskursiver Vermittlung von Lehre und einem Vorbild, in dem sie sich verwirklicht, entspricht dabei genau der neuen, durch die apostolische Bewegungen des 12. und 13. Jahrhunderts geprägten Auffassung einer Predigt verbo et exemplo, die in besonderer Weise geeignet ist, die Verbreitung des in dieser Zeit neu geschaffenen laikalen Bußideals zu befördern. ${ }^{271}$

Im Folgenden entwirft Barlaam seinem Schüler auf der Grundlage der dogmatisch-heilsgeschichtlichen Dimension der christlichen Lehre eine darin begründete Lebenslehre. $^{272}$ Diese charakteristische Verbindung von heilsgeschichtlicher Katechese mit der Einführung in eine entsprechende Praxis fasst Barlaam nach zahlreichen Gleichnissen, Auslegungen und Ermahnungen pointiert zusammen:

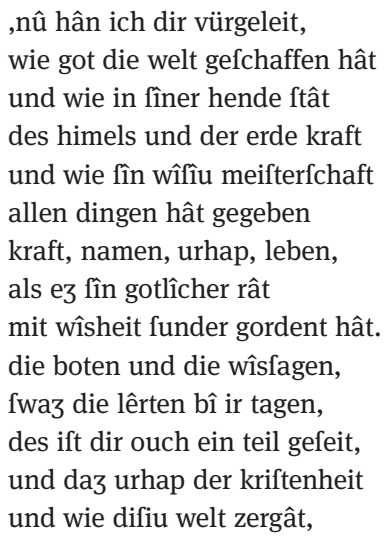

271 Vgl. Wehrli-Jons, Voraussetzungen und Perspektiven mittelalterlicher Laienfrömmigkeit, S. 298299. Vgl. ausführlicher dazu oben in Kap. 3.3.1 Martyrium und Mission im frühen Franziskanertum, S. $155-156$.

272 Vgl. Rupp, Rudolfs von Ems Barlaam und Josaphat, S. 34. 


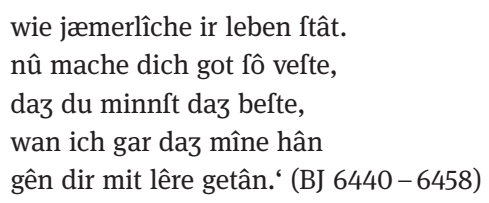

In apostolischer Sukzession reiht sich Barlaam mit seiner Glaubensunterweisung in die Tradition der boten und wîsfagen ein. In diese universale Ausbreitungsbewegung des Christentums durch der boten lêre (BJ 179), wie sie schon im Prolog entworfen wird, erscheint die gesamte Erzählung eingebettet, wenn an ihrem Beginn das Heilshandeln Gottes und besonders die Erlösung der Menschheit durch den Tod Christi stehen, die den Ausgangspunkt für die Verbreitung des Glaubens und die Nachfolge der Heiligen und Anachoreten bilden (BJ 165-195). Zugleich sind in dieser Zusammenfassung die Vorzeichen benannt, unter denen das Ideal religiösen Vollzugs entworfen wird: ,wie difiu welt zergât, / wie jæmerlîche ir leben ftât‘ (BJ 6453-6454).

Natürlich lässt sich die Josaphat von Barlaam vermittelte lêre auch auf einige wenige Kernaussagen zu Reue, Buße und Umkehr reduzieren:

Die Lehren des Werkes lassen sich in wenige Worte fassen: Wer sich selbst zum christlichen Glauben bekennt und durch seinen vorbildlichen christlichen Lebenswandel andere zum Glauben führt, kann des höchsten himmlischen Lohnes gewiß sein. Und: Die Bekehrung ist jedem möglich - Gott nimmt in seiner unendlichen Güte alle Sünder an, die aufrichtige Reue zeigen und zur Buße bereit sind. ${ }^{273}$

Eine solche Engführung unterschlägt allerdings die komplexe inhaltliche wie inszenatorische Verbindung von Lehre und Erzählung, die den Barlaam-und-Josaphat-Stoff bestimmt. Denn Konversion bedeutet hier die Hinwendung zu einem christlichen Asketenleben und, insofern es sich um eine Legende handelt, die conversio zur Heiligkeit. Das, was Barlaam als zur Verwirklichung auffordernden Gehalt der christlichen lêre in den zahlreichen exemplarischen und gleichnishaften Einschüben anschaulich macht, steht grundlegend unter dem Eindruck der Vergänglichkeit alles Irdischen. Damit ist in der spezifischen Verkündigung des christlichen Heilswissens wie im durch Barlaam verkörperten Vorbild immer schon ein asketisches Ideal vorgezeichnet, demzufolge die weltlichen Bindungen in der Einsicht in die wahre Natur der Dinge auf die Transzendenz hin zu überschreiten sind.

Dieses Grundmotiv deutet sich schon zu Beginn in Barlaams kurzer Auslegung des Gleichnisses vom Sämann an, wenn rîcheit, wîp, vriunde, kint (BJ 1615) zu den Dornen gerechnet werden, von den vil kûme felten iht / guotes iht durch got gefchiht (BJ 1617-1618). Auf Josaphats Frage hin, wie er nach der Taufe leben solle, entwirft er dann über die Gleichnisse von den zwei Wegen, dem verlorenen Sohn und dem Guten

273 Eckart Conrad Lutz: Rhetorica divina. Mittelhochdeutsche Prologgebete und die rhetorische Kultur des Mittelalters. Berlin/New York 1984 (Quellen und Forschungen zur Sprach- und Kulturgeschichte der germanischen Völker. Neue Folge. 82=206), S. 274. 
Hirten, schließlich mit Petrus und Maria Magdalena als Exempelfiguren für Reue und Umkehr (BJ 4013 - 4390) eine dichotomische Situation zwischen Sünde und Buße, die zur Entscheidung drängt und die weltliche Sicht auf die erstrebenswerten Güter umkehrt. Das erkennt Josaphat und ist bereit, diese Einsicht umzusetzen:

,fwenne ich gar nâch dîner fage

die gotes lêre gelerne

fô hüete ich vreuden gerne

und bin in vreuden gerner fô,

dannich von fünden werde unvrô.‘ (BJ 4408-4412)

Mit der Ergänzung, dass niemand zwei Herren gleichzeitig dienen kann, beschreibt Barlaam das Vorbild der Märtyrer, die als Blutzeugen ihr Leben ließen, und der Anachoreten, die wegen ihres entsagungsreichen Lebens Märtyrer genannt werden:

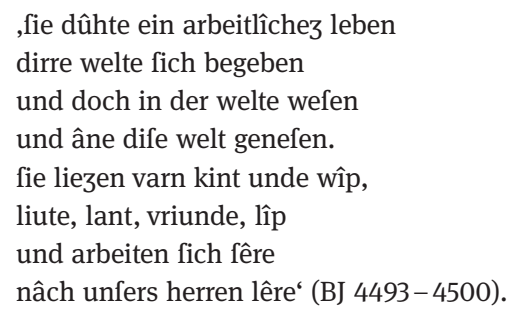

Der zentrale Gedanke, dass die lêre Christi die konsequente Abkehr von der Welt meine, findet sich kurz darauf noch drastischer formuliert, wenn Barlaam zusammenfasst, dass, diu welt solde gehazzet fin', denn, fi ze ftæte nihtes gert' und ,fi ift ir vriunde vîent‘ (BJ 4566/4568/4579). Es ist diese „Gegenüberstellung von rechter und falscher Glaubenshaltung mit den daraus resultierenden gegensätzlichen Einstellungen zur Welt des Materiellen und zur irdischen Wirklichkeit überhaupt“274, die das gesamte Lehrgespräch und darüber hinaus die folgenden Auseinandersetzungen um den christlichen Glauben bestimmt. Sie bildet auch das verbindende Motiv der Parabeln, mit denen Barlaam Josaphat die Welt in seinem Sinne deutet und entsprechende Handlungsweisen exemplarisch anschaulich macht. Auch wenn sie sich immer auf eine allgemeingültige Aussage hin verstehen lassen und daher zur unabhängigen Tradierung anbieten, sind sie nicht losgelöst vom Handlungsrahmen, sondern als ein wichtiger Teil seiner Glaubensunterweisungen eng mit Inhalt und Struktur des Textes verflochten. Denn Barlaam setzt seine Parabeln und Gleichnisse bewusst ein, indem er ihren exemplarischen Gehalt auf die konkrete Situation des Lehrgesprächs beziehungsweise Josaphats bezieht. Exemplarizität meint ja gerade auch die Möglichkeit einer solchen konkreten Ausdeutung, die hier auf Figurenebe-

274 Vgl. Salvan-Renucci, Heidentum und christliche Theologie im Barlaam und Josaphat Rudolfs von Ems, S. 125. 
ne - wiederum exemplarisch mit Blick auf die intendierte Wirkung bei den Rezipienten - mehrfach vollzogen wird.

Auf welchen Voraussetzungen diese Auslegung grundsätzlich beruht, nämlich der Möglichkeit eines allegorischen, moralischen und anagogischen Verständnisses jedes Geschehens in einem mehrfachen Schriftsinn, der auf christliche, geistliche Wahrheit zielt, wird mit dem ersten Gleichnis paradigmatisch ausgestellt. Indem es die Bedingungen der Vermittlung christlicher Lehre überhaupt absteckt, wird ein Bedeutungshorizont für das angemessene Verständnis des Folgenden eröffnet. Barlaam kann nur mit einer List zu Josaphat in den abgeschirmten Palast gelangen. Er verkleidet sich als Kaufmann und erklärt einem der heidnischen Lehrer des Prinzen, er habe einen über alle Maßen kostbaren Edelstein für diesen. Nur wer reinen Herzens sei, dürfe ihn sehen, er bringe Erlösung, Trost und Erkenntnis (BJ 1470 -1490). Als der Meister den Stein sehen will, um sich ganz überzeugen zu lassen, erwidert Barlaam, dass er dessen Kraft nicht gewachsen sei. Davon lässt sich der Fragende überzeugen und bekennt seine eigene Sündhaftigkeit, gibt aber dem tugendreichen Josaphat bereitwillig das Gesagte weiter. Die Erklärung für dieses offensichtliche Missverstehen ist als Erzählerwissen auf eine einprägsame Formel gebracht:

\footnotetext{
Die rede er weltlich verftuont, als ie diu kint der welte tuont. der bezeichenunge hort erkande er niht. [...] (BJ 1545-1548)
}

In seiner rein immanenten Weltsicht kann der Heide - anders als das christliche Publikum, das diese überwunden hat, so die extradiegetische Funktion dieser Situation - den Edelstein nicht als Bild für den Glauben sehen, weil sich ihm der Wortsinn nicht auf die Transzendenz hin öffnet. ${ }^{275}$ Damit ist die antithetische Struktur von irdischem Trug und geistlicher Wahrheit auf einen Erkenntnisprozess bezogen, in dem sich die Konversion zum christlichen Glauben vollzieht. Die Einsicht in die wahre Natur der Dinge beruht auf dem rechten Verständnis der bezeichenunge, das nicht beim weltlichen, heidnischen Verstehen stehenbleibt. Die Erschließung der verhüllten Wahrheit über das bezeichenliche Sprechen wird hier in actu dargestellt und dabei in ihren Funktionsmechanismen reflektiert. Sie erschließt dabei ,jene[n] Bereich der doppelbödigen Aussage, des mehrdeutigen Sprechens, des Metaphorischen, der für die mittelalterlich-christliche Hermeneutik und Schriftexegese konstitutiv ist“ . ${ }^{276}$ In diesem epistemologischen Modell liegt der Kern der lêre, der tief ins Syntagma der Erzählung eingeprägt ist: „Offenbar ist genau dieser Dualismus, der das Seiende in

275 Vgl. ebd., S. 125-126.

276 Vgl. Christian Seebald: ,Hermeneutischer Dialog‘ Rudolfs von Ems Barlaam und Josaphat und die Lehre von der bezeichenunge. In: Sprechen mit Gott. Redeszenen in mittelalterlicher Bibeldichtung und Legende. Hrsg. von Nine Miedema, Angela Schrott, Monika Unzeitig. Berlin 2012 (Historische Dialogforschung. 2), S. 285-306, hier S. 286, Zitat ebd. 
eine Abhängigkeit zu Gott setzt, nicht nur eine Art Weltmodell, das hinter den Gleichnissen steht, sondern vielmehr sogar ein Strukturprinzip des Romans.“277

Die notwendige Einsicht in die Vergänglichkeit des Irdischen und die daraus folgenden Konsequenzen werden zunächst exemplarisch in den sich anschließenden vanitas-Parabeln durchgespielt, die als festes Korpus charakteristisch für den Stoff sind. Die erste besteht aus der Verknüpfung zweier Elemente, Todesposaune und Kästchengleichnis, im Exempel vom ernsthaften König:

Ein König wirft sich zwei zerlumpten Armen zu Füßen und verehrt sie in jeder Weise. Als ihn die großen des Reichs und sein Bruder darob tadeln, zeigt er diesem, welche Angst den Menschen angesichts des Todes befällt, und weist jenen nach, daß sie nach dem äußeren Augenschein urteilen; Überzeugungsmittel sind dabei die ,Todesposaune‘, die Gericht und (Todes-) Urteil ankündet [...], und ,vier Kästchen', von denen zwei vergoldete moderndes Totengebein und zwei mit Pech bestrichene Edelsteine, Perlen und duftende Salben enthalten [...] Beide Motive illustrieren die Lehre vom richtigen Sehen, daß man nicht auf das Äußerliche achten, sondern nach innen blicken soll, um die Boten Gottes, die zum Gericht rufen, fürchten zu lernen und die Sünden als Ursache des Todes zu erkennen. ${ }^{278}$

Dieses Motivgeflecht hat eigenständig eine weite Verbreitung in der mittelalterlichen Literatur gefunden, hier ist es indes funktional ganz eingebunden, wenn Barlaam die Erzählung mit den Worten eröffnet: ,Des wil ich dich gelîchen / einem künege rîchen“ (BJ 1691-1692). Noch bevor es um die Vermittlung von konkretem Heilswissen geht, vergleicht Barlaam, die erfolgreiche Unterweisung vorwegnehmend, seinen Schüler mit dem weisen König des Gleichnisses: ,dem herren guot gelîche ich dich. / daz dû fô wol enphienge mich / ûf guoter gedinge wân` (BJ 1933-1935). Die Bedeutung der vier Schreine wird zudem noch in der Parabel selbst durch den König ausgelegt und damit Josaphat wie dem Rezipienten dargelegt: ,iu fint diu dinc niht vürbaz kunt / wan als iuwer ouge fiht“ (BJ 1892-1893) und ,Ich wil iuch hie befcheiden“ (BJ 1897). Daraufhin fragt Josaphat nach Barlaams Herrn und wird, wie oben dargestellt, in der Heilsgeschichte unterwiesen.

Ähnlich eingebunden sind die Parabeln, die sich daran anschließen, wie die vom Einhorn, das einen Mann, der exemplarisch dirre welte volger (BJ 4603) darstellt, in eine Grube treibt. Der Verfolgte kann sich an einem dürren Ast festhalten und auf einen kleinen Vorsprung stützen, während zwei Mäuse an den Wurzeln nagen, ein Drache unter ihm Feuer speit und vier giftige Schlangen den Boden zu seinen Füßen untergraben. Als er von seinem Ast Honigseim fließen sieht, vergisst er seine Not und lässt sich diesen in den Mund tropfen. Das geschilderte Geschehen wird Josaphat von Barlaam sogleich allegorisch ausgedeutet, indem dieser nach dem Schema ,der ein-

277 Gottfried Kerscher: Barlaam und Josaphat. Überlegungen zur Bildwürdigkeit der Askese im Mittelalter. In: Das Mittelalter 15, 1 (2010), S. 66-81, hier S. 72.

278 Jürgen Stohlmann: Orient-Motive in der lateinischen Exempla-Literatur des 12. und 13. Jahrhunderts. In: Orientalische Kultur und europäisches Mittelalter. Hrsg. von Albert Zimmermann, Ingrid Craemer-Ruegenberg. Berlin/New York 1985 (Miscellanea Mediaevalia. 17), S. 123-150, hier S. 142. 
hürne dêft der tôt, / der mit ängeftlîcher nôt / allez menschenkünne jaget‘ (BJ 4713-4715) jedes Element in seiner übertragenen als der eigentlichen Funktion benennt, wobei der Honig der welte unftætiu füeze (BJ 4748) meint, und auf die allgemeine Erkenntnis zielt: , hie fî̀ dir bilde bî gegeben, / daz dû dirre welte leben / rehte erkenneft, wie fie ftât. ' (BJ 4753-4755) Josaphat bekräftigt den Wert diese Unterweisung in Gleichnissen:

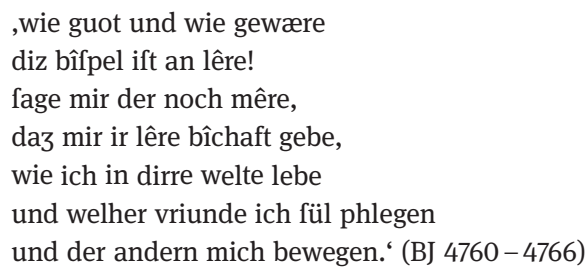

Erfolgreiche Vermittlung von lêre, als Erkenntnisprozess, der zur Konversion führt, vollzieht sich also im Erzählen, der konkretisierenden Auslegung und im verstehenden Hören der Parabeln. Diese gehen dabei inhaltlich ineinander über, indem sie auf die Nachfragen Josaphats antworten und dessen fortschreitenden Erkenntnisprozess widerspiegeln. So zufällig und austauschbar ihre Reihenfolge auch scheint, so werden sie doch geschickt miteinander verknüpft und auf ein einheitliches Ziel hin ausgerichtet: die Weltabkehr des Unterwiesenen.

Entsprechend schließt die direkt folgende Parabel an die Frage nach den rechten Freunden an. Denn in ihr bittet ein in Not geratener Mann drei Freunde um Hilfe. Die beiden ersten stehen sinnbildlich für Besitz und Macht sowie die Verwandtschaft, der dritte und vernachlässigte aber für die guten Werke, und nur dieser letzte steht ihm bei. Josaphat erkennt daran, ,wie ich die welt erkennen fol' (BJ 5031). Er will aber genauer wissen, ,wie man fîfô lâze / daz man von ir ficher var / mit unverirten vreuden gar` (BJ 5038-5040), und Barlaam antwortet ihm mit der Geschichte vom Einjahreskönig, die für die Vergänglichkeit irdischer Macht und Reichtums steht, gleichzeitig aber die Bedeutung der wahren Schätze, im übertragenen Sinne der Almosen, anschaulich macht. Ein guter Ratgeber offenbart nämlich dem König der Parabel, dass er nach Jahresfrist von seinen Untertanen auf eine Insel ins Elend gejagt werden wird, und dieser sorgt daraufhin vor, indem er Schätze dorthin bringen lässt. Mit diesem Ratgeber vergleicht Barlaam sich selbst:

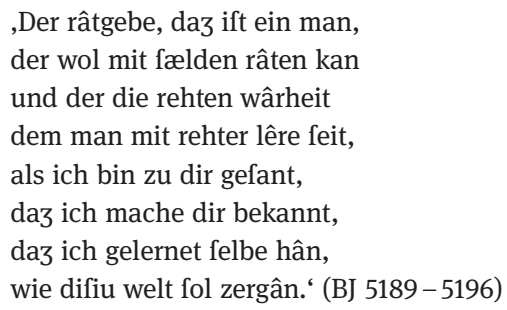


Barlaams Aufgabe erscheint hier also im Gleichnis: Die lêre, die er selbst gelernet hat, soll er an Josaphat weitergeben, und ihr Kern ist die Vergänglichkeit der Welt und die Besinnung auf die wahren Schätze, mithin die Notwendigkeit zur conversio. Dafür nun ist Barlaam nicht nur Lehrer, sondern Vorbild: ,der welte rîcheit unde ir guot / liez ich unde ir armuot / und kêrte an got mînen muot‘ (BJ 5257-5259).

Immer enger werden die Gleichnisse auf diese Weise von Barlaam auf Josaphat bezogen. So lässt er ihn seinen Willen bekräftigen, seine Lehre wie sein Leben als vorbildhaftes Beispiel zu nehmen:

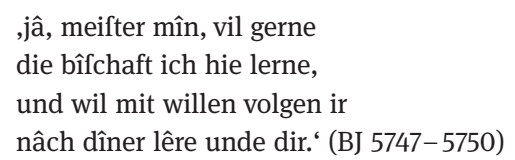

Josaphat drängt es nun zur konsequenten Verwirklichung der lêre auf Grund der Einsicht in die Vergänglichkeit und den falschen Schein der Welt, die ihm Barlaams Unterweisung eröffnet hat. Der entsprechende religiöse Vollzug ist mit dem Beispiel der Märtyrer und Anachoreten schon zu Beginn idealtypisch dargestellt und gewinnt schließlich mit dem Vorbild Barlaams eine konkrete Gestalt. Auf die Frage Josaphats nach seinem Alter antwortet er ihm mit der Unterscheidung zwischen einer körperlichen und einer geistlichen Lebenszeit, deren letztere allein dem Leben Sinn verleiht und für ihn erst mit seinem anachoretischen Dasein auf der Insel Sennaar begonnen

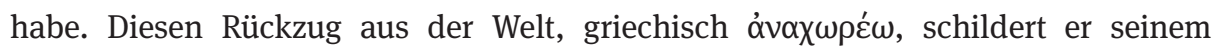
Schüler - ganz in der christlichen Dialektik der Fremdheit, als zur Buße der Sünden und Wiedereingliederung in die göttliche Ordnung von jedem Christen zu vollziehende Abkehr von der Welt ${ }^{279}$ - als Hinwendung zum wahren Leben, weil das weltliche Leben als ein sündhaftes dem Tod geweiht sei (BJ 6283-6290). Barlaam muss ihm weiter über den entbehrungsreichen Alltag der Einsiedler und Anachoreten berichten, wie sie in völliger Armut nur von dem leben, was ihnen Gott in der Natur oder durch Almosen gibt, und welches einfache und raue Gewand sie tragen. Anschaulich wird all das an Barlaam selbst, denn sein Körper trägt die Spuren der Askese und Kasteiungen, die der Rezipient mit Josaphats Blick mitverfolgen kann: dô fach Jôfaphât an in (BJ 6484). Josaphat will nun, wie es folgerichtig scheint, nach seiner Taufe Barlaams Vorbild und Lehre ganz folgen, doch wehrt dieser entschieden ab:

,dâ von ift mîn lêre,

daz dû belîbeft, niender varft,

und mit dem toufe dich bewarft,

und wis ein bredigære gotes,

unde ein lêrer fîns gebotes,

wan dûs gar gewaltic bift:

279 Vgl. oben in Kap. 5.1.1 Konversion als Grundmuster christlicher Identitätsbildung, S. 271. 
alhie fô kreftic niemen it, der wider dir getürre fîn.' (BJ 6568-6575)

Die Irritation, die eine solche Ablehnung nach einer langen Unterweisung über die Notwendigkeit einer asketischen, wenn nicht sogar anachoretischen Existenz verursachen muss, wird aber zugleich in einer höheren Logik aufgefangen: Josaphat soll zunächst ein Prediger Gottes sein, bevor er sich aus der Welt zurückziehen darf, denn alle Menschen müssen die christliche Lehre hören können: ,Den gotes touf enphâhen / und fînem zeichen nâhen, / daz fol niemen fîn erwert.' (BJ 6613-6615) Neben dem asketischen und anachoretischen Grundmotiv in der Glaubensunterweisung Barlaams findet sich auch schon davor an einigen Stellen die Aufforderung zur Verbreitung der christlichen Lehre: Als Josaphat fragt, warum nicht alle die lêre von der Nichtigkeit des Irdischen und den wahren Schätzen annehmen, ob sie überall gelte und sich auch sein Vater bekehren werde, sagt ihm Barlaam voraus, dass ihm dieser noch zum geistlichen Kind werde, wenn er ihm das wahre Leben zeige (BJ 5489-5496). Außerdem erzählt Barlaam ihm ein Gleichnis von der Bekehrung eines Königs, das er ausdrücklich auf Avenier bezieht (BJ 5704-5705). Und als Josaphat sich auf das Gleichnis vom jungen Edelmann hin gehorsam dem Willen und der Lehre seines Meisters übergibt, wünscht dieser, ,daz dû der boten fîft genôz / und der vil reinen wîsfagen‘ (BJ 6126-6127).

Die Worte Barlaams, Josaphat solle bleiben, sind insgesamt also nicht so zu verstehen, als ob er ihm als Fürstensohn grundsätzlich und dauerhaft eine andere Lebensform zumessen würde, etwa weil er ,auf Grund seiner Stellung in der Welt ,christlicher' leben und mehr für Gott und für sein Seelenheil tun [könne] als als Eremit“. ${ }^{280}$ Der Genitiv von ,wan dûs gar gewaltic bift ${ }^{\star}$ (BJ 6573) bezieht sich unverkennbar auf die Josaphat zugemessene und in der göttlichen Providenz abgesicherte Rolle, ,bredigære` und ,lêrer ${ }^{`} \mathrm{zu}$ sein: Als Herrscher kann Josaphat am besten die Ausbreitung des Glaubens befördern und allein darauf hin ist seine Herrschaft als ,Mittel zum Zweck` entworfen und zeitlich begrenzt. ${ }^{281}$ Barlaam hat seine Ablehnung außerdem schon zuvor mit einem Gleichnis begründet, in dem ein reicher Mann ein Rehkitz bei sich aufzieht, das dann aber mit seinesgleichen ziehen will, woraufhin er seine Knechte die Herde verjagen, etliche Tier töten und das eine endgültig einsperren lässt. Aus Barlaams Mund versteht sich das als Warnung, Josaphats sofortiger Weggang mit ihm würde nur zur Verfolgung der Christen oder Eremiten führen, bei der für den Glauben am Ende nichts gewonnen wäre. Damit aber ist die Anachorese nicht grundsätzlich abgewertet, wie in der Forschung immer wieder diskutiert worden ist, ${ }^{282}$ vielmehr ergibt sich ein Nacheinander zweier Aufgaben, die beide eine je spezifische

280 Rupp, Rudolfs von Ems Barlaam und Josaphat, S. 18.

281 Vgl. Brackert, Rudolf von Ems, S. 217.

282 So beispielsweise Schnell, Rudolf von Ems, S. 88. 
Form des Vollzugs der christlichen lêre und folgerichtigen Konversion darstellen, deren jede ihre Zeit hat. So fährt Barlaam fort:

\author{
,daz rât ich, lieber herre mîn: \\ fô danne got vüege dir \\ die rehten zît, fô kum ze mir, \\ da ich mich dîn geniete. \\ fwie daz got gebiete, \\ daz wir behalten unfer leben, \\ des fuln wir im volge geben, \\ wan ich gedinge an gotes kraft, \\ daz uns ein gefellefchaft \\ mit vrœlîcher ftætekeit \\ ze himelrîche fî bereit. ' (BJ 6576-6586)
}

Gott entscheidet über die Aufgaben der beiden Protagonisten, wird sie aber am Ende wieder zusammenführen, so die Verheißung. Dass Josaphat Barlaam nicht gleich folgen kann, erklärt sich dabei auch aus den Erfordernissen legendarischen Erzählens: Dem Heiligen müssen Bewährungen auferlegt sein, in denen sich seine Tugendhaftigkeit zeigen kann, denn sie kann nicht einfach postuliert, sondern muss narrativ dargestellt werden; dazu aber bietet sich der Kampf gegen Heidentum und innerweltliche Versuchungen viel stärker an als Askese und Anachorese, die ungleich schwerer darstellbar sind, weil sie immer einen Verzicht darstellen, der aber nicht das Eigentliche ist, und daher in ihrer Beschreibung immer etwas gezeigt werden muss, was nicht ist. ${ }^{283}$ Eine Konversion kann nicht einfach mit der Taufe abgeschlossen werden, sondern muss sich ,in der Welt‘ verwirklichen, wozu sich am besten eine Umkehrung der Rollen anbietet, in der der Bekehrte nun seinerseits zum Bekehrer wird. Dazu bietet sich im Falle eines Herrschers die Mission seines Volkes an, ja sie erscheint geradezu als notwendige Aufgabe. Mit diesem Auftrag tauft Barlaam daher den Prinzen, bevor er Abschied nimmt.

\title{
5.3.3 Der Bekehrte als Bekehrer: Josaphats Mission und Anachorese
}

Die Disputation mit den verschiedenen heidnischen Religionen über den wahren Glauben (BJ 9159-10982) stellt gegenüber der nichtchristlichen Stofftradition einen Einschub dar. Vom inhaltlichen Anspruch her ist diese Episode zunächst fremd, denn es geht hier nun nicht mehr um einen christlich-asketischen Lebensvollzug, sondern um die dogmatische Auseinandersetzung mit dem Heidentum. Zudem scheint ihre narrative Relevanz und Einbindung gering: Zwar handelt es sich zunächst um eine List

283 Die Heiligkeit von Anachoreten und Asketen erweist sich deshalb auch nicht in Anachorese und Askese selbst, also in der Wirksamkeit ihres, eigentlichen“ Tuns, sondern in Visionen und Wundern, die sich zu Lebzeiten durch sie oder nach ihrem Tod an ihrem Grab ereignen. 
Aveniers, der seinen Sohn vom Christentum abbringen will, indem er einen falschen Barlaam auftreten lässt, der gegenüber den Heiden unterliegen soll. Doch bekehrt sich Nachor schon vorher zum christlichen Glauben und kann so die Lehre der anderen Religionen widerlegen. Damit aber ist das intradiegetische Ziel vorweggenommen und der Disput scheint auf eine breite Darlegung theologischer Aussagen hinauszulaufen, ${ }^{284}$ die sich vom Weg der beiden Protagonisten löst und mehr der Belehrung und Selbstvergewisserung des extradiegetischen Publikums dient.

Dennoch bildet der Religionsdisput einen integralen Bestandteil der Erzählung: Mit der vorangegangenen Glaubensunterweisung ist er im Grundmotiv der ScheinSein-Problematik verbunden, denn auch er handelt von der Einsicht in die wahre Natur des Materiellen und der irdischen Welt als dem rechten Verständnis der bezeichenunge. Die Kritik an den heidnischen Göttern zielt dabei immer auf die Frage nach dem, was sie aus christlicher Sicht eigentlich sind, nämlich Abgötter, also nicht wahrhaft göttlich, weil geschaffene Dinge oder Wesen. Das Gespräch zwischen Barlaam und Josaphat, insbesondere das Edelsteingleichnis, wird so zum Muster für die umfassende Konfrontation des christlichen Glaubens mit dem Heidentum. ${ }^{285}$ Es geht also um die diskursive Wahrheit der christlichen Lehre, die sich in ihren spezifischen Inhalten erweisen muss, weshalb der Disput auch nicht wie im Fall der Silvesterlegende über ein Wunder als ultima ratio, sondern allein durch die Argumentation entschieden werden kann. ${ }^{286}$

Denn der Vorwurf Zardans, der den König von der Bekehrung und Taufe seines Sohnes berichten muss, die er als Palastaufseher nicht hat verhindern können, gegenüber der Lehre und den Vertretern des Christentums ist schwerwiegend und bezieht sich auf den Geltungsstatus der christlichen lêre überhaupt: Barlaam sei ein ,zouberære‘, der Josaphat ,mit finer lüge‘ (BJ 7561 und 7562) verführt habe. Die Frage nach der Wahrheit ist zudem eine nach den Grenzen menschlicher Autorität, wenn Avenier den jungen Prinzen mehrfach auffordert, ihm den gebotenen Gehorsam als Sohn zu erweisen und seiner Lehre zu folgen: , lâ dir die valfchen lêre fîn / unwert unde unmære gar / und nim mîner lêre war.‘ (BJ 8246-8248) Josaphat versucht seinerseits, den Vater zu überzeugen und bekennt seinen christlichen Glauben, der allein wahres Leben verheiße, während die heidnischen Götter nur Abgötter seien, ,gegozzen unde gefniten، (BJ 8361). Die göttliche Wahrheit wertet er letztlich höher als den Gehorsam gegenüber dem Vater. In dieser Konfrontation zweier Autoritätsbehauptungen soll der anberaumte Glaubensdisput verbindliche Klarheit für beide Seiten bringen, wie

284 Vgl. Ulrich Wyss: Rudolfs von Ems Barlaam und Josaphat zwischen Legende und Roman. In: Probleme mittelhochdeutscher Erzählformen. Marburger Colloquium 1969. Hrsg. von Peter F. Ganz. Berlin 1972 (Publications of the Institute of Germanic Studies. 13), S. 214-238, hier S. 226.

285 Vgl. Salvan-Renucci, Heidentum und christliche Theologie im Barlaam und Josaphat Rudolfs von Ems, S. 133.

286 Vgl. Rupp, Rudolfs von Ems Barlaam und Josaphat, S. 35. Die wundersame Bekehrung Nachors wäre dann nur als narrativer ,Gegentrick` zu sehen, der es überhaupt erst möglich macht, dass sich die christliche Wahrheit - entgegen der heidnischen List Aveniers - in der Argumentation erweisen kann. 
Avenier fordert: ,fwer dâ gefiget, des lêre ift guot; / dem volgen beide, dêft mîn muot. (BJ 8891-8892).

Das Streitgespräch läuft aber nicht nur auf ein definitives Urteil angesichts zweier entgegengesetzter Wahrheitsansprüche hinaus, sondern mit dem Glauben wird zugleich die Frage nach der richtigen Lebensform entschieden. Denn das asketische Armutsideal, wie es in Barlaams Vorbild und Unterweisung untrennbar mit der christlichen Lehre verknüpft ist, steht der höfischen Bestimmung Josaphats entgegen. Akzentuiert und dramatisch zugespitzt wird diese Entscheidungssituation, wenn Josaphat dem vermeintlichen Barlaam Gewalt und einen schändlichen Tod androht, falls dieser im Disput unterliegen und sich seine Lehre ihm gegenüber als Lüge und Verführung erweisen sollte: ,fô mac dich dîn valfcher got / des behüeten niht vor mir / ich reche mînen zorn an dir' (BJ 9082-9084). Dabei erinnert er ihn daran, ,in welher rîcheit ich was`(BJ 9024), bevor Barlaam ihm den Reichtum der Welt als einen falschen erklärt habe. Josaphat scheint als noch nicht völlig überzeugt, seinen neuen Glauben unter allen Anfechtungen zu behaupten, wie es das Legendenschema im Sinne des Bekenner- oder Märtyrertypus erwarten lassen würde, zumal bei der vergeblichen Suche nach Barlaam zuvor etliche Christen bereitwillig Marter und Tod auf sich genommen haben, um diesen und ihren Glauben nicht zu verraten (BJ 7759-7938). Seine Konversion muss sich erst noch in der Konfrontation mit dem Heidentum bewähren und nichts scheint dazu - was die Ebene der diskursiven Vermittlung von christlichem Heilwissen betrifft - besser geeignet als ein Religionsdisput, der die Wahrheit ein für alle Mal und für alle verbindlich erweisen soll.

Urheber der christlichen lêre ist hier nun wiederum Gott selbst: Der heidnische Zauberer begibt sich in eine aussichtslose Lage, indem er einwilligt, die Rolle Barlaams zu übernehmen, weil ihm nun in jedem Fall Gewalt droht, egal welche Seite er gewinnen lässt. Entweder er muss dafür büßen, dass er Aveniers Auftrag nicht erfüllt, oder er erleidet Josaphats Strafe, die eigentlich dem richtigen Barlaam und seiner Lehre gelten würde. Angesichts dieser Situation entscheidet sich Nachor, wenigstens der wârheit kemphe (BJ 9124) sein zu wollen, und macht sich damit zum Werkzeug Gottes, wobei menschlicher Entschluss und göttliche Gnade wiederum in enger Wechselwirkung stehen:

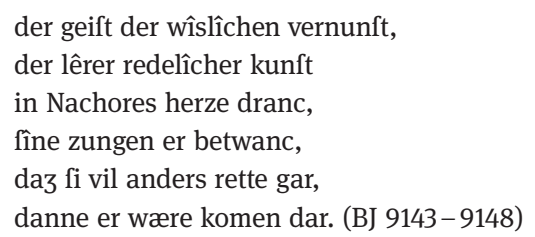

Er wird zu gotes wîgant (BJ 9665), der nicht einfach passiv bleibt und sich überwinden lässt, sondern seinerseits die heidnischen Gelehrten herausfordert. Der Ablauf des Religionsdisputs ist bei Rudolf von Ems dialogisiert und auf diese Weise dramatisiert, denn während er in der lateinischen Vorlage als ein langer Monolog des christlichen Streiters gestaltet ist, besteht er bei Rudolf in vier Reden Nachors und drei Gegenreden 
der Heiden. ${ }^{287}$ Damit wird wohl die geschlossene Form der Bekenntnis- und Verteidigungsrede des verfolgten Heiligen der Märtyrerlegenden aufgegeben, dafür aber das didaktische und narrative Potential eines Religionsdisputes ausgeschöpft: Auch wenn der Sieg des christlichen Glaubens zwangsläufig ist, müssen sich seine Argumente als richtig und überlegen erweisen und seine Lehren anschaulich gemacht werden - auch in Nachors Widerlegung der verschiedenen heidnischen Irrlehren zeigt sich „die Überzeugungskraft der Botschaft in actu, weil er - so hat es Rudolf gegenüber der Quelle eingeführt - jeweils mit einem der Religionsvertreter disputiert“. ${ }^{288}$

Die heidnischen Religionen stehen dabei in einem ständigen Rechtfertigungszwang gegenüber dem universalen Anspruch des Christentums, dem sie in ihrer Widerlegung letztlich Stichwortgeber für seinen überhöhenden Triumph sind. Dem liegt als hermeneutisches Modell „das typologische Verhältnis von Heidnisch-Hinweisendem und Christlich-Erfüllendem“ zugrunde, in dem die christliche Offenbarung jeden „menschlicher Teilerkenntnis entstammende[n] Glaubenssatz der Heiden“289 aufgreift und überwindet. Inhaltlich-argumentativ entspricht das Dargestellte dem in der Tradition vorgegebenen Typus von Religionsdisputen und dem durch sie im Mittelalter verfügbaren ,interreligiösen' Wissen, denn es geht zurück auf die frühchristliche Apologie des Aristides aus dem 2. Jahrhundert, die als die älteste erhaltene Apologie des Christentum gilt. ${ }^{290}$ Als solche ist ihr Charakter kein mit Nachdruck polemischer oder missionarischer, sondern sie soll den christlichen Glauben einem philosophisch gebildeten heidnisches Publikum in dessen eigenen Kategorien darstellen und befördert damit auch die Selbstvergewisserung der Christen, die ihren Glauben als logische Konsequenz der Suche nach religiöser Wahrheit sehen können. ${ }^{291}$

Der Gang der Argumentation ist bei Rudolf der folgende: Der Himmel, den die Chaldäer anbeten, hat Anfang und Ende, ist als Kosmos von Gott geordnet, also von ihm geschaffen. Auch die Elemente wie Feuer und Wind, Sonne sind unbeständig, also nicht letztes Prinzip und daher ,gotes handtgetât‘ (BJ 9621) und nicht mit ihm zu verwechseln. Das Schweigen der heidnischen Meister gegenüber dieser Beweisführung wird hier wie auch später immer wieder als Sieg für Nachor gedeutet. Den An-

287 Vgl. Czizek, Rudolfs von Ems Barlaam und Josaphat und seine lateinische Vorlage, S. 22.

288 Mertens, Langweilige Heilige - heilige Langeweile?, S. 264.

289 Roy Wisbey: Zum Barlaam und Josaphat Rudolfs von Ems. In: ZfdA 66 (1955/56), S. 293-301, hier S. 298.

290 Diese wurde die dem griechischen Barlaam-Roman einverleibt und ist überhaupt nur in diesem in seiner griechischen Fassung überliefert. Vgl. Peri, Der Religionsdisput der Barlaam-Legende, S. 30 - 31. $291 \mathrm{Zu}$ dieser Apologie vgl. Susanne Hausammann: Alte Kirche. Zur Geschichte und Theologie in den ersten vier Jahrhunderten; Bd.1: Frühchristliche Schriftsteller: ,Apostolische Väter', Häresien, Apologeten. Neukirchen-Vluyn 2001, Kap. 3.2.1, S. 170 -175, die (S. 175) zusammenfasst, die Apologie des Aristides sei „eine äußerst gekonnte und treffsichere Werbeschrift, die ohne Weitschweifigkeiten und mit voller Einhaltung der Arkandisziplin präzise und klar alle nötigen Informationen für einen Vergleich zwischen den im römischen Reich gesellschaftlich relevanten Religionen und dem Christentum liefert und dabei die Punkte zur Sprache bringt, die auch für einen heidnischen Philosophen jener Zeit bedenkenswert sein müssen“. 
spruch der Griechen, die die Machtbereiche ihrer Götter vorbringen, wehrt er mit dem euhemeristischen Vorwurf ab, dass es sich bei diesen letztlich um Menschen handele, die mit ihren Zauberkünsten beeindruckten und an sich glauben machten. Dazu kommt der Vorwurf ihres allzu menschlichen, niederträchtigen Verhaltens, wofür besonders die Liebesaffären des Zeus angeführt werden. Außerdem müsse Gott ein Mann sein (BJ 10256-10259), wodurch mit einem Schlag alle weiblichen Gottheiten widerlegt sind. Wieder geht es um Schein und Sein und die Frage nach der wahren Natur der Dinge, wenn es über Zeus und sein Geschlecht heißt, sie wären ,Sôdômîten, / roubære und zouberære / und valfche trügenære (BJ 10036-10038), die Vorbilder zur Sünde abgeben. Auch die Äypter bekennen ihre Götter, die Nachor wiederum als Menschen entlarvt, wobei vor allem das inzestuöse Verhältnis der Geschwister Osiris und Isis als Beleg für ihre nicht-göttliche Natur angeführt wird (BJ 10465-10469, 10487-10492), denn Gott muss in allem vollkommen, die unvollkommene Schöpfung kann nicht Gott sein.

Längst führt Nachor das Gespräch und nachdem er Chaldäer, Griechen und Ägypter widerlegt hat, kommt er zu den Juden, deren Glauben er verhandelt, ohne dass sie als Disputanten auftreten. Der lêre Gottes steht die Untreue des Volkes Israel gegenüber, das das Goldene Kalb anbetet, die Propheten missachtet und schließlich den Messias verkennt und damit endgültig vom Glauben abfällt. Mit dem falschen jüdischen Glauben ist der Übergang zur christlichen Wahrheit gelegt, die sich vor diesem Hintergrund herausstellen lässt, denn der Disput mündet in eine Verkündigung des Glaubens der Christen, die der wahren lêre folgen: Allein ,fie fint ungelouben $v \hat{\imath}^{\varsigma}$ (BJ 10797), denn sie glauben an den allmächtigen und lebendigen Gott, der in Christus Mensch geworden ist und so Wahrheit verbürgt:

,Die kriften triegent fich niht.

ir geloube in des vergiht,

da3 Krift ûf der erde hie

mit lêre zeichen vil begie.

Des vaters lêre er lêrte,

diu apgot er verkêrte. (BJ 10825-10830)

Diese Lehre, die sich in den zwölf Boten bis nach Indien verbreitet hat, ist richtig und gut, weil Christus, ir lebennes lêrære, / ift guot, reht und vil gewære“ (BJ 1087910880) - ihm und seiner lêre, die er verkündet und verkörpert hat, folgen die Christen, denn sie führt zur wahren Freude, zur Erlösung und zum ewigen Leben.

Wenn schließlich die Inhalte des christlichen Lebens in kurzen Punkten angeführt werden: Nächstenliebe, Barmherzigkeit, Abkehr von aller Zauberei, Feindesliebe, fällt auf, dass Askese und Armut hier keine Rolle spielen. Im Disput geht es also letztlich um eine andere Frage, nämlich die dogmatische Wahrheit der christlichen lêre: Weil Christus ,ein got mit gotlîcher kraft / und ein fchepher aller gefchaft‘ (BJ 10959-10960) ist, sollen sich alle $\mathrm{zu}$ ihm bekehren, um nicht verloren $\mathrm{zu}$ gehen. Nachors Rede schließt mit einer rhetorischen Kimax auf den christlichen Schöpfer, deren letzte, lateinische Worte ,dâ lebet diu gots efsentiâ / per infinit â feculâ‘ (BJ 10979-10980) an 
„traditionelle Predigtklauseln“ anklingen und damit die inhaltliche wie performative Bedeutung des Religionsdisputs in einen Appell an den Hörer münden lassen. ${ }^{292}$

Mit dieser Apologie des christlichen Glaubens müssen sich der König und seine Getreuen geschlagen geben, doch ist ihre intradiegetische Funktion damit noch nicht erschöpft, denn Nachors Widerlegung des Heidentums ist Ausdruck der Wirksamkeit der christlichen lêre, wie sie mit Barlaams Paränese an Josaphat begonnen hat. Nun ist es Josaphat, der Nachor, dessen Verstellung er durchschaut hat, im christlichen Glauben unterweist und damit die spontan vollzogene innere Bekehrung in dessen diskursiven Kategorien als Konversionsgeschehen verstehbar macht. Nachor selbst stellt in seiner Antwort an Josaphat seine Bekehrung als Erkenntnisprozess dar: ,fwa3 kriftenman gelouben fol', das habe er immer schon geglaubt, ,wan ich an manegen buochen las, / fwaz trügelich unde gewære was‘ (BJ 11145 und 11146-11147), womit zugleich seine profunden dogmatischen Kenntnisse im Disput immanent plausibilisiert werden, doch sei er noch verstockt gewesen:

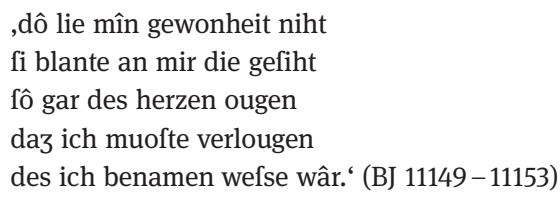

Die gläubige Annahme des im Studium der Bücher erworbenen Heilwissens bleibt also auch im Kontext der als Erkenntnisprozess verstandenen Konversion des heidnischen Meisters in Gottes Ratschluss transzendent begründet (BJ 11135-11190), der Religionsdisput damit ein Offenbarungsgeschehen im göttlichen Heilshandeln. Dieses erweist sich weiterhin an Nachor, der nun, da er zur Buße und Umkehr zu Gott bereit ist (BJ 11161-11190), vollends die verwandelnde Kraft des christlichen Glaubens erfährt und ein heiliger man wird: die kriftenheit er began / nâch kriftenlîchen êren / mit rehten werken lêren (BJ 11261 und 11263-11264).

Josaphats Konversion muss sich aber noch auf einer weiteren Ebene bewähren, denn sie besteht ja eben nicht nur in der äußeren Dimension des Glaubenswechsels, sondern gleichzeitig in der Entscheidung für einen asketischen Lebenswandel. Die Frage der Religion ist also mit jener nach der Geltung der höfischen Lebensweise verknüpft, der Josaphat sich, nun noch bestärkt durch das Ergebnis des Religionsdisputs, entzieht:

fwaz iemen kurzewîle treip,

tanz, buhurt oder fpil

und ander kurzewîle vil,

daz was im gar als ein fpot.

fîn kurzewîle was, daz er got

fîner gnaden bat. (BJ 11266-11271)

292 Vgl. Peri, Der Religionsdisput der Barlaam-Legende, S. 67, Zitat ebd. 
Nachdem Aveniers Versuch, seinen Sohn durch einen betrügerischen Religionsdisput von seiner lêre zu überzeugen, gescheitert ist, folgt nun konsequenterweise die Versuchung Josaphats in ebendieser Enthaltsamkeit: Die Konversion zur christlichen lêre muss nach deren dogmatischem Sieg jetzt im asketischen Vollzug ihre Wirksamkeit erweisen. Angesichts seiner Niederlage im Disput lässt Avenier seine heidnischen Gelehrten im Zorn geißeln, blenden und nackt durch die Straßen jagen und versagt seinen Göttern die Opfer, woraufhin der Zauberer Theodas auf den Plan tritt und ihn an die heidnischen, höfisch codierten Feste erinnert:

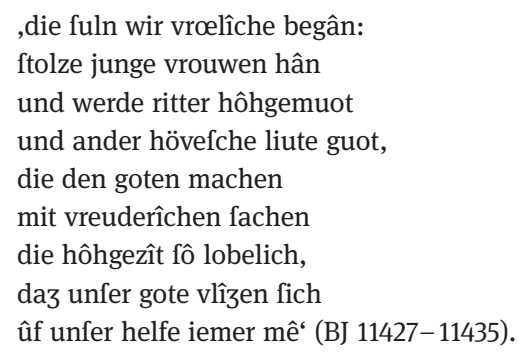

Die heidnische Religion ist nicht einfach nur der Glaube ist, der an Aveniers Hof vorherrscht, sondern eine ,höfische Religion', insofern sie ihre Wirksamkeit nur in und durch eine höfische Welt erweist. Darin liegt die Bedeutung von Theodas' Plan: Die ,juncvrouwen, fchœene und wolgetân' (BJ 11561), die Josaphat versuchen sollen, bedrohen nicht nur seine Enthaltsamkeit, sondern verkörpern die höfische Werthaltung. Niemand könne der Kraft ,wîplîcher minne‘ (BJ 11577) widerstehen, wie er in einer Parabel ausführt, die als diabolische Spiegelung der christlichen Unterweisung Barlaams zu verstehen ist und die Schein-Sein-Problematik verkehrt: Ein Königssohn, der erst mit zehn Jahren die Welt sehen darf, hält die Frauen sogar dann noch für das Schönste, was er je gesehen hat, als ihm jemand sagt, man nenne sie auch den ,tiuvel, der den man / betriegen und verleiten kann` (BJ 11693-11694).

Der König folgt dem Rat und Theodas versucht Josaphat durch Zauberei und Teufelsbündlerei ins Schwanken zu bringen, doch besteht dieser durch Gebet und Gottes Hilfe die Anfechtungen. Als die Prinzessin von Syrien zu ihm geschickt wird, macht er sich angesichts ihrer Jugend und Schönheit Sorgen um ihr Seelenheil und fordert sie auf, sich zu bekehren. Sie lässt sich darauf ein, fordert aber von ihm, eine Nacht bei ihr zu liegen, dann wolle sie sich gleich am nächsten Morgen taufen lassen (BJ 12233-12246). Der Konflikt, den der junge Prinz auszutragen hat, ist also nicht einfach der zwischen höfisch-weltlichem und monastisch-asketischem Frauenbild, sondern letztlich eine geistliche Anfechtung, mit der die Versuchungen Jesu in der Wüste aktualisiert werden und die Berechtigung der Askese in der christlichen Tradition überhaupt zur Frage steht. Denn die Prinzessin erinnert ihn daran, dass es der christliche Glaube nicht verbiete, eine Frau zu haben, im Gegenteil die Patriarchen und sogar Petrus , mit gote wîbe phlâgen, / bî den fie kiufche lâgen“ (BJ 12206-12207). Josaphat beruft sich demgegenüber auf seine Verpflichtung zur Keuschheit, die er mit 
seiner Taufe gegeben habe, ist aber durch ihr Ansinnen in ernsthaftere Zweifel gebracht, als ie getet fin vater ê (BJ 12254).

Es kommt aber zu keiner weiteren offenen Konfrontation, denn Josaphat trägt den Kampf innerlich und geistlich aus, bis seine Standhaftigkeit zu einem weiteren Sieg des christlichen Glaubens gegenüber dem Heidentum führt. Er müht sich in Gebet, Fasten und Kasteiung, bis er eine Traumvision erfährt (BJ 12341-12505), in der er einerseits die himmlische Herrlichkeit, andererseits die ewige Verdammnis sieht, die mit Keuschheit beziehungsweise unkeuschem Leben verbunden sind. Die Legenda aurea deutet diese Vision mit unverkennbar monastisch-klerikaler Polemik gegen die Sündhaftigkeit und Vergänglichkeit der Welt aus: Josaphat erwacht und pulchritudo illius puellae et ceterarum stercore foetidior ei videbatur (LA 2344). ${ }^{293}$ Bei Rudolf hingegen wird er vor Kummer über das Leid der Sünder, das er geschaut hat, krank und will Barlaam in die Wüste folgen, der Fokus liegt wiederum auf einem inneren Geschehen und Erkennen. Avenier erschrickt und verzweifelt ob der Entschlossenheit seines Sohnes, die von Theodas geschickten Teufel müssen fliehen.

In einem letzten Versuch begeben sich Avenier und Theodas zu Josaphat, woraufhin sich ein Glaubensdisput zwischen den letzten beiden entspinnt (BJ 1267313178). Josaphat vertritt nun seinerseits im Disput die christliche Religion, spiegelbildlich zum falschen Barlaam, und bewährt seine Konversion im offenen Streitgespräch mit einem der führenden Heiden. Der Ton wird dabei, gerade im Vergleich zur vorangegangen öffentlichen Disputation, immer aggressiver, wenn Josaphat schimpft: ,finnelôser Thêodâ, / dû bift vil lîhte âne vernunft, / ein tumber efel, âne kunft (BJ 12994-12996) und ihm vorwirft nur ,mit tumben touben mæren“ (BJ 12999) zu argumentieren. Nachdem das Heidentum durch Nachor argumentativ bereits überwunden worden ist, kann ein Festhalten daran nur noch als uneinsichtige Torheit und Böswilligkeit gelten. Allein die christliche lêre umfasse die volle Wahrheit, denn sie gründe in Gott selbst: , alfô hât ez der boten munt / gemachet in der welte kunt. / ir wort, daz fint diu gotes wort‘ (BJ 13091-13093). Dem kann Theodas schließlich nichts mehr entgegensetzen, er wirft sich Josaphat zu Füßen, bekennt Avenier seine und damit auch die finale Niederlage des Heidentums: ,wir fîn an difen ftunden / mit wârheit überwunden' (BJ 13206-13207) und bekundet, Gott habe durch Josaphat zu ihnen gesprochen (BJ 13213-13214). Wie Nachor steht auch Theodas der Weg der Buße und Umkehr - und damit der conversio zur Heiligkeit - offen, er verbrennt seine Zauberbücher und wird nun selbst gote ein predigære (BJ 13302).

Josaphats Konversion - und damit die mit Barlaam begonnene Vermittlung christlicher lêre an die Heiden überhaupt - bewährt sich und erweist ihre Wirksamkeit schließlich in seiner vorbildlichen christlichen Herrschaft und der Mission des ganzen Reiches. Denn als sich Avenier zum zweiten Mal überwunden sieht und keinen Rat mehr weiß, weist ihm einer seiner Fürsten als einzigen möglichen Weg die Teilung des Reiches. Vielleicht, so das heidnisch-weltliche Kalkül, werde der Reichtum Josaphat 
von seinem Glauben abbringen; wenn nicht, läge es immerhin außerhalb der Verantwortung des Königs (BJ 13357-13370). Josaphat nimmt diese Entscheidung im Gehorsam gegenüber seinem Vater an und lässt sich krönen, obwohl er die Gefahr sieht, daz im der welte rîchez guot / von gote drunge finen muot (BJ 13411-13412). Die Königswürde erscheint ihm also eher als ein Hindernis auf seinem asketischen Weg denn als Möglichkeit zur Verbreitung des christlichen Glaubens und seiner eigenen Bewährung, die sie im Folgenden wird - der Gedanke lässt sich also vor allem funktional als Ermahnung des Publikums zu einer geistlichen Gesinnung sehen, die sich aber nicht vom weltlichen Reichtum beirren lässt, ganz so wie sie Josaphat nun verkörpert. Herrschaft und Wirken in der Welt sind somit nicht grundsätzlich negativ konnotiert, sondern werden als göttliche Prüfung verstanden, trotz des weltlichen Umfeldes den Blick stets auf Glaubensdinge gerichtet $\mathrm{zu}$ halten und sich nicht zur Wertschätzung des nichtigen Reichtums verführen zu lassen. ${ }^{294}$

Josaphat findet sich schnell in seine Aufgabe als christlicher Herrscher: Er lehrt seine Untertanen Gottes Wort und führt sie zur Taufe, seine Sorge gilt nun nicht mehr sich selbst, sondern wie er daz lant bekêrte / und gotes gelouben lêrte (BJ 13501-13502). Er lässt Kreuze auf die Zinnen und Tore setzen, die heidnischen Gebetshäuser samt ihren Grundfesten niederreißen, ihre Schätze zerstreuen und die Götterbilder zerstören. Die bisher verfolgten und im Verborgenen lebenden Christen hält er an, ihren Glauben zu verbreiten, baut eine Kirche und setzt einen Erzbischof ein. Die breite Verkündigungsarbeit führt zu zahlreichen Taufen und erfasst das ganze Land, denn was Josaphat in seiner Hauptstadt veranlasst hat, wird nun von den Getauften selbst und überall vollzogen. Die christliche Lehre erweist ihre Wirksamkeit im existentiellen Vollzug der Gläubigen: der fêle und ouch des lîbes leben / bezzerte vrœlîche fich / an den liuten tägelich (BJ 13600-13602) und die Heidenmission wandelt sich rasch zur Glaubensverkündigung an die Laien im Inneren: ze allen zîten hiez er dort / die phafheit daz gotes wort / den leien künden unde fagen. (BJ 13573-13575)

Zur Verbreitung des christlichen Glaubens trägt dabei nicht nur die Macht bei, mit der Josaphat als neuer Herrscher die Verkündigung vorantreibt, sondern wesentlich auch sein Vorbild. Als sich bei der Zerstörung der Gebetshäuser lautes Geschrei der Teufel erhebt, die sich vertrieben sehen, geraten die Menschen in Angst:

\footnotetext{
difiu vil grôze vorhte

wol an den liuten worhte

die kriftenlîchen lêre.

ie mêre und aber mêre

began daz liut von finnen

got und von herzen minnen.
}

\footnotetext{
294 Hendrik Lambertus: Der Weg aus der Welt im Wandel. Welt und Weltflucht in Rudolfs von Ems Barlaam und Josaphat und der altnorwegischen Barlaams saga ok Josaphats vor dem Hintergrund der indischen Buddhacarita-Tradition. In: Mediaevistik. Internationale Zeitschrift für interdisziplinäre Mittelalterforschung 24 (2011), S. 37-110, hier S. 76.
} 
ouch kunde in guot vorbilde geben

des küneges reineclîchez leben. (BJ 13637-13644)

Als mustergültiger christlicher König, der sich an Gottes lêre hält und den Armen hilft, wird Josaphat mit den biblischen Vorbildern David und Salomo gleichgesetzt. Indem Josaphat sich als gerechter Herrscher demütig der göttlichen Weltordnung unterordnet, verwirklicht er ein christliches Idealkönigtum, das ,als direkte Kontrafaktur zur anfänglich geschilderten Herrschaft König Aveniers zu sehen [ist], der zwar in allen weltlichen Belangen als vorbildlicher Herrscher geschildert wird, in spiritueller Hinsicht jedoch blind dem Heidentum verhaftet ist“".295

Schließlich verblasst der Ruhm Aveniers neben dem seines Sohnes, sodass er sein Unrecht erkennt und sich endlich bekehrt, wofür Josaphat beständig gebetet hatte. In einem Brief gesteht er ihm seine Schuld ein und bittet um Unterweisung in der christlichen lêre, nach der er dem Unglauben entsagt und sich einem gottgefälligen Leben zuwendet. ${ }^{296}$ Seine Taufe hat eine Konversionswelle zur Folge: diu ftat und al daz lant / wart geloubic fâ zehant, / in gotes namen getoufet / unde gote wider gekoufet (BJ 14165-14168). Er übergibt nun auch seinen Teil des Reiches an den Sohn und lebt als ein reine $[r]$ gotes dienftman (BJ 14222), bis ihn der Tod ereilt. Als er in dessen Angesicht noch einmal über seine Sünden zu verzweifeln droht, verweist ihn Josaphat auf die unendliche Gnade Gottes. Der Erzähler lässt den ehemaligen Christenverfolger sodann mit himelvreuden grôz in Abrahâmes fchôz (BJ 14331 und 14332) eingehen, während sein Sohn in siebentägigem Gebet bittet, dass er in die Gemeinschaft gerade derer aufgenommen werde, die durch ihn die Marter erlitten haben:

\author{
,ouch fante dir hie vor fîn fwert \\ mangen reinen erben wert; \\ die ruoche im ouch mit minnen \\ ze vriunden gar gewinnen. (BJ 14399-14402)
}

Wenn selbst der schlimmste der Heiden in einen Erkenntnisprozess gelangen kann, der ihn zur Konversion führt und zum Heiligen werden lässt, und wenn dabei die alten irdischen Gegensätze in der Transzendenz vollends aufgehoben werden können, dann ist Josaphats Integrationsleistung in der missionarischen Ausbreitung des Christentums durch Unterweisung und Vermittlung christlicher Lehre schließlich eine umfassende. Sie gründet in seiner eigenen Heiligkeit, die sich nicht erst in seinem Anachoretentum, sondern auch in seiner Rolle als Herrscher konkretisiert. Damit ist

295 Ebd., S. 73.

296 Insgesamt scheint dieser Wandel bei Rudolf von Ems gegenüber seiner Vorlage noch besonders herausgehoben, indem er sie breiter ausführt und ergänzt, wie der einstmals heidnische König nun seinerseits die Abgötter zerstören und ihre Schätze den Armen geben lässt sowie öffentlich seinen Glauben an den dreifaltigen Gott bekennt (BJ 14103-14135). Vgl. Czizek, Rudolfs von Ems Barlaam und Josaphat und seine lateinische Vorlage, S. 56-57. 
Josaphats Weg nicht nur der einer persönlichen Bekehrung und asketischen Weltflucht, sondern er wird vorher noch „zum idealen Vertreter christlichen Königtums, der durch sein Vorbild (nicht durch Gewalt) andere für das Christentum gewinnt“. ${ }^{297}$

Gemessen an der Bedeutung und dem Umfang seines eigenen Weges ist Josaphats Bekehrung des Volkes und seines Vaters allerdings nur eine kurze, wenngleich syntagmatisch unverzichtbare Episode, eine zu absolvierende Aufgabe, bevor er sich in der Anachorese seiner eigentlichen Bestimmung zuwendet. Denn Josaphats Bestreben ist es, sich der Krone zu entledigen und Barlaam in die Wüste zu folgen. Sein erster Versuch endet erfolglos: Nach dem Tod seines Vaters ruft er seine Untertanen zusammen und tut ihnen seinen Entschluss kund. Diese aber wollen keinen anderen Herrscher, sodass er seinen Plan zunächst aufgeben muss. Daraufhin versucht er es weniger öffentlich: Er vertraut sich dem Hofbeamten Barachias an, der schon Avenier treu gedient und sich noch vor Josaphats Geburt zum christlichen Glauben bekehrt hatte, und will ihm die Krone übergeben. Dieser nun wirft ihm mangelnde Nächstenliebe vor und offenbart somit die Zwiespältigkeit der Situation:

,ob dich daz weltlîche guot

dunket üppic, als ez tuot,

wil dû danne gunnen mir,

des dû wilt felbe erbunnen dir,

fô bift dû mir niht alfô holt,

fô dû nâch gotes lêre solt.' (BJ 14647-14652)

Josaphat will die Welt verlassen, muss dafür aber einen anderen der Gefahr für das Seelenheil aussetzen, die mit weltlicher Macht und Besitz verbunden ist. Auf den Vorwurf seines Getreuen will oder weiß er nichts zu antworten und gibt sein Streben zunächst auf: Dô fweic der künic Jôfaphât. (BJ 14661)

Der dritte Anlauf führt schließlich zum Erfolg, wenngleich immer noch gegen den Willen der Beteiligten: Josaphat zieht sich zurück, schreibt einen Brief an seine Fürsten, in dem er sie auf gotes lêre (BJ 14677) verpflichtet und Barachias als seinen Nachfolger nennt. Dann verlässt er in aller Heimlichkeit den Palast. Als seine Flucht entdeckt wird, eilt man ihm nach und führt ihn zurück, aber vergeblich, denn:

dô fwuor der gotes dieneftman,

daz er niemer mêre

wolder weltlîch êre

weltlîche gewinnen,

noch weltlîch guot geminnen. (BJ 14730 -14734)

Er beruft sich darauf, dass er seine Aufgabe erfüllt und allen den christlichen Glauben gelehrt habe, und nun ,eine vart‘ leisten wolle, ,der mir iemer was ze muote` (BJ 14744

297 Johannes Erben: Zu Rudolfs Barlaam und Josaphat. In: Germanistische Studien. Hrsg. von dems., Eugen Thurnher. Innsbruck 1969 (Innsbrucker Beiträge zur Kulturwissenschaft. 15), S. 33-39, hier S. 34. 
und 14745). Barachias wehrt sich zwar noch, doch wird ihm schließlich von den Versammelten die Krone ûf fîn houbet dâ gefat / gewalteclîche fchône (BJ 14758-14759).

In der Forschung ist die Bewertung dieses Abschieds immer wieder diskutiert worden, weil man daraus Rudolfs persönliche Haltung zum Geschehen und damit die Aussage des Textes erschließen wollte. ${ }^{298}$ Den aufscheinenden Gegensatz von Askeseideal und Herrschaftsaufgabe, zwischen persönlichem Heilsweg und der Verpflichtung für das Seelenheil und Gemeinwohl der Untertanen, sollte man aber nicht psychologisierend vom Hintergrund der Stofftradition ablösen, die ein nicht ohne Weiteres veränderbares Syntagma vorgibt: Josaphat hat seinen Auftrag als Bekehrer seines Volkes erfüllt, nun muss er seinem eigenen Weg folgen, denn er ist auch zum Anachoreten bestimmt. Sein Reich aber braucht einen Nachfolger auf dem Königsthron und dazu ist im Gegenzug Barachias bestimmt. Das Verstummen des Königs Josaphat kann man vor diesem Hintergrund als Ausdruck einer Aporie sehen, wenn mit diesem Vers nicht einfach gemeint sein soll, dass er seinen Versuch vorerst aufgibt, um auf anderem Wege zum Ziel zu kommen. Das Schweigen macht dann aber ebenso deutlich, dass eine inhaltliche Klärung gar nicht angestrebt ist. Die Reaktionen der Betroffenen zeigen zwar, dass in Josaphats Abschied unterschiedliche Ansprüche und Werte aufeinandertreffen - grundsätzlich infrage zu stellen vermögen sie ihn aber nicht. ${ }^{299}$

Bei Rudolf scheint der Kontrast erzählerisch eher noch abgemildert, wenn er die heftigen Gefühlsausbrüche des Volkes und die Drohungen Josaphats bei seinem Abschied auslässt, die in der lateinischen Fassung geschildert werden. ${ }^{300}$ Die Versuche der Untertanen, Josaphat zurückzuhalten, seine Nachgiebigkeit, die einer offenen Konfrontation ausweicht, seine Vorsorge hinsichtlich seiner Nachfolge, der Kummer bei seinem endgültigen Abschied - all das dient eher der Betonung der Vorbildlichkeit des vollkommenen christlichen Königs, Heidenbekehrers und Lehrers, und als Hintergrund, vor dem sich seine zu allen Prüfungen bereite Glaubensstärke abhebt. ${ }^{301}$ Auch der Kummer und die Klage des Barachias sind kaum dahingehend zu deuten, der Abschied Josaphats solle negativ dargestellt und dem Protagonisten damit ernsthaft mangelnde Nächstenliebe vorgeworfen werden. Denn gerade in der Beteuerung seiner eigenen Schwäche und der Weigerung, „an eine Herrschaftsübernahme überhaupt

298 „Rudolf sieht sicher den Egoismus des Josaphat hinter dem so streng christlich anmutenden Lebenswandel. [...] Dadurch, daß das Büßerdasein erkauft wird mit dem Kummer anderer Menschen, erscheint dem Dichter diese Askese verdächtig." Schnell, Rudolf von Ems, S. 90.

299 Einen anderen Sinn erhält der Vers, wenn man mit Biesterfeldt, Moniage, S. 92 „das Gewicht auf die für Josaphat hier zum letzten Mal verwendete Königstitulatur“ legt, womit lediglich der endgültige Charakter der Herrschaftsentsagung markiert wäre. Allerdings scheint mir diese Lesart, die zwar in eine verdienstvolle Argumentation gegen Schnell eingebettet ist, wiederum allzu harmonisierend. Die Worte Barachias' bleiben unkommentiert und Josaphat ist eben an dieser Stelle noch nicht endgültig seiner Herrschaftsaufgaben ledig. - Im Übrigen findet sich das Schweigen des Königs auch im Laubacher Barlaam, es kann also keine gänzlich eigenständige Zutat Rudolfs sein: Dô der künc vernam den man, / dô liez er die rede vergân. (LB 14970 -14971)

300 Vgl. Czizek, Rudolfs von Ems Barlaam und Josaphat und seine lateinische Vorlage, S. 158-159. 301 Vgl. Biesterfeldt, Moniage, S. 93. 
nur zu denken, qualifiziert er [= Barachias, F.P.] sich im Sinne der das Werk bestimmenden Lehre auf das vortrefflichste“ ${ }^{302}$ In der Demut werden die Würde und Eignung des Nachfolgers offenbar, die sich im Folgenden auch in dessen Herrschaft erweisen, wobei die mit der Macht verbundenen Gefahren keine Rolle mehr spielen. ${ }^{303}$

Barachias muss zudem aus erzähllogischen, legendentheoretischen Gründen in der Welt bleiben, um dafür sorgen zu können, dass die Geschichte aufgezeichnet wird und die intendierte Wirkung ze bezzerunge der kriftenheit (BJ 16103), wie es im Epilog heißt, entfalten kann. ${ }^{304}$ Würden alle beteiligten Figuren der Welt entsagen und Josaphat unmittelbar folgen, dann gäbe es die Legende nicht und sie hätte dann auch keinen Sinn, weil sich ihr exemplarischer und admirativer Anspruch nur angesichts einer gläubigen Gemeinschaft entfalten kann, deren Mehrheit eben nicht zur radikalen Nachahmung der Weltabkehr bestimmt ist. Allgemein gesprochen funktioniert die Legende als Erzählung vom Einbruch des Heiligen in die Welt nur unter der Maßgabe, dass nicht alle Menschen Heilige sind beziehungsweise noch nicht zu solchen geworden sind. Ihre Berechtigung bezieht sie aus der Notwendigkeit, vom Transzendenten in das Immanente narrativ vermitteln zu müssen. Josaphats Weg in die Wüste bleibt daher ein einsamer und singulärer, der nur im Erzählen und Hören der Geschichte mitvollzogen werden kann.

Nach seinen letzten Worten an Barachias, in denen er ihn vor allem an die Demut als Herrscher gemahnt, will Josaphat daz ellende [...] lân / und vrolîche wider gân / zuo finen vriunden in fin lant (BJ 14913-14915). Er strebt also aus der als Fremde verstandenen Welt der ihm gemäßen Lebensform und der wahren und unvergänglichen Heimat zu, doch mit mehrfachem owê (BJ 14923-14934) beklagt der Erzähler den einsamen Abschied Josaphats, dem niemand aus dem ellende in die wahre heimuot folge (BJ 14930 und 14931). In einer erweiterten und allegorischen Auslegung sind damit alle Menschen gemeint, Erzähler und Rezipienten mit eingeschlossen: ${ }^{305}$

Hie meine ich dirre welte kint,

die mit houbetfünden fint

302 Vgl. ebd., S. 91.

303 Im Übrigen findet sich Barachias' Worte, die Übertragung der Herrschaft an ihn stehe im Widerspruch zum von Josaphat selbst gelehrten Gebot der Nächstenliebe, schon im lateinischen Text: , $O$ rex, quam iniustum est iudicium tuum, quamque non secundum mandatum tuum est sermo! Si enim diligere proximum, sicut teipsum edoctus es, qua ratione onus quod ipse deponere festinas michi conaris imponere? Nam si bonum est regnare, ipse quod bonum est tene. Si autem istud est anime scandalum atque offendiculum, cur michi imponis illud et uis me supplantare?‘ VB 502. „,Oh König, wie ungerecht ist dein Urteil, wie steht dein Wort zum (göttlichen) Gebot in Widerspruch! Denn wenn du weißt, dass man seinen Nächsten lieben soll wie sich selbst, aus welchem Grund versuchst du mir die Last aufzubürden, die du selbst eilig ablegen willst? Denn wenn es gut ist zu herrschen, behalte selbst, was gut ist. Wenn es jedoch für die Seele etwas Anstößiges und ein Hindernis ist, warum bürdest du es mir auf und willst, dass ich stolpere?““ (Übersetzung F. P.) Auch hier antwortet Josaphat ihm nicht, es fehlt sogar der Hinweis auf sein Schweigen. Er zieht sich einfach zurück, um seinen Brief zu schreiben.

304 Vgl. Cordoni, Barlaam und Josaphat in der europäischen Literatur des Mittelalters, S. 310.

305 Vgl. ebd., S. 286. 
und in den fô ftille ftânt

und niht mit dem rehten gânt

ûz den fünden in daz leben

dem niemer ende wirt gegeben. (BJ 14935-14940)

Der Erzähler reiht sich explizit in die Menge der Sünder ein: owê, war gât nû Jofaphât, / daz manec fîn vriunt fô ftille ftât, / der ich leider einer bin (BJ 14941-14943), um sich schließlich in seiner Rolle als Vermittler des Geschehens an seinen Protagonisten zu binden:

nû wil ich in niht eine lân

und wil im gefellefchaft

mit gefelleclîcher kraft

leiften mit dem mære. (BJ 14946-14949)

Die Nachfolge des Heiligen besteht in der Rezeption seiner Legende, über deren Mitvollzug sich der Erzähler legitimiert, dabei aber sein Schaffen in den höheren Zusammenhang religiöser Offenbarung und geistlicher Wirkung stellt. ${ }^{306}$ Diese Art der Nachfolge steht aber auch dem intendierten Publikum offen, das nicht unbedingt aufgerufen ist, Josaphat auf seinem Weg in die Wüste zu folgen, wohl aber diesen im Hören der Legende zu begleiten und aneignend mitzuvollziehen.

Josaphats Weg zur Heiligung, wie er in der Stofftradition vorgegeben ist, muss in die Wüste führen muss, denn er wird letztlich nicht als Herrscher heilig, sondern als Asket. Beide Funktionen aber bleiben wichtig für das Bild des Heiligen und seine Funktion für ein christliches Publikum, er ist eben sowohl ein „strahlendes Exempel asketischer Weltflucht“ als auch ein „gottgefälliger Herrscher in der Welt“:

Diese doppelte Exemplum-Funktion des heiligen Josaphat für den weltlichen wie für den monastischen Bereich kann als einer der Hauptgründe für die große Verbreitung und Beliebtheit des

306 Mit Wyss, Rudolfs von Ems Barlaam und Josaphat zwischen Legende und Roman, S. 231 die zitierten Verse 14946-14949 als „literarischen Witz“ zu verstehen, in dem „Rudolf sich ironisch von der Vorbildlichkeit seines Helden distanziert“, ist letztlich nur möglich, wenn man unbedingt Belege für diese Distanz beziehungsweise eine Spannung zwischen Roman und Legende im Barlaam und Josaphat sucht. Ähnlich hat zuletzt Matthias Meyer mit Blick auf die Erzählerexkurse zum Thema Minne und Frauen (BJ 11735-11870 und 12267-12289) konstatiert, Rudolf rede hier „vom vorgeblichen Anlass her gegen die Binnengeschichte, eigentlich aber gegen seinen eigenen Roman an“. Matthias Meyer: Barlaam, die Heilsgeschichte und der/die Erzähler. In: Rudolf von Ems. Beiträge zu Autor, Werk und Überlieferung. Hrsg. von Elke Krotz [u. a.] Stuttgart 2020 (ZfdA. Beihefte. 29), S. 97-111, hier S. 94. Es scheint mir allerdings sowohl inhaltlich-thematisch als auch erzähltheoretisch kurzschlüssig, diese Exkurse schlicht als Infragestellung der im Weg Josaphats verkörperten religiös-asketischen Geltungsansprüche zu verstehen. Vgl. dazu meinen Beitrag: Heiliger Herrscher und Anachoret. Die Aushandlung divergierender Ansprüche an ein religiöses Leben in Rudolfs von Ems Barlaam und Josaphat. In: vita perfecta? Zum Umgang mit divergierenden Ansprüchen an religiöse Lebensformen in der Vormoderne. Hrsg. von Daniel Eder, Henrike Manuwald, Christian Schmidt. Tübingen [erscheint 2021] (Otium. Studien zur Theorie und Kulturgeschichte der Muße). 
Legendenstoffes im europäischen Hochmittelalter und auch darüber hinaus angesehen werden. ${ }^{307}$

Dass aber der exemplarische Gehalt gerade des Eremitendaseins ein großes Identifikationspotential für ein christliches Publikum, Laien wie Religiose gleichermaßen, entfalten kann, zeigen die Ausführungen des Erzählers über der keftegunge vünve (BJ 15146), die eine Zutat Rudolfs von Ems sind, aber auf eine allgemeine theologische Tradition zurückgreifen. ${ }^{308}$ Dieser Exkurs vertieft den Gedanken der Nachfolge, macht somit das Geschehen auf einer geistlichen Ebene verständlich und durchsichtig hin auf die Logik legendarischen Erzählens und die Notwendigkeit innerer conversio: Josaphat gibt nach dem Abschied seine Kleider den Armen als Almosen, nimmt das Büßergewand, das er von Barlaam erhalten hatte und begibt sich auf die Suche nach seinem Lehrer. Zwei Jahre lebt er in Hunger und Armut asketisch in der Wüste und wird mehrfach vom Teufel versucht, nimmt aber alles als Prüfung auf sich.

Der Inhalt der fünf Züchtigungen, die Gott über seine Frommen verhängt, ist kurz gefasst dieser: Gott schickt den Menschen Leid, um ihre Geduld zu prüfen, sich in seiner Allmacht zu offenbaren, damit sie sich bessern, damit sie ihre Sündhaftigkeit erkennen, und schließlich als Strafe für diejenigen, die sich dem Teufel zuwenden. Grundthema ist also das Leid der Welt in seinen Ursachen, dem sich jeder einzelne stellen muss. ${ }^{309}$ Vor diesem Hintergrund ist die Anachorese Josaphats zu verstehen: Er muss sich in der christlichen lêre und somit als Heiliger bewähren und ist in dieser Bewährung in der Gnade Gottes aufgehoben. Gleichzeitig transportiert dieser Exkurs in exemplarischer Form eigenständige lêre, die Gültigkeit für jeden christlichen Vollzug beanspruchen kann, unabhängig davon, wie radikal er sich in der Wahl der Lebensform gestaltet.

Das Ende der Erzählung folgt legendentypischen Mustern, die die Heiligkeit der Protagonisten ausstellen und ihre Geschichte für die gläubige Verehrung anschlussfähig machen: Josaphat wird schließlich von Gott zu einer Höhle geführt, die Barlaams Einsiedelei ist. Dieser erkennt seinen von der Askese gezeichneten Schüler kaum wieder, denn dessen Haut ist schwarz geworden, der Leib ist abgemagert und kraftlos,

\footnotetext{
307 Lambertus, Der Weg aus der Welt im Wandel, S. 106. - In diese Richtung weist auch die Beobachtung von Johannes Traulsen, dass sich dies- und jenseitiger Luxus in Rudolfs Fassung nicht ausschließen, vgl. Diesseitige und jenseitige rîchheit in Rudolfs von Ems Barlaam und Josaphat. In: Fremde - Luxus - Räume. Konzeptionen von Luxus in Vormoderne und Moderne. Hrsg. von Jutta Eming [u. a.]. Berlin 2015 (Literaturwissenschaft. 43), S. 43-62.

308 Vgl. Nägler, Studien zu Barlaam und Josaphat von Rudolf von Ems, S. 120 -121.

309 Vgl. Schnell, Rudolf von Ems, S. 102. Wobei der Gegensatz zwischen Bewährung in der Welt und Weltflucht, den Schnell mit Blick auf Rudolfs von Ems Euvre insgesamt konstruiert: „Nicht Weltflucht, sondern Weltbewältigung will Rudolf in seinen Werken darstellen, weil er in ihr die Aufgabe unsres Lebens sieht.“ (S. 92) und: „Warum sollten wir aus der Welt fliehen, wenn uns Gott gerade hier begegnet?“ (S. 103), gerade für den Barlaam und Josaphat irreführt, denn Josaphats Anachorese meint ja gerade eine spezifische Form der Weltbewältigung. ,Welt' in einem allgemeinen Sinne ist von den geistlichen Implikationen des Begriffs zu trennen.
} 
das Gesicht trägt die Spuren der durchlittenen Mühen, das Haar verfilzt und lang: fîn lip was im niht erkant, / wan er in gar verwandelt vant. (BJ 15339-15340) Wesen und Vollzug der lêre erscheinen am Körper, der metonymisch für die innere Wandlung Josaphats steht und die bekannte Frage von Schein und Sein vergegenständlicht. Auf die Wiedersehensfreude folgt ein kurzer Abschnitt über das gemeinsame Leben der beiden Eremiten, die vereint den Weg der Heiligung vollenden: ir reiniu wandelunge / bezzerte fich tägelich (BJ 15400-15401), bis Barlaams Ende naht. In seinen Abschiedsworten ermahnt er den Schüler, weiter in der Wüste zu bleiben, das Herz fest an Gott zu halten und dem Teufel zu widerstehen, ,biz daz dû lebeft ' (BJ 15448), also bis er das ewige Leben nach dem Tod errungen habe. Für die irdischen Mühen und Armut stellt er reichen himmlischen Lohn in Aussicht.

Nach einer gemeinsamen Messe stirbt fante Barlââm, wie er nun genannt wird (BJ 15569/15632/15661), woraufhin Josaphat ihn mit der Hilfe von Engeln zu Grabe trägt. Der einstige Schüler, nun ganz auf sich gestellt, wendet sich im Gebet an Gott und erfährt seine zweite Traumvision. Ihm erscheinen Engel mit leuchtenden Kronen und verkünden ihm:

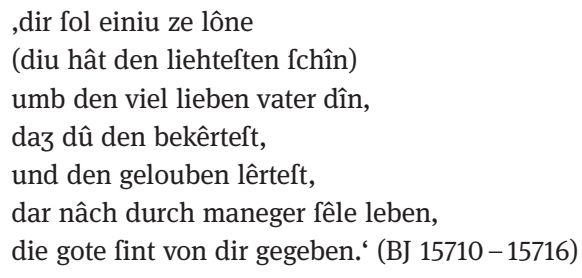

Also nicht zuvorderst die Weltflucht führt zur himmlischen Krone, sondern die Bekehrung des Vaters und des ganzen Volkes. ${ }^{310}$ Dieser Aspekt scheint hier bewusst herausgearbeitet, denn im Laubacher Barlaam beispielsweise findet sich keine solche Erwähnung der Mission und der Lohn wird Josaphat allein für seinen heiligmäßigen asketischen Lebenswandel in der Wüste zugesprochen. ${ }^{311}$ Allerdings werden diese beiden Heiligkeitsmuster bei Rudolf von Ems nicht gegeneinander ausgespielt, denn Verbreitung der christlichen Lehre und Anachorese gehen ineinander über. Nachdem die zweite Krone Avenier zugeordnet worden ist, heißt es in der göttlichen Verkündigung weiter:

\footnotetext{
,dir ift diz himelifche lant

behalten, daz wil dir got geben,

wil dû ftæten im dîn leben
}

310 Vgl. Heinz Rupp: Rudolf von Ems und Konrad von Würzburg. Das Problem des Epigonentums. In: Der Deutschunterricht 17, 2 (1965), S. 5-17, hier S. 10.

311 ,Diu eine krône diu ist dîn / durch daz reine herze dîn / und durch die sêle manicvalt / die von dir sint got gezalt. / Sie sol gezieret werden baz / und wir noch schœener ume daz / durch des lebens minne / dâ dû dich üebest inne / in der einœede alle zît, / ob dû volendest wol den strit.' (LB 16319-16328) 


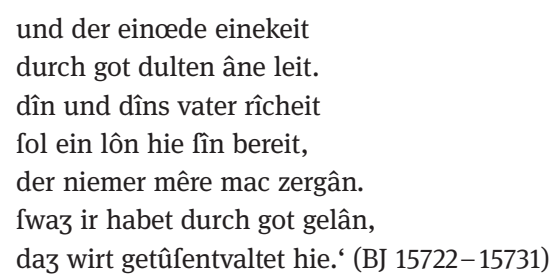

Bevor Josaphat seine Krone empfangen kann, sind ihm weitere Mühen in der Wüste bestimmt: er müefte fich arbeiten $\hat{e}$ / durch got in dirre welte mê (BJ 15783-15784), bekommt er von Barlaam persönlich aufgetragen, der ihm in der Vision ebenfalls erscheint. Als marteraere und begihtaere (BJ 15816 und 15817) erfüllt er den ihm von Gott vorgegebenen Weg: der boten lôn fîn leben nam, / wan er sô manigen lêrte, / daz er ze got kêrte. (BJ 15812-15814) ${ }^{312}$ Glaubensbote ist er dabei sowohl in seiner Funktion als Missionar wie als Anachoret, die beide unter dem Zeichen der Askese stehen.

Erst nach insgesamt 35 Jahren des Büßerlebens stirbt fante Jôfaphât (BJ 15854 und 15877) als der heilege (BJ 15840). Ein anderer Eremit bekommt von Gott den Auftrag, den Toten bei seinem Meister zu begraben und den Tod der beiden Heiligen in Indien kundzutun, woraufhin Barachias ihre unverwesten und wohlriechenden Leichname in die Kathedrale der Hauptstadt überführen lässt, wo sie für viele Wunder und Taufen sorgen, außerdem werden ihre Gewänder ze grôzem heiltuom (BJ 16020) in fremde Länder verteilt. Dazu sorgt der Nachfolger auf dem Königsthron dafür, dass die Lebensgeschichte Barlaams und Josaphats ze vorbilde den liuten (BJ 16025) aufgezeichnet wird, womit die Wahrheit der Überlieferung intratextuell und im Hinweis auf die kultische Verehrung der Reliquien außerliterarisch abgesichert wird, die Legende letztlich überhaupt erst als solche konstituiert wird.

Der admirative Mitvollzug des asketischen Lebens Josaphats ist auf diese Weise im Text selbst schon angelegt und wird in den sich direkt daran anschließenden Ausführungen des Epilogs auf die ,literarische Situation“ hin geöffnet. Denn der Erzähler betont hier zum einen die Treue einer Überlieferung, die direkt auf die Augenzeugen zurückgeht, ähnlich wie die Evangelien dies für das Leben Jesu beanspruchen: zuo dirre wârheit / niht mê noch minner wart geleit (BJ 16043-16044). Zum anderen stellt er nochmals den in dieser reinen Wahrheit verbürgten Nutzen und geistlichen Geltungsanspruch seiner Erzählung heraus. Wie auch schon im Prolog erscheint Johannes von Damaskus fälschlicherweise als Übersetzer aus dem Griechischen ins Lateinische. Dabei werden seine lateinische Übertragung, die direkt auf die von Barachias in Auftrag gegebene Vita zurückgeführt wird, und das Latein als Vermittlersprache generell gerühmt. Denn nur diese Vermittlung ermöglicht den im Griechischen Unkundigen einen Zugang zur Legende von Barlaam und Josaphat, wie es entsprechend für die Heilige Schrift gilt (BJ 16048-16056).

312 Vgl. Erben, Zu Rudolfs Barlaam und Josaphat, S. 36. 
Neben der bereits dargestellten geistlichen Legitimierung durch die Figur des Abts Wido und seinen Konvent verortet der Erzähler sein Schaffen im Kontext der Vermittlung religiöser lêre und Heilswissens:

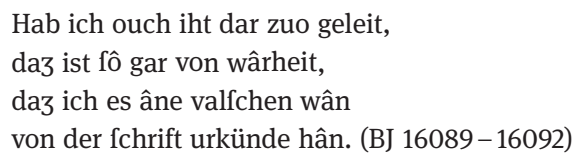

Über den topischen Charakter dieser Beteuerung hinaus lässt sich die Treue zur $\int$ chrift als Garant der Wahrhaftigkeit nicht nur auf die schriftliche Quelle für die vorliegende Legende beziehen, sondern ebenso auf die Autorität der Heiligen Schrift. ${ }^{313}$ Ebendiese beiden Dimensionen klingen an, wenn der Erzähler ausführt, was ihn diu fchrift gewîfet hât / mit rehter orthabunge (BJ 16100-16101), das habe er getreulich weitergegeben ze bezzerunge der kriftenheit (BJ 16103). Dieses Vorgehen setzt er mit den eingangs zitierten Versen gegenüber den sonst üblichen höfischen, fiktiven Stoffen ab und damit der weltlichen Unwahrheit die religiöse Ernsthaftigkeit seines mære entgegen, das zur beständigen inneren conversio auffordere: fwer ez hœre oder lefe, / da3 er fich bezzernde wefe (BJ 16077-16079). 